\title{
Molecular Mechanisms of Ultraviolet Radiation-Induced DNA Damage and Repair
}

\author{
Rajesh P. Rastogi, ${ }^{1}$ Richa, ${ }^{1}$ Ashok Kumar, ${ }^{2}$ Madhu B. Tyagi, ${ }^{3}$ and Rajeshwar P. Sinha ${ }^{1}$ \\ ${ }^{1}$ Laboratory of Photobiology and Molecular Microbiology, Centre of Advanced Study in Botany, Banaras Hindu University, \\ Varanasi 221005, India \\ ${ }^{2}$ School of Biotechnology, Banaras Hindu University, Varanasi 221005, India \\ ${ }^{3}$ Mahila Maha Vidyalaya, Banaras Hindu University, Varanasi 221005, India \\ Correspondence should be addressed to Rajeshwar P. Sinha, r.p.sinha@gmx.net
}

Received 11 June 2010; Revised 15 August 2010; Accepted 28 September 2010

Academic Editor: Shigenori Iwai

Copyright ( $) 2010$ Rajesh P. Rastogi et al. This is an open access article distributed under the Creative Commons Attribution License, which permits unrestricted use, distribution, and reproduction in any medium, provided the original work is properly cited.

DNA is one of the prime molecules, and its stability is of utmost importance for proper functioning and existence of all living systems. Genotoxic chemicals and radiations exert adverse effects on genome stability. Ultraviolet radiation (UVR) (mainly UV-B: $280-315 \mathrm{~nm}$ ) is one of the powerful agents that can alter the normal state of life by inducing a variety of mutagenic and cytotoxic DNA lesions such as cyclobutane-pyrimidine dimers (CPDs), 6-4 photoproducts (6-4PPs), and their Dewar valence isomers as well as DNA strand breaks by interfering the genome integrity. To counteract these lesions, organisms have developed a number of highly conserved repair mechanisms such as photoreactivation, base excision repair (BER), nucleotide excision repair (NER), and mismatch repair (MMR). Additionally, double-strand break repair (by homologous recombination and nonhomologous end joining), SOS response, cell-cycle checkpoints, and programmed cell death (apoptosis) are also operative in various organisms with the expense of specific gene products. This review deals with UV-induced alterations in DNA and its maintenance by various repair mechanisms.

\section{Introduction}

The stratospheric ozone layer is continuously depleting due to the release of atmospheric pollutants such as chlorofluorocarbons (CFCs), chlorocarbons (CCs), and organobromides (OBs). Consequently there is an increase in the incidence of UV radiation (UVR) on the Earth's surface [1] which is one of the most effective and carcinogenic exogenous agents that can interact with DNA and alter the genome integrity and may affect the normal life processes of all organisms ranging from prokaryotes to mammals [210]. However, wide variations in tolerance to UV-B among species and taxonomic groups have been reported. Moreover, ozone depletion followed by increased UV exposure has been predicted to continue throughout most of this century [11]. In all the groups of UVR (i.e., UV-A: $315-400 \mathrm{~nm}$; UVB: $280-315 \mathrm{~nm}$; UV-C: $<280 \mathrm{~nm})$ UV-B radiation produces adverse effects on diverse habitats, even though most of the extraterrestrial UV-B is absorbed by the stratospheric ozone [12]. UV-A radiation has a poor efficiency in inducing DNA damage, because it is not absorbed by native DNA. UVA and visible light energy (up to 670-700 nm) are able to generate singlet oxygen $\left({ }^{1} \mathrm{O}_{2}\right)$ that can damage DNA via indirect photosensitizing reactions [13]. UV-C radiation is quantitatively absorbed by oxygen and ozone in the Earth's atmosphere, hence does not show much harmful effects on biota. Solar UV radiation is responsible for a wide range of biological effects including alteration in the structure of protein, DNA, and many other biologically important molecules, chronic depression of key physiological processes, and acute physiological stress leading to either reduction in growth and cell division, pigment bleaching, $\mathrm{N}_{2}$ fixation, energy production, or photoinhibition of photosynthesis in several organisms $[3,9,10]$. It has been documented that UV-B severely affects survival, fecundity, and sex-ratio in several intertidal copepods [14]. One of the most prominent 


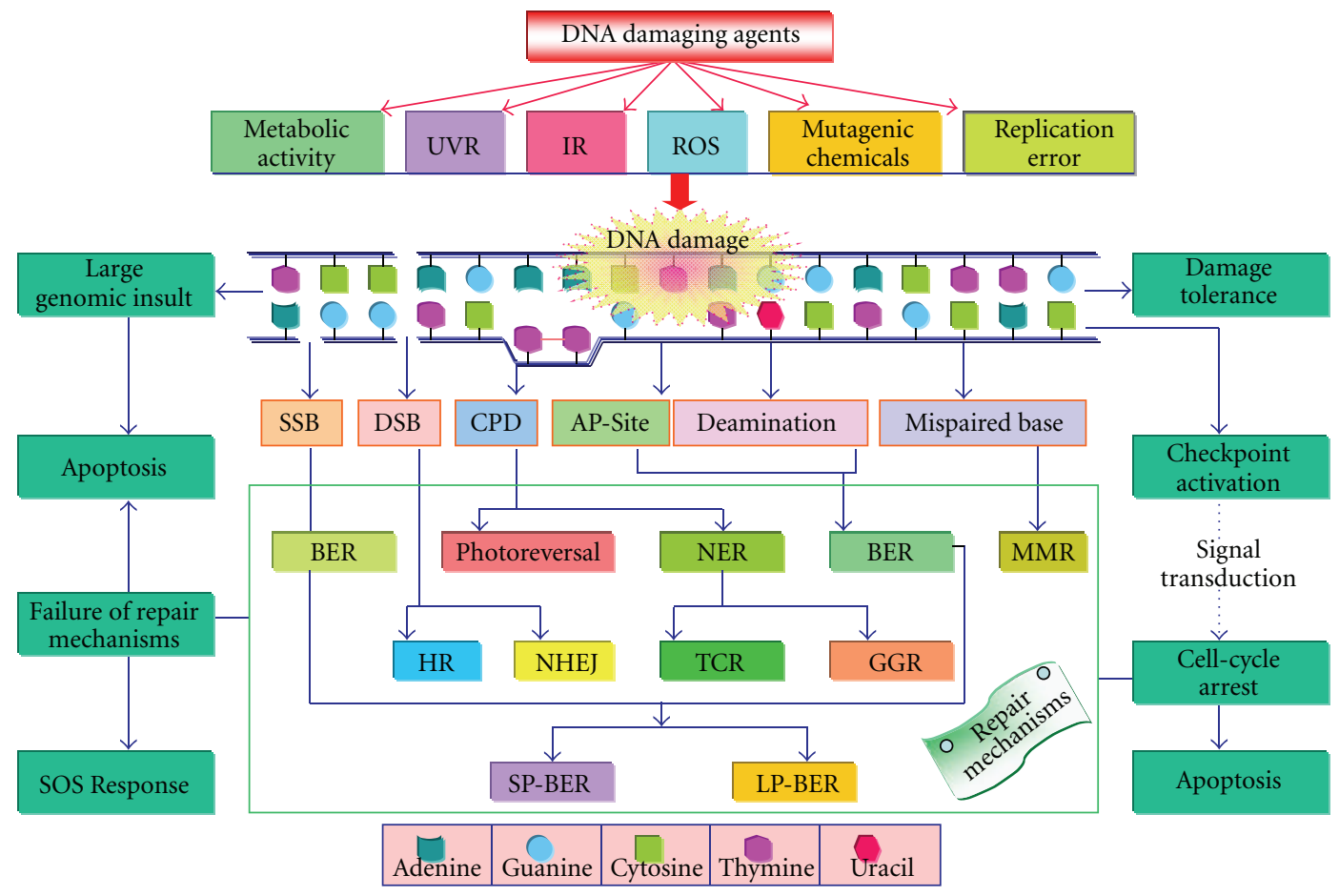

FIGURE 1: DNA damage and maintenance. Genomic lesions produced by various DNA damaging agents trigger several specific repair machinery to conserve the genomic integrity. In case of severe damage and/or failure of repair mechanisms, cells undergo apoptosis or induce a complex series of phenotypic changes, that is, SOS response. Sometimes the potentiality of lesions in the genome is mitigated by a phenomenon known as damage tolerance, during which DNA lesions are recognized by certain repair machinery, allowing the cells to undergo normal replication and gene expression. The cellular response to DNA damage may activate cell-cycle checkpoint by means of a network of signaling pathway that gives the cell extra time to repair the genomic lesions or may induce cell suicide response/programmed cell death (PCD).

targets of solar UV-radiation is cellular DNA, which absorbs UV-B radiation and causes adverse effects on living systems such as bacteria $[15,16]$, cyanobacteria [17], phytoplankton [18], macroalgae [19], plants [20], animals, and humans [21-23].

Although UV-B radiation has less than $1 \%$ of total solar energy, it is a highly active component of the solar radiation that brings about chemical modification in DNA and changes its molecular structure by the formation of dimers. Certain UV-absorbing pigments are produced by a number of organisms as a first line of defense; however, they are unable to avoid UV-radiation completely from reaching DNA in superficial tissue [28-32]. Certain enzymes, such as superoxide dismutase (SOD), catalase (CAT), peroxidase (POD), and scavengers such as vitamin $\mathrm{C}, \mathrm{B}$, and E, cysteine, and glutathione play an additional role in defense against UV radiation [33]. However, as a second line of defense several organisms have developed a number of specific and highly conserved repair mechanisms such as photoreactivation, excision repair, mismatch repair (MMR), double strand break (DSB) repair and certain other mechanisms like damage tolerance (dimer bypass), SOS (save our soul) response, checkpoint activation, and programmed cell death (PCD) or apoptosis (Figure 1) that efficiently remove DNA lesions ensuring the genomic integrity [22]. Plants are unique in the obligatory nature of their exposure to UVR; it is also conceivable that they may also have evolved certain efficient repair mechanisms for the elimination of UV-induced DNA damage. However, a number of questions concerning the basic phenomena of the DNA repair in plants remain to be elucidated. In the following, we discuss the molecular mechanisms of UV-induced DNA damage and repair mechanism (s) operative in various organisms.

\section{UV-Induced DNA Damage}

Induction of DNA damage by solar UVR is a key event that drastically influences the normal life processes of all organisms. A number of endogenous factors such as free radicals [34] generated during metabolic processes as well as exogenous factors such as UV or ionizing radiations [35] are known to interfere with genome integrity. DNA damage results in (i) misincorporation of bases during replication process, (ii) hydrolytic damage, which results in deamination of bases, depurination, and depyrimidination [36], (iii) oxidative damage, caused by direct interaction of ionizing radiations (IR) with the DNA molecules, as well as mediated by UV radiation-induced free radicals or reactive oxygen species $[37,38]$, and (iv) alkylating agents that may result in modified bases $[36,39]$. The hydrolytic deamination (loss of an amino group) can directly convert 


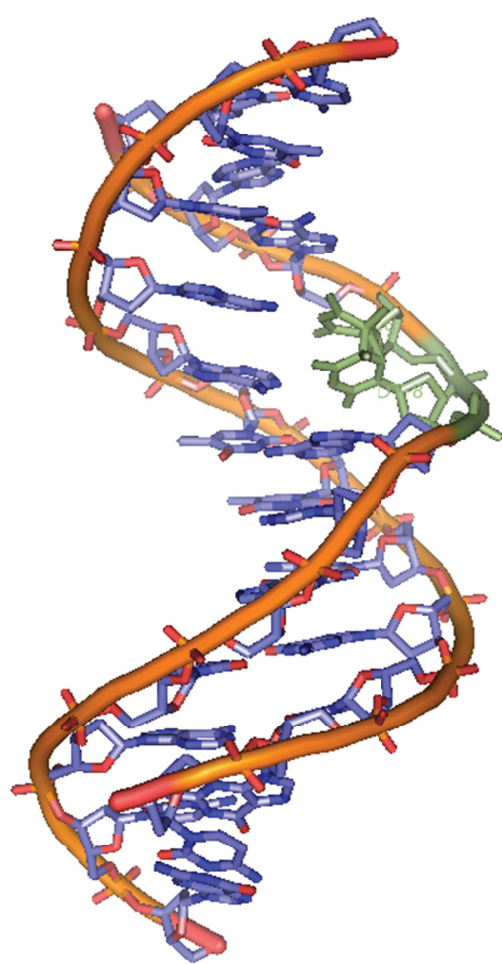

(a)

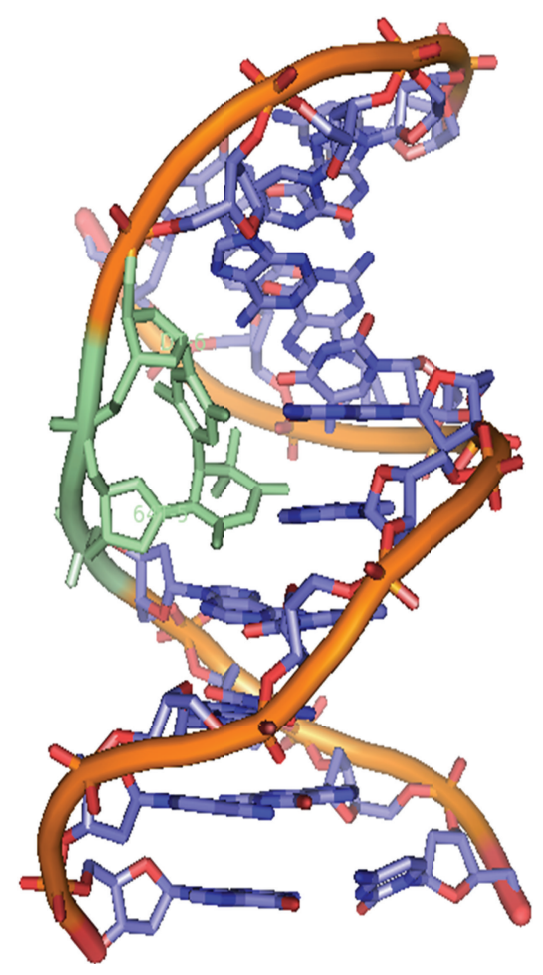

(b)

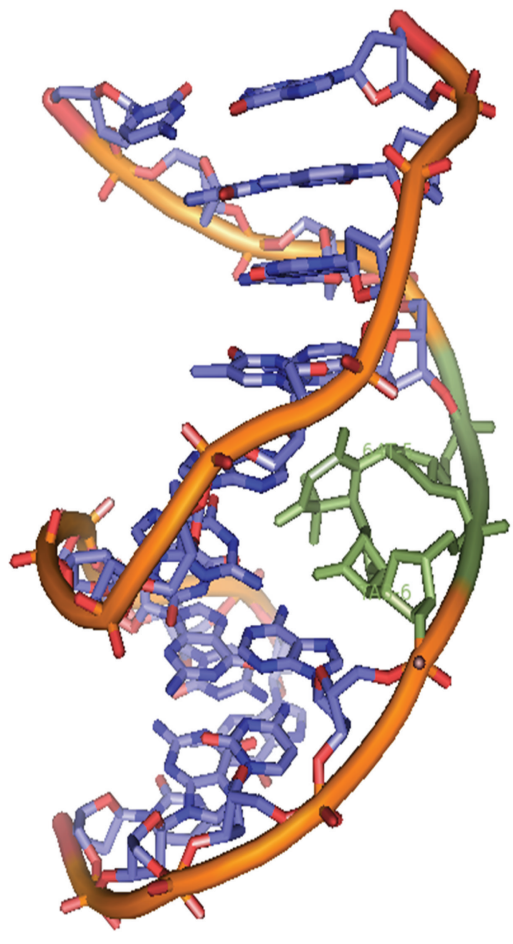

(c)

FIgure 2: Structures of DNA duplexes showing the presence of lesions (in green) such as CPD (a), 6-4PP (b), and 6-4 Dewar dimer (c). Hydrogen atoms are not shown, prepared from PDB entries 1TTD [24], 1CFL [25], and 1QKG [26] using PyMol. (version 1.1r1) [27].

one base to another; for example, deamination of cytosine results in uracil and at much lower frequency adenine to hypoxanthine. In depurination/depyrimidination, there are complete removals of purine/pyrimidine bases, leaving the deoxyribose sugar depurinated/depyrimidinated, that may cause breakage in the DNA backbone. The exposure of UVR, IR, and certain genotoxic chemicals may result in single as well as double DNA strand breaks. Among different types of damages, DNA double strand breaks (DSBs) are the most deleterious, since they affect both strands of DNA and can lead to the loss of genetic material. At high concentrations oxygen-free radicals or, more frequently, reactive oxygen species (ROS) can induce damage to cell structure, lipids, proteins as well as DNA and results in oxidative stress which has been implicated in a number of human diseases [40]. The hydroxyl radicals $\left(\mathrm{OH}^{\circ}\right)$ can damage all components of DNA molecules such as purine and pyrimidine bases and also the deoxyribose backbone, inhibiting the normal functions of the cell $[37,38]$.

\section{UV-Induced Pyrimidine Photoproducts}

UV-B radiation is one of the most important energetic solar components that may lead to the formation of three major classes of DNA lesions, such as cyclobutane pyrimidine dimers (CPDs), pyrimidine 6-4 pyrimidone photoproducts (6-4PPs), and their Dewar isomers (Figure 2) [5, 22, 23, 4143]. CPDs correspond to the formation of a four-member ring structure involving $\mathrm{C} 5$ and $\mathrm{C} 6$ of both neighboring bases whereas 6-4PPs are formed by a noncyclic bond between C6 (of the $5^{\prime}$-end) and C4 (of the $3^{\prime}$-end) of the involved pyrimidines via spontaneous rearrangement of the oxetane (when the $3^{\prime}$-end is thymine) (Figure $3(\mathrm{a})$ ) or azetidine (when the $3^{\prime}$-end is cytosine) (Figure 3(b)) intermediates $[5,44]$. The 6$4 \mathrm{PPs}$ are eagerly converted into their Dewar valence isomers upon exposure to UV-B or UV-A radiation that may further undergo reversion to the 6-4PPs upon exposure to shortwavelength UV radiation [45]. Two adjacent cytosines are considered as mutation hotspots of UVB and UVC radiations [42]. It has been found that $\mathrm{T}-\mathrm{T}$ and $\mathrm{T}-\mathrm{C}$ sequences are more photoreactive than $\mathrm{C}-\mathrm{T}$ and $\mathrm{C}-\mathrm{C}$ sequences [46]. The diastereoisomers of pyrimidine dimers (Figure 4) can be observed in free solution that differ in the orientation of the two pyrimidine rings relative to the cyclobutane ring, and on the relative orientations of the C5-C6 bonds in each pyrimidine base [44]. It has been demonstrated that the main photoproducts are cis-syn-configured CPD lesions, while trans-syn-configured CPD lesions are formed in much less quantity [47]. In double stranded B-DNA, where the dimer entails two adjoining pyrimidine bases on the same DNA strand, only the syn isomers can be generated, whereas the cis isomer is preferred over the trans isomer to a great extent [42]. The incidence of trans-syn isomer in single-stranded or denatured DNA is more common because of the increased flexibility of the DNA backbone. A few CPD lesions (i.e., cissyn or trans-anti isomers) can also be detected in aqueous 


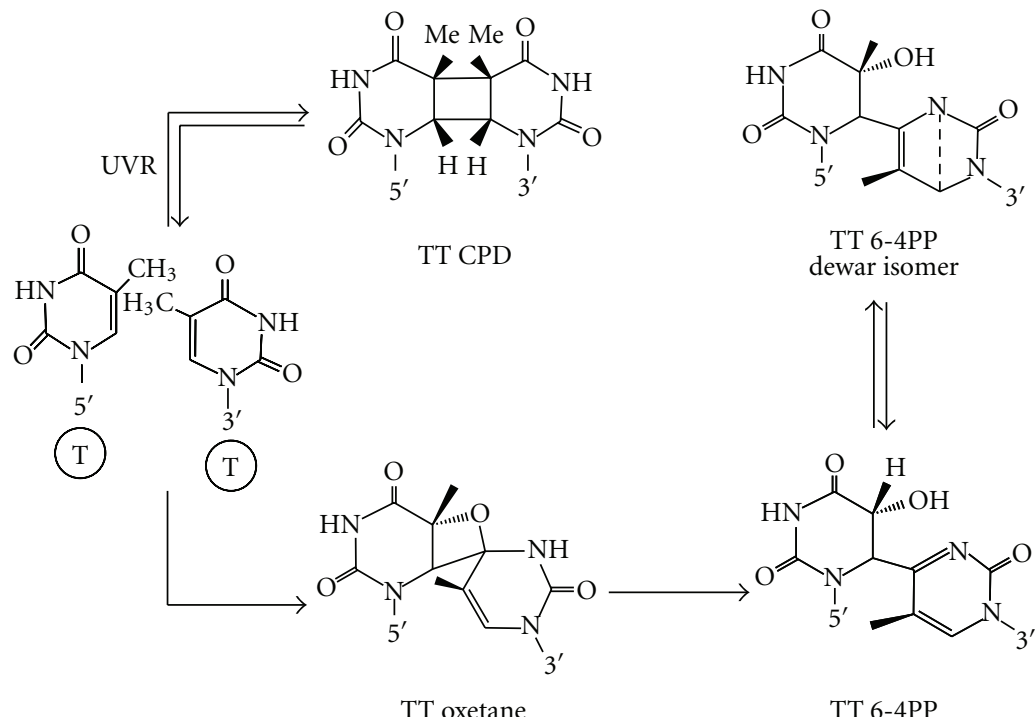
(unstable intermediate)

(a)<smiles>Cc1cn(-c2ccccc2)c(=O)[nH]c1=O</smiles>

(b)

Figure 3: Pathway of UVR-induced T-T (a) and T-C (b) CPD, 6-4PPs, and their Dewar isomers.

solutions by UV-C irradiation [48]. The formation of "spore photoproduct" has been detected in UV-irradiated bacterial spores by the addition of methyl group of one thymine residue to the $\mathrm{C} 5$ position of an adjacent thymine. In most cellular environments, there is no much significance of this photoproduct, since it requires anhydrous conditions for its formation [49].

The base damage by UVR is determined by the flexibility of the DNA strand as well as nature and position of the base. CPDs are formed at higher quantity by cycloaddition reaction between two pyrimidine bases [47] in singlestranded DNA (ssDNA) and at the flexible ends of poly (dA)-(dT) tracts, but not at their rigid centre $[50,51]$. Bending of DNA towards the minor groove reduces CPDs formation [52]. One of the transcription factors, TATA-box binding protein (TBP), promotes the selective formation of 6-4PPs in the TATA-box, where the DNA is bent, but CPDs are formed preferentially at the edge of the TATA box and outside where the DNA is not bent [53]. The amounts of CPDs and 6-4PPs are about 75 and 25\%, respectively, of the total UV-mediated DNA damage products [22]; however, the ratio between the yield of CPDs and 64PPs mainly depends upon the two adjacent bases involved in the formation of dimers [54]. Thus the heterogeneous distribution of the UV-induced photolesions in the DNA depends on the sequences that facilitate DNA bending as well as the chromatin modulation through the binding of specific protein [55]. Mapping of CPDs in the nucleosome core 


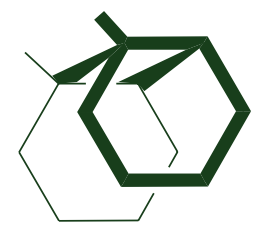

Cis-syn

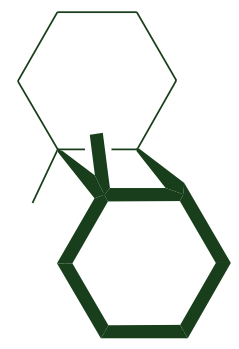

Trans-syn
Cis-anti

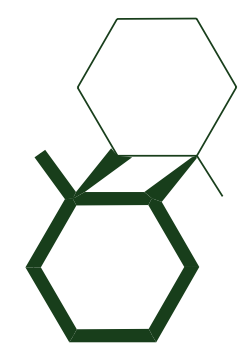

Trans-anti

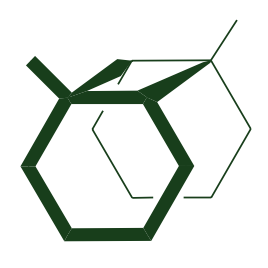

FIgURE 4: Possible diastereoisomers of pyrimidine $\mathrm{T}<\mathrm{T}$ dimer.

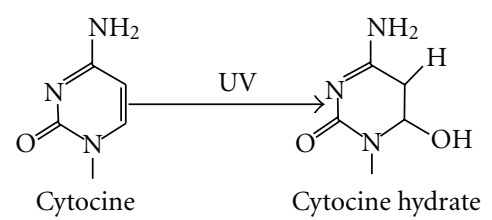

FIGURE 5: Formation of cytosine photohydrate (6-hydroxy-5,6dihydrocytosine) as a result of photohydration reaction.

regions of UV-treated chromatin has revealed the formation of CPDs with an average distance of 10.3 bases, away from the surface of histones [56]. The formation of photoproducts is not restricted to cells exposed to UV-B or UV-B + UV-A radiations; UV-A-induced formation of CPDs has also been observed in bacteria as well as in eukaryotic cells and whole skin [57-59]. Recent studies on the effects of UV-A radiation on rodent and human skin cells have revealed that CPDs are in larger yields than 8-oxo-7,8-dihydroguanine (the most frequent UVA-induced DNA lesion) and DNA strand breaks $[48,60]$. The occurrence of 5-methylcytosine-containing photoproducts in UV-irradiated DNA is still controversial. However, Su et al. [61] have reported a new photoproduct of 5-Methylcytosine and Adenine characterized by highperformance liquid chromatography and mass spectrometry. An additional photochemical characteristic for cytosine is the formation of monomeric pyrimidine photoproduct "cytosine photohydrate" (6-hydroxy-5,6-dihydrocytosine) as a result of photohydration reaction (Figure 5) [62]. There is little information concerning the formation of cytosine hydrates in UV-irradiated DNA due to instability of the resulting photoproduct [63]. The oxidation product of pyrimidine bases such as pyrimidine glycols is also formed by means of hydration reaction [42].

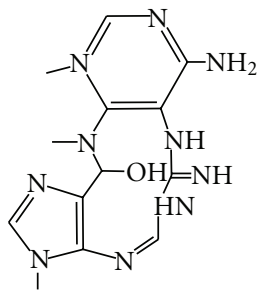

Adenine dimer<smiles>CN=CNc1ncn(C)c1-c1nc2c(N)ncnc2n1C</smiles>

Porschke photoproduct

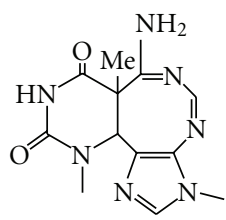

T-A photoadduct
FIGURE 6: Structure of purinic photoproduct, that is, adenine dimer, porschke photoproduct and thymine-adenine photoadduct.

\section{UV-Induced Purine Photoproducts}

Although dipyrimidine photoproducts are the preferential outcome of UV-B radiation, the biological importance of UV radiation-induced modifications of DNA purine bases has also been recognized [64]. These comprise the photoproducts that involve, at least, one adenine residue that undergoes photocycloaddition reactions with contiguous adenine or thymine (Figure 6) upon exposure to UV-B radiation [65, 66]. The extent of adenine-containing photoproduct (A-T) is very low $\left(1 \times 10^{-5}\right.$ in native DNA) but these lesions may contribute to the biological effects of UV radiation in view of the fact that the $\mathrm{A}-\mathrm{T}$ adduct has been shown to be mutagenic $[67,68]$. Photodimerization of adenine (A) involves the cycloaddition of N7-C8 double bond of the $5^{\prime}-\mathrm{A}$ across the $\mathrm{C} 6$ and $\mathrm{C} 5$ positions of the $3^{\prime}-\mathrm{A}[65,69]$ and generates a very unstable azetidine intermediate. This intermediate photoproduct undergoes competing reaction pathways to form two distinct adenine photoproducts such as adenine dimer $(\mathrm{A}=\mathrm{A})$ and Pörschke photoproduct (Figure 6) [70]. Conversion of both these photoproducts into 4,6-diamino-5-guanidinopyrimidine (DGPY) and 8(5-aminoimidazol-4-yl)adenine (8-AIA), respectively, can be detected from individual acid hydrolysates of UVirradiated polynucleotides and DNA [71]. It has been found that complexing of UV-irradiated poly(dA)-poly(dT) effectively reduces the formation of $\mathrm{A}=\mathrm{A}$ photoproduct [71]. Moreover, photoreactivity of adjoining adenine bases in DNA is strongly suppressed by the complementary base pairing $[50,72]$. UV-induced ROS acts as a powerful oxidant that may cause oxidative DNA damage. A number of oxidation products of purine bases such as 8-oxo7,8-dihydroguanyl (8-oxoGua), 8-oxo-Ade, 2,6-diamino4-hydroxy-5-formamidoguanine (FapyGua), FapyAde, and oxazolone have been reported to form upon exposure of DNA to UV radiation $[44,73,74]$.

Overall, it has been concluded that UV-induced DNA lesions such as CPDs, 6-4PPs, abasic site, strand breaks, and oxidative product are the predominant and most persistent lesions and if not repaired may cause severe structural distortions in the DNA molecule, thereby affecting the important cellular processes such as DNA replication and transcription, compromising cellular viability and functional integrity and ultimately leading to mutagenesis, tumorigenesis, and cell death $[30,36]$. 


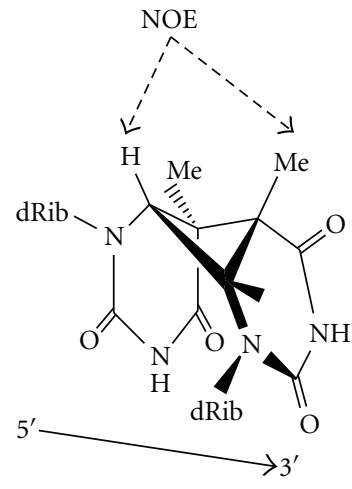

(a)

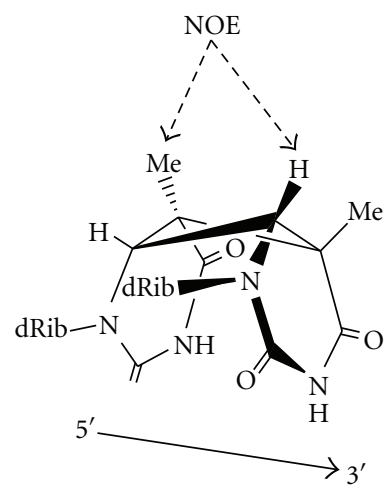

(b)
Figure 7: Cis-syn CPD showing the right-handed or left-handed twist in DNA duplex. Dotted arrows elucidate the strongest nuclear overhauser enhancement (NOE) interaction in both cases (Adopted from Lukin and de los Santos [75]).

\section{Differential Effects of CPDs and 6-4PPs on DNA Conformation}

UV-induced DNA lesions such as CPDs and 6-4PPs show differential effects on DNA conformation, impairing their regulatory functions and other dynamic processes [24, 26, 75, 76]. Nuclear Magnetic Resonance (NMR) spectroscopy has presented new insights on UV radiation-induced nucleic acid conformation. It has been well established that the comparative orientation of damaged residues is unusual from that observed in unmodified DNA duplexes [75]. Nuclear overhauser enhancement (NOE) study of interactions among the photoadduct $\mathrm{H} 6$ and methyl $\left(\mathrm{CH}_{3}\right)$ groups has established that the cis-syn CPD changes the cyclobutane conformation from a left-handed twist (observed in the isolated dimer) to a right-handed twist in DNA duplex [46] (Figure 7). Assessment of the chemical shift data suggests that the DNA helix is disturbed more along the $3^{\prime}$ - and $5^{\prime}$-side of the cis-syn and trans-syn dimer, respectively. It was revealed that the presence of trans-syn CPD causes distortion to a great extent than the cis-syn product by means of a kink or dislocation at the $5^{\prime}$-side of the dimer in double-stranded DNA [77]. NMR and X-ray diffraction studies of the ultraviolet photoproduct, cis-syn CPD, with the S-cyanoethyl phosphotriester have revealed that the two pyrimidine bases are rotated by $-29^{\circ}$ base twist, contrasting to the right-handed $36^{\circ}$ value observed in B-form DNA $[78,79]$. Moreover, in contrast to the cis-syn CPD, the duplex spectra of the trans-syn lesion illustrated no abnormally shifted ${ }^{31} \mathrm{P}$ or imino proton signal, signifying the absence of major distortions in the conformation of the sugarphosphate backbone [75]. The thymine (T) residues of the CPD form stable wobble pairs with the opposite guanine (G) residues. The T6-G15 wobble pair of the CPD formed hydrogen bonds between the T6-imino and G15-O6 and between the G15-imino and T6-O2. The two T (T5, T6) residues of the $\mathrm{CPD}$ in the $\mathrm{CPD} / \mathrm{GG}$ duplex form wobble base pairs with the opposite $\mathrm{G}$ residues, similar to the T6G15 base pair in the CPD/GA duplex [80]. It has been reported that the preexisting CPDs in the DNA molecule can influence its rotational setting on the histone surface during nucleosome formation [81]. Recently, Rumora et al. [82] have examined the thymine dimer-induced structural changes to the DNA duplex with several small, base-selective reactive chemical probes. The formation of 6-4PPs and their Dewar isomers cause remarkable change in the conformation of DNA duplex. The one- and two-dimensional NMR data on the (6-4)-adduct-containing DNA duplex decamer was analyzed in $\mathrm{H}_{2} \mathrm{O}$ and $\mathrm{D}_{2} \mathrm{O}$ solutions to elicit the base pairing and unusual conformation in the vicinity of the lesion [76, $83,84]$. The distortion of the double helix caused by the 6$4 \mathrm{PP}$ is much greater than that of the CPD [85].

The main conformational perturbations caused by the (6-4) adduct and Dewar product are concerned with their effects on global DNA curvature. Both duplex decamers are significantly bent at the lesion sites. In contrast to the 6-4PPs, the 5,6-dihydro-5-hydroxythymine base is the most perturbed part of the 6-4 Dewar lesion. Even though there are no hydrogen bonds between 5,6-dihydro-5-hydroxythymine and its partner adenine residue, this lesion produces minor distortions in comparison to the 6-4PP. In general helical bending induced by the (6-4) adducts and the Dewar product is $44^{\circ}$ and $21^{\circ}$, respectively [76]. All the supplementary imino proton resonances from the flanking base pairs were observed in the hydrogen-bonded region, which indicate that the structure of the (6-4) adduct inside the duplex shows a distinctive base orientation due to (6-4) covalent linkage which makes a normal Watson-Crick-type hydrogen bonding unfavorable at the $3^{\prime}$-side of the lesion site with an empty space between the $3^{\prime}$-thymine (T6) and its opposite base (A15) [76]. Contrary to the duplex (6-4) decamer which retains a hydrogen-bonded imino proton at the $5^{\prime}$-side (T5) of the (6-4) lesion, the T5 imino proton of the Dewar lesion is not hydrogen-bonded. The NMR characterization of a 6 -4PP dimer containing duplex showed that the $5^{\prime}$-residue of the lesion remains essentially unperturbed. However, the 5 -pyrimidine residue looses aromaticity and acquires an additional hydrophilic group $[75,83]$. The glycosyl bond torsion angle at the T5 residue of the (6-4) lesion and the Dewar lesion prevails in the anti and high-anti conformation, respectively, and thus both the lesions exhibit considerable differential effects on DNA backbone conformation. It has been observed that the large structural distortion induced by the (6-4) lesion may ensure a favorable recognition by the repair enzyme, which may possibly elucidate the correlation with the elevated repair rate of the T-T (6-4) adduct than of the T-T Dewar product and the T-T cis-syn dimer [76].

\section{UV-Induced DNA Double Strand Breaks}

The generation of DNA double strand breaks (DSBs) in UV-irradiated cells, specifically in replicating DNA, has been known for a long time [86]. DNA strand breaks are observed extensively in cells under UV-B irradiation $[87,88]$. UV-B-induced ROS [89] as well as DNA lesions 


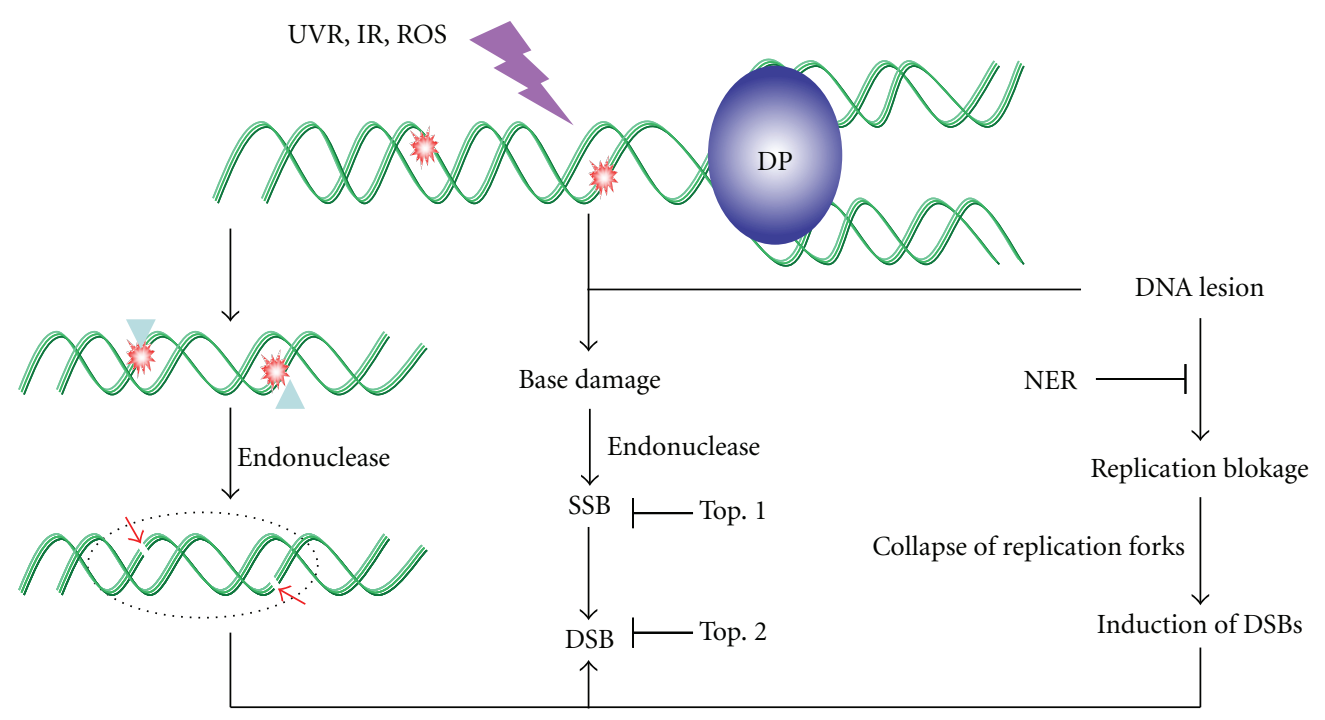

FIGURE 8: Schematic representation showing different pathways of DSBs.

(CPDs and 6-4PPs) may cause primary as well as secondary breaks, respectively. These lesions are commonly associated with transcription/replication blockage that may lead to production of DNA double-strand breaks (DSBs) at the sites of collapsed replication forks of CPDs-containing DNA [90, 91] (Figure 8). Dunkern and Kaina [92] also observed UVC-induced DNA DSBs, arising from replication of damaged DNA. A significantly low amount of DSBs was found in the cell where replication was inhibited. It was assumed that initial photoproducts are converted into DSBs during DNA replication, due to not a distinct process, that is, "collapse of replication forks" [93]. After labeling of replicating DNA of UV-irradiated SV40-transformed human cell lines with radioactive precursors, an increased number of DSBs was observed in NER deficient cells in comparison to NER proficient cells. These results further support the view that DSBs are produced during the replication of unrepaired UVinduced DNA lesions [91]. DSBs can be formed in response to the repair of single strand breaks (SSBs) passing through base excision repair (BER) [94, 95]. Overall, it seems that UV radiation does not directly produce DNA DSBs but rather produces pyrimidine dimers and other photoproducts leading to replication arrest and DSBs. UV-induced replication arrest in the xeroderma pigmentosum variant (XPV) followed by the accumulation of Mre11/Rad50/Nbs1 complex and phosphorylated histone H2AX $(\gamma-\mathrm{H} 2 \mathrm{AX})$ in large nuclear foci at sites of stalled replication forks also suggests that UV damage leads to the formation of DSBs during the course of replication arrest $[90,95]$.

A number of pathways have been considered for the formation of DSBs at a stalled replication fork. It was shown that when the DNA replication machinery encounters a replication-blocking lesion, DNA polymerase (DP) enzyme is stalled at the blocked site resulting in the formation of a Yshaped DNA structure, which may be recognized by a specific endonuclease, that successively makes a nick in the template strand resulting in the induction of a DSB close to the replication-blocking lesion [144]. Furthermore, replication stresses may trap topoisomerase I (Top1) cleavage complexes leading to generation of DSBs by preventing Top1-mediated DNA religation [145]. Free radicals may also cause DSBs [146] by preventing the topoisomerase II (Top2)-mediated DNA religation [144, 147]. Recently, Harper et al. [148] have shown that radiation-induced SSBs and non-DSB DNA damage contribute to the formation of replication-induced DSBs. In spite of the above possible facts regarding the formation of DSBs, more experimental evidences are still needed.

\section{Detection of DNA Damage}

Several workers have attempted to detect different types of DNA lesions and presently a number of detection strategies are widely used (Table 1). An alkaline gel method for quantitating single-strand breaks (SSBs) in nanogram quantities of nonradioactive DNA was developed by Freeman et al. [149]. Mitchell et al. [150] have developed a method for the detection of CPDs, where DNA is labeled with radioactive substances followed by agarose gel electrophoresis and densitometric analysis and finally digesting with endo. III and endo.V before analyzing on sequencing gels. UV-B induced DNA damage in mammalian genome was reported by Wang et al. [96] using the PCR-based short interspersed DNA element- (SINE-) mediated detection method. For analyzing the 6-4PPs, terminal transferase-dependent PCR (TD-PCR) has been used [97]. UV-induced decrease in template activity of genomic DNA of cyanobacterium Anabaena strain BT2 was documented by Kumar et al. [98] using the PCRbased assays such as random amplified polymorphic DNA (RAPD) and rDNA amplification. Similarly, UV-B-induced DNA damage was also detected in Anabaena variabilis PCC 7937 and Rivularia sp. HKAR-4 by PCR (data not published). The formation of thymine $\operatorname{dimer}\left(\mathrm{T}^{\wedge} \mathrm{T}\right)$ within 
TABLE 1: Various strategies for the detection of damaged DNA.

\begin{tabular}{|c|c|c|}
\hline DNA damage detection strategies & Types of lesions detected & References \\
\hline $\begin{array}{l}\text { PCR based assay (TDPCR, LMPCR, ICPCR, } \\
\text { SINE) }\end{array}$ & Decrease in DNA template activity, $\mathrm{T}<>\mathrm{T}$ CPDs, $6-4 \mathrm{PPs}$ & {$[96-99]$} \\
\hline Commet assay (Single-cell gel Electrophoresis) & Oxidative DNA damage and single/double strand break & {$[100,101]$} \\
\hline Halo assay/AHA/FHA & Chromatin fragility/single strand breaks at the single cell level & {$[102,103]$} \\
\hline TUNEL assay & Single/double strand breaks, apoptosis & {$[104,105]$} \\
\hline HPLC-MS/MS & $\begin{array}{l}\text { Oxidative DNA damage; CPDs, } 6 \text {-4PPs and their related Dewar } \\
\text { valence isomers; 5-hydroxy-2-deoxyuridine,8-oxo-7,8-dihydro- } \\
\text { 2-Deoxyadenosine; 5-Methylcytosine and } \\
\text { adenine }\end{array}$ & {$[48,54,61,106]$} \\
\hline FISH & Chromosomes with numerical aberrations & {$[107,108]$} \\
\hline FCM & $\begin{array}{l}\text { Chromosomal aberrations, sister chromatid exchange, chemical } \\
\text { adducts to DNA and DNA strand breakage }\end{array}$ & {$[109,110]$} \\
\hline Annexin V labeling & $\begin{array}{l}\text { Chromatin condensation, DNA fragmentation, } \\
\text { radiation-induced apoptosis }\end{array}$ & {$[109,111]$} \\
\hline Immuno-dot-blot assay & CPDs, 6-4PPs and their Dewar valence isomers & {$[17,59,112,113]$} \\
\hline RIA & CPDs and 6-4PPs & {$[114,115]$} \\
\hline GC-MS & $\begin{array}{l}\text { Strand break, modified bases, abasic sites, DNA-protein } \\
\text { crosslinks and other oxidative DNA damage. }\end{array}$ & {$[39]$} \\
\hline FADU & Single/double strand breaks and alkali-labile sites & {$[88,116]$} \\
\hline NMR spectroscopy & Lesions induced distortions of DNA duplex & {$[78-80]$} \\
\hline
\end{tabular}

human genomic DNA has been detected by immunocoupled PCR (IC-PCR) [99]. DNA damage such as SSBs, DSBs, and oxidative DNA damage caused by UVR, ultrasound electromagnetic frequency radiation, and so forth may be detected by comet assay [100]. Recently, a modified version of comet assay (apo/necro-comet assay) has been developed that differentiates viable, apoptotic, and necrotic cells and also correlates the DNA fragmentation pattern [101]. Both single and DSBs as well as apoptosis can also be detected by TUNEL assay [104, 105]. However, it has been experienced that TUNEL assay is not able to distinguish various types of cell death; hence, an alternate method based on flow cytometry (FCM) has been developed for the detection of apoptosis [109]. Recently, apoptosis in tumor cells caused by X-rays has been analyzed using ${ }^{125-}$ I-labeled annexin $\mathrm{V}$ [111]. FCM assay is useful in detecting chromosomal aberrations, sister chromatid exchange, chemical adducts to DNA, and DNA strand breakage [110]. Alkaline unwinding FCM (AU-FCM) may be used to detect nucleotide excision repair (NER) [151]. The changes in DNA organization in the individual cells can be determined by halo assay [102]. SSBs at the single cell level can be assessed by alkaline-halo assay (AHA), where cells are embedded in melted agarose and spread on the microscope slide and then incubated in a high-salt alkaline lysis solution followed by another incubation in a hypotonic alkaline solution and, finally, stained with ethidium bromide (EtBr). Under these conditions, single-stranded DNA fragments diffuse radically from the nuclear cage [103]. DNA strand breaks (SSBs, DSBs, and alkali-labile sites) induced by genotoxic agent such as UVR can also be detected by fluorometric analysis of DNA unwinding (FADU) assay, which was first reported by Birnboim and Jevcak [116] to detect Xray-induced DNA damage in mammalian cells. Numerical aberrations in chromosome can be detected efficiently by fluorescence in situ hybridization (FISH) method [107]. Recently, immuno-dot-blot assay is used extensively to detect UV-induced photoproducts in various organisms such as mammals, cyanobacteria, phytoplankton, macroalgae, and liverwort $[17,59,112,113]$. This technique is based on use of thymine-dimer specific antibodies followed by blotting and chemiluminescence method. Another detection strategy includes radio-immunoassay (RIA) which is used to estimate CPDs and 6-4PPs [114]. The very low amount of CPDs caused by UVR in bacterioplankton and marine viruses may be detected very efficiently using RIA method [115]. Kara et al. [152] have studied the electrochemical detection of DNA damage by direct and indirect irradiation with radioactive technetium (TC-99m) and iodine (I-131). Certain photoproducts such as 5-Methylcytosine and adenine can be detected by high-performance liquid chromatography and mass spectrometry [61]. Recently, Kumari et al. [108] have made an attempt to dissect various strategies for detection of DNA lesions produced by a number of genotoxic agents. 
TABle 2: Photolyase enzymes in four different kingdoms.

\begin{tabular}{|c|c|c|c|c|}
\hline Kingdom & Organism & CPD Photolyase & $\begin{array}{c}\text { 6-4PP } \\
\text { Photolyase }\end{array}$ & References \\
\hline \multirow{3}{*}{ Archaebacteria } & Halobacterium halobium & + & - & [117] \\
\hline & Methanobacterium thermoautotrophicum & + & - & {$[118,119]$} \\
\hline & Sulfolobus tokodaii & + & - & [120] \\
\hline \multirow{8}{*}{ Eubacteria } & Bacillus firmus & + & - & [121] \\
\hline & Escherichia coli & + & - & {$[122,123]$} \\
\hline & Salmonella typhimurium & + & - & [122] \\
\hline & Anacystis nidulans & + & - & [124] \\
\hline & Synechocystis sp. PCC 6803 & + & - & [125] \\
\hline & Streptomyces griseus & + & - & [126] \\
\hline & Myxococcus xanthus & + & - & [127] \\
\hline & Vibrio cholerae & + & - & {$[128]$} \\
\hline \multirow{15}{*}{ Eukaryotes } & Saccharomyses cerevisiae & + & - & {$[122]$} \\
\hline & Neurospora crassa & + & - & {$[129,130]$} \\
\hline & Drosophila melanogaster & + & + & [131] \\
\hline & Homo sapiens & $?$ & $?$ & {$[118,132]$} \\
\hline & Carassius auratus & + & - & [133] \\
\hline & Oryzias latipes & + & - & {$[118]$} \\
\hline & Monodelphis domestica & + & - & {$[134]$} \\
\hline & Potorous tridactylis & + & - & [118] \\
\hline & Xenopus laevis & + & + & [135] \\
\hline & Arabidopsis thaliana & + & + & [136] \\
\hline & Chlamydomonas reinhardtii & + & - & [137] \\
\hline & Cucumis sativus & + & - & {$[138,139]$} \\
\hline & Ginkgo biloba & + & - & {$[140]$} \\
\hline & Medicago sativa & + & - & {$[20]$} \\
\hline & Triticum sp. & + & - & [141] \\
\hline \multirow{3}{*}{ Viruses } & Fowl pox virus $(\mathrm{FPV})$ & + & - & [142] \\
\hline & $\begin{array}{c}\text { Melanoplus sanguinipes entomopox virus } \\
(\mathrm{MsEPV})\end{array}$ & + & - & [143] \\
\hline & $\begin{array}{l}\text { Chrysodeixis chalcites nucleopolyhedrovirus } \\
\text { (ChchNPV) }\end{array}$ & + & - & {$[106]$} \\
\hline
\end{tabular}

\section{DNA Repair}

The idea about the ability of living beings to overcome the lethal effects of UV-radiation emerged as early as the mid 1930s [153], but the existence of repair mechanisms was observed by Kelner [154] and Dulbecco [155] independently. The determination of a particular repair pathway within the cell mainly depends on the types and location of lesions in the genome [156]. The biochemical and molecular studies on repair pathways have been extensively investigated in some model organisms such as E. coli, S. cerevisiae, and human, where specialized repair proteins scan the genome continuously and encounter the DNA lesions by triggering several distinct repair mechanisms such as photoreactivation, excision repair (BER and NER), mismatch repair (MMR), and some specialized forms of repair system such as SOS response, damage tolerance, and apoptosis.

\section{Photoreactivation}

The process of photoreactivation is executed by means of a photoreactivating enzyme known as "photolyase", which is well conserved and found throughout the three domains of life (Table 2). The enzyme binds specifically to the CPDs (CPD photolyase) or 6-4PPs (6-4 photolyase) and directly monomerizes the cyclobutane ring of the pyr $<$ pyr, using the energy of visible/blue-light and protects the genome from deleterious effects of UVR [157, 158]. The absorption of every blue-light photon may split approximately one dimer [159]. CPD photolyases have been reported in diverse groups such as archaea, bacteria, fungi, virus, plants, invertebrates, and many vertebrates including aplacental mammals (Table 2). On the other hand, 6-4 photolyases have been identified in certain organisms like Drosophila, silkworm, Xenopus laevis, and rattle snakes [22]. Photolyases seem to be 


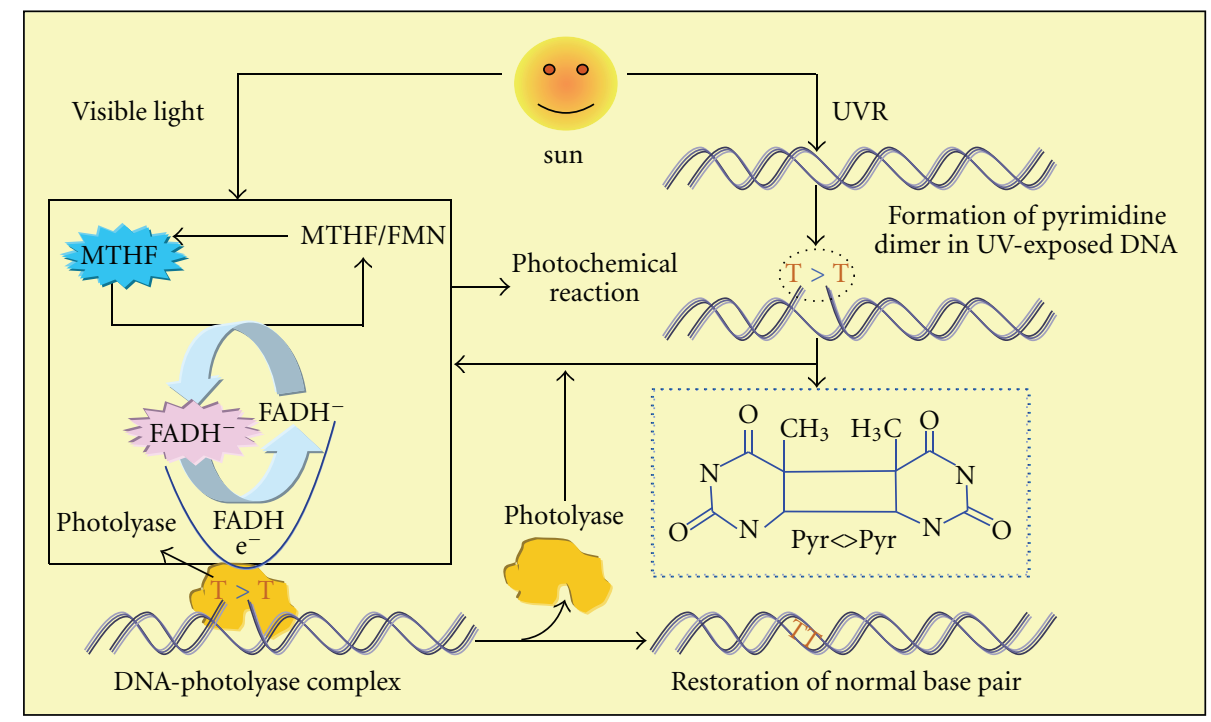

FIGURE 9: Photoreactivation: incidence of ultraviolet radiation (UVR) results in pyrimidine lesion (thymine dimer), which is recognized by a photoreactivating enzyme "photolyase". The light energy $(>380 \mathrm{~nm})$ is trapped by the antenna molecules of photolyase (such as MTHF/8$\mathrm{HDF} / \mathrm{FMN}$ ) and transfers them to catalytic cofactor $\mathrm{FADH}^{-}$which becomes excited and transfers energy to the pyrimidine dimer in the form of $\mathrm{e}^{-}$, splitting the CPD into two monomeric unit, and then electron is transferred back to the flavin molecule.

absent or nonfunctional in placental mammals like human $[118,132,160]$. However, Sutherland [161], Sutherland and Bennett [162], and Harm [163] have demonstrated photolyase activity in cells and tissues, including white blood cells (WBCs) of several placental mammals, such as humans, ox, cat, and mouse. A number of workers have identified a human photolyase which shows homology with Cry gene (plant blue-light receptor) and about $40 \%$ sequence identity to the Drosophila 6-4 photolyase, but their exact roles in repair process, whether it acts as a photolyase or as a photoreceptors, are still under investigation [164].

DNA photolyases (45-66 kDa) having 420-616 amino acid residues [158] are monomeric flavin-dependent repair enzymes, consisting of two known cofactors, a catalytic cofactor and a light-harvesting cofactor. Till date, 5,10-methenyltetrahydrofolate (MTHF) [122], 8-hydroxy-5deaza-riboflavin (8-HDF) [124], and FMN [165] are known as light-harvesting cofactors, which absorb light energy efficiently and transfer them to $\mathrm{FADH}^{-}$[166]. Deprotonated reduced flavin adenine dinucleotide $\left(\mathrm{FADH}^{-}\right)$is found in all known photolyases as a catalytic cofactor, which transfers energy in the form of an electron to the CPD, splitting the cyclobutane ring with the generation of two monomeric bases [157, 167] (Figure 9).

In comparison to other eukaryotic systems, reports on the repair of UV-induced DNA damage in plants are still very limited. To avoid the deleterious effects of UVR, plants have acquired two main protective strategies; shielding by flavonoids and phenolic compounds [168, 169] and DNA repair by photoreactivation. Photoreactivation mediated by the enzyme photolyases is thought to be the major DNA repair pathway in several higher plants such as rice, Arabidopsis, wheat, and maize [170-172]. Studies on Arabidopsis seedling, rice, and alfalfa indicate that photoreactivation greatly enhances the rate of removal of dimers, although, in the absence of photoreactivating (blue) light, dimers are slowly eliminated from bulk DNA and 6-4PPs are generally observed to be repaired more quickly than CPDs $[173,174]$. Plants grown in the presence of photoreactivating radiation can eliminate the majority of both 6-4 products and CPD lesion within hours, or in some cases minutes, of their induction [30]. The structural information about the interaction between CPD lesions and photolyases became clear with the help of X-ray crystallography [175] and nuclear magnetic resonance (NMR) spectroscopy [176]. However, how DNA photolyases find lesions in the DNA molecule is still not clear [158]. It has been observed that about $240 \mathrm{KJ} / \mathrm{mol}$ of energy is captured upon absorption, out of which about $125 \mathrm{KJ} / \mathrm{mol}$ energy is consumed during the initial electron transfer from the excited FADH to CPD lesions [177]. The splitting of CPD lesion proceeds rapidly within 0.6 nanosecond [ 167 , 178]. The back-transfer of electrons from the CPD lesion to the FADH radical is efficiently avoided by the enzyme before completion of cleavage of the cyclobutane ring [157]. With the help of ultrafast femtosecond laser spectroscopy, MacFarlane and Stanley [178] have suggested that photolyase enzyme is indeed left in the semiquinonid state after accomplishment of repair of the CPD lesion. However, Kavakli and Sancar [179] have analyzed the role of intraprotein electron transfer in photoreactivation by DNA photolyase and found that photoreduction process is not a regular part of the photolyase photocycle under physiological conditions, because the enzyme may undergo at least 25 repair cycles before loosing its activity. After completion of DNA repair, a thymine pair is flipped back into the duplex DNA to form a hydrogen bond with their complementary adenine base. Fourier transform infrared spectroscopy (FTIR) has revealed that the relaxation of DNA backbone proceeds very slowly 
than the repair of CPD lesions [180]. In the absence of photoreactivating light, the enzyme binds to pyr $<$ pyr and stimulates the removal of UV damage by stimulating the NER system in vivo or in vitro and defense against DNA damage even in the absence of light [181].

\section{Excision Repair}

Unlike photoreactivation, excision repair is a multistep, dark repair pathway, where an abnormal or damaged base is removed by two major subpathways: (i) base excision repair (BER) and (ii) nucleotide excision repair (NER).

10.1. Base Excision Repair (BER). BER is the predominant DNA repair pathway against base lesions arising from hydrolytic deamination, strong alkylating agents, ionizing radiation (IR), or by different intracellular metabolites and, indirectly, also by UV radiation via generation of ROS [182$184]$ and proceeds through a series of repair complexes that act at the site of DNA damage $[185,186]$. The efficiency and specificity of the repair pathway are determined by several forms of DNA glycosylase which removes different types of modified bases (Table 3 ) by cleaving the $\mathrm{N}$-glycosidic bond between the abnormal base and deoxyribose creating either an abasic site or an SSB [187]. Recently, Parsons et al. [188] have discovered that the formation of DNA repair complexes on damaged DNA stabilizes BER proteins. On the contrary, BER proteins that are not involved in repair are ubiquitylated by carboxyl terminus of $\mathrm{Hsc70}$ interacting protein (CHIP) and subsequently degraded by the proteasome.

The extent of BER conservation among E. coli and mammals has led to progress in our understanding of mammalian BER and here, a general overview of the mammalian BER pathway will be discussed. As a result of multiple interactions with a number of repair proteins XRCC1 plays a crucial role in the coordination of BER and SSB repair [189]. The interaction between XRCC1 and polymerase $\beta$ (Pol. $\beta$ ) and its functional aspects was confirmed after UV-A-induced oxidative damage in living mammalian cells [190]. The AP-site is removed by the action of AP endonuclease-1 (APE-1) along with phosphodiesterase that breaks the DNA strand along $5^{\prime}$ or $3^{\prime}$ to the AP site, respectively, and subsequently the gap is filled by a repair DNA polymerase and the strand is joined by a DNA ligase (Figure 10) $[182,191]$. It has been reported that the repair Pol. $\beta$ itself has the capacity to excise the $5^{\prime}$ deoxyribose phosphate residues, that is, generated by the combined actions of DNA glycosylase and ClassII AP endonuclease [192]. The major APE-1 that was discovered independently as an abasic site-specific endonuclease homologous to the E. coli Xth protein [193] incises duplex oligonucleotides containing 5,6-dihydroxyuracil (DHU), 5-hydroxyuracil (5$\mathrm{ohU}$ ), and alpha-anomeric $2^{\prime}$-deoxynucleosides (i.e., $\alpha \mathrm{dA}$ and $\alpha \mathrm{T})$ residues in human cells [194].

DNA having one nucleotide lesion is removed by short-patch BER (SP-BER) whereas two/more nucleotide lesion is repaired by long-patch BER (LP-BER) pathway [195] (Figure 10). Recently, Almeida and Sobol [184] have proposed a unified model of SP-BER and LP-BER. On the basis of measuring the BER efficiency and presence of a single modified base in a plasmid molecule transfected into mammalian cells, Sattler et al. [196] made the first attempt to verify the occurrence of LP-BER in vivo. It is assumed that majority of repair takes place through SP-BER, initiated either by monofunctional or by bifunctional glycosylase [184]. The pathway of SP-BER after excision of damaged base involves the recruitment of poly (ADP-ribose) polymerase-1 (PARP-1) followed by scaffold protein XRCC1 and DNA pol. $\beta$ to replace the damaged nucleotide. DNA ligase III (Lig. III) seals the nick and restores the intact DNA.

It has been observed that radiation- (X-rays, $\gamma$-rays) induced breaks exist mainly as $5^{\prime} \mathrm{p}$ and $3^{\prime} \mathrm{p}$ at the margin of the gap $[197,198]$ which is converted by the polynucleotide kinase (PNK) or APE1 into $5^{\prime} \mathrm{P}$ and $3^{\prime} \mathrm{OH}$ moieties, necessary for the DNA synthesis [199]. Unlike SP-BER, LP-BER involves proliferating cell nuclear antigen (PCNA) coupled with DNA pol. $-\delta / \varepsilon$ or $\beta$ which extends and fills the gap by inserting 2-13 nucleotide [184]. The replication factor C (RF-C) is required to load PCNA onto the damaged DNA [195]. The flap endonuclease (Fen1) protein then displaces the ensuing DNA flap leaving a nick which is ligated by DNA ligase I (Lig. I) [200, 201].

In several plant species, some of the genes requisite for dark repair have been identified [171, 172, 202-204]. The available evidence supports the additional existence of enzyme-mediated excision-repair mechanisms in a variety of systems including pollen, whole seedlings and plants, and protoplasts derived from leaves and cultured cells $[205,206]$. The formation of AP sites has been observed in seeds of Zea mays during early germination. This phenomenon was attributed to the action of DNA glycosylases on lesions accumulated during seed storage [207], implying the presence of BER in this species. Likewise, an enzyme activity attributed to uracil-DNA glycosylase was found in cultured cells of Daucus carota [208]. Recently, it has been reported that the mechanisms of BER and NER (but not photoreactivation) in higher plants are active in proliferating cells [172].

10.2. Nucleotide Excision Repair (NER). NER is critically important in the repair of UV-induced DNA lesions and is one of the most versatile and flexible repair systems found in most organisms but highly conserved in eukaryotes. It sorts out a wide range of structurally unrelated DNA lesions, such as CPDs and 6-4PPs caused by UVR, bulky chemical adducts, DNA-intrastrand crosslinks, and some forms of oxidative damage, that cause helical distortion of the DNA double helix as well as modification of the DNA chemistry and interfere with DNA duplication and transcription $[209,210]$. Although both 6-4PPs and CPDs are removed presumably by the same NER proteins, the relative repair efficiency of both of these lesions varies considerably in mammalian cells. It has been established that in human and hamster cells, the elimination of 6-4PP is at least fivefold faster than that of CPDs [211].

Discovery of NER was first described in E. coli [212, 213] where about six proteins such as UvrA, B, and C 
TABLe 3: DNA glycosylases and their probable substrate in bacteria, yeast, and human (modified from Sinha and Häder [22]).

\begin{tabular}{|c|c|c|c|}
\hline Glycosylases & Organisms & Genes & Substrate \\
\hline \multirow{6}{*}{ (1) Uracil DNA glycosylase } & E. coli & Ung & uracil from ss- and ds-DNA \\
\hline & & Dug/mug & $\begin{array}{l}\mathrm{U} \text { from } \mathrm{U}: \mathrm{G} \text {, ethenocytosine, hypoxanthine and } \\
\text { 5-hydroxycytosine }\end{array}$ \\
\hline & & Dut & $?$ \\
\hline & S. cerevisiae & $U N G$ & Uracil \\
\hline & Human & UNG1/UNG2 & uracil from ss- and ds-DNA \\
\hline & & SMUG1 & uracil from ss-DNA, hydroxymethyluracil, formyluracil \\
\hline \multirow{4}{*}{$\begin{array}{l}\text { (2) 3-methyl adenine DNA } \\
\text { glycosylase }\end{array}$} & E. coli & $\operatorname{tag}$ & 3-methyladenine \\
\hline & & alkA & $\begin{array}{l}\text { 3-methyladenine, } 7 \text {-methylguanine, 2-methylcytosine, } \\
\text { 5-formyluracil }\end{array}$ \\
\hline & S. cerevisiae & MAG1 & 3-methyladenine, 7-methylguanine \\
\hline & Human & $\begin{array}{l}M P G \\
\text { Aag }\end{array}$ & 3-methyladenine hypoxanthine \\
\hline \multirow{6}{*}{ (3) UV-endonuclease } & $\mathrm{T} 4$ & $\operatorname{den} V$ & cis-syn-cyclobutane-type pyrimidine dimer \\
\hline & E. coli & $?$ & $?$ \\
\hline & Bacillus subtilis & $U V D E$ & Pyrimidine dimers \\
\hline & S. cerevisiae & $?$ & $?$ \\
\hline & S. pombe & $U V D E$ & Pyrimidine dimers \\
\hline & Human & $?$ & \\
\hline \multirow{4}{*}{$\begin{array}{l}\text { (4) Endonuclease } \\
\text { III/thymine glycol DNA } \\
\text { glycosylase }\end{array}$} & E. coli & Nth & 5-hydroxycytosine, thymine glycol, urea \\
\hline & S. cerevisiae & NTG1 & $\begin{array}{l}\text { oxidative DNA damage, thymine glycol and } \\
\text { formamido-pyrimidines, oxidized pyrimidines, } 2 \\
\text { formamido-pyrimidine-G, } \mathrm{Me}^{7} \text { - } \\
\text { formamido-pyrimidine-G }\end{array}$ \\
\hline & & NTG2 & $\begin{array}{l}\text { oxidative DNA damage, Thymine glycol and } \\
\text { formamido-pyrimidines residues, } 5 \text {-hydroxycytosine, } \\
\text { oxidized pyrimidines, } \mathrm{Me}^{7} \text {-fapy-G }\end{array}$ \\
\hline & Human & NTH1 & oxidized guanine lesions \\
\hline \multirow{5}{*}{ (5) Endonuclease VIII } & E. coli & $n e i$ & $\begin{array}{l}\text { Thymine, thymine glycol, urea, 5-hydroxycytosine, } \\
\text { dihydrothymine, and b-ureidoisobutyric acid }\end{array}$ \\
\hline & S. cerevisiae & $?$ & $?$ \\
\hline & Human & NEIL1 & $\begin{array}{l}\text { 5-hydroxyuracil, 5-hydroxycytosine, 5,6-dihydrouracil, } \\
\text { thymine glycol, formamido-pyrimidines (FapyA/G) }\end{array}$ \\
\hline & & NEIL2 & 5-hydroxyuracil and 5-hydroxycytosine \\
\hline & & NEIL3 & $?$ \\
\hline \multirow{3}{*}{$\begin{array}{l}\text { (6) fapy/8-oxoguanine } \\
\text { DNA glycosylase }\end{array}$} & E. coli & fpg/mutM & $\begin{array}{l}\text { 2,6-diamino-5-formamidopyrimidine } \\
\text { 8-oxo-7,8-dihydroguanine, 5-hydroxycytosine }\end{array}$ \\
\hline & S. cerevisiae & OGG1 & $\begin{array}{l}\text { 2,6-diamino-5-formamidopyrimidine } 8 \text {-oxoG, } 2 \\
\text { formamidopyrimidine-G, } \\
\mathrm{Me}^{7} \text {-formamidopyrimidine-G }\end{array}$ \\
\hline & Human & hOGG1 & 8-hydroxyguanine, $\mathrm{Me}^{7}$-formamidopyrimidine- $\mathrm{G}$ \\
\hline \multirow{3}{*}{$\begin{array}{l}\text { (7) A-G-mismatch DNA } \\
\text { glycolsylase }\end{array}$} & E. coli & mut $Y$ & Adenine/C \\
\hline & S. pombe & $s p M Y H$ & 2-aminopurine/G and A/2-aminopurine, Adenine/C \\
\hline & Human & MYH & Adenine from G:A, 8-oxoG: A, 2-hydroxyadenine \\
\hline \multirow{5}{*}{$\begin{array}{l}\text { (8) G-T-mismatch DNA } \\
\text { glycosylase }\end{array}$} & E. coli & $?$ & $?$ \\
\hline & $\begin{array}{l}\text { M. ther- } \\
\text { moautrophicum }\end{array}$ & Mig-Mth & Thymine residues from $\mathrm{T}-\mathrm{G}$ mismatches \\
\hline & S. pombe & $\operatorname{thp} 1$ & Uracil from $\mathrm{G}: \mathrm{U}$ \\
\hline & Human & $\begin{array}{l}\text { MBD4 } \\
(\approx M E D 1)\end{array}$ & Thymine from $\mathrm{T}: \mathrm{G}$ \\
\hline & & $T D G$ & Recognizes a G: T mispair in a CpG sequence \\
\hline
\end{tabular}


Table 3: Continued.

\begin{tabular}{llll}
\hline Glycosylases & Organisms & Genes & Substrate \\
\hline & E. coli & mug & Formyluracil mispaired with A \& G \\
& & mutM & $?$ \\
$\begin{array}{l}\text { (9) Formyluracil DNA } \\
\text { glycosylase }\end{array}$ & mutS cerevisiae & $?$ & Formyluracil mispaired with G \\
& Human & MBD4 & $?$ \\
& & hNTH1 & Formyluracil mispaired with G \\
(10) Hydroxymethyl uracil & E. coli & $?$ & $?$ \\
DNA glycosylase & S. cerevisiae & $?$ & $?$ \\
& Human & $?$ & 5-hydroxymethyluracil mispaired with G \\
\hline
\end{tabular}

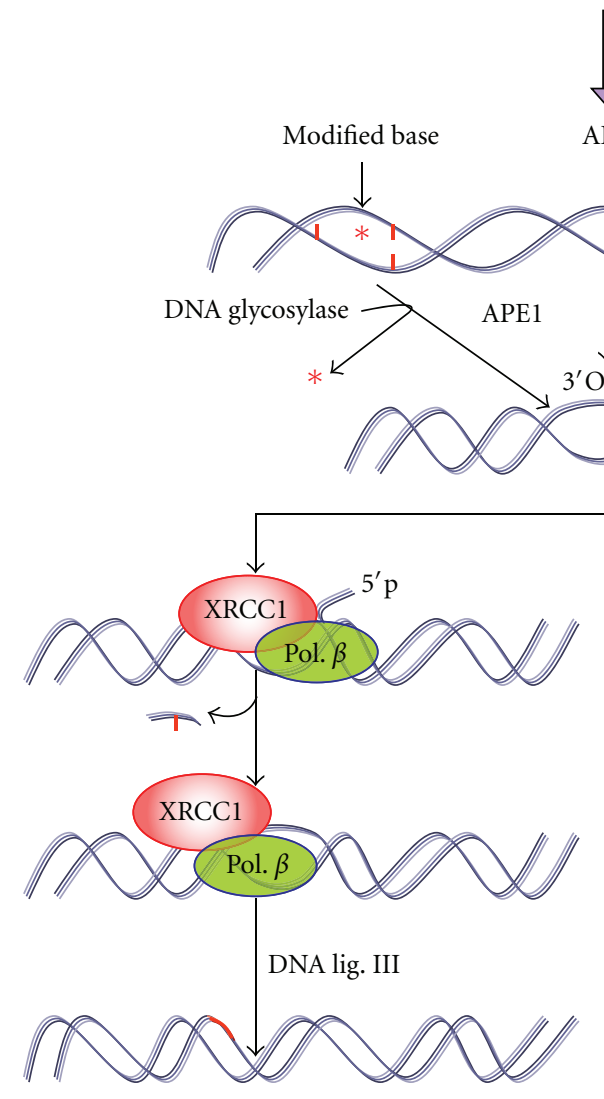

(a) SP-BER
ROS, alkylation, deamination, IR (X-rays, $\gamma$-rays)

SSB

$\mathrm{p} \downarrow \mathrm{p}$

\section{B}

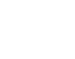




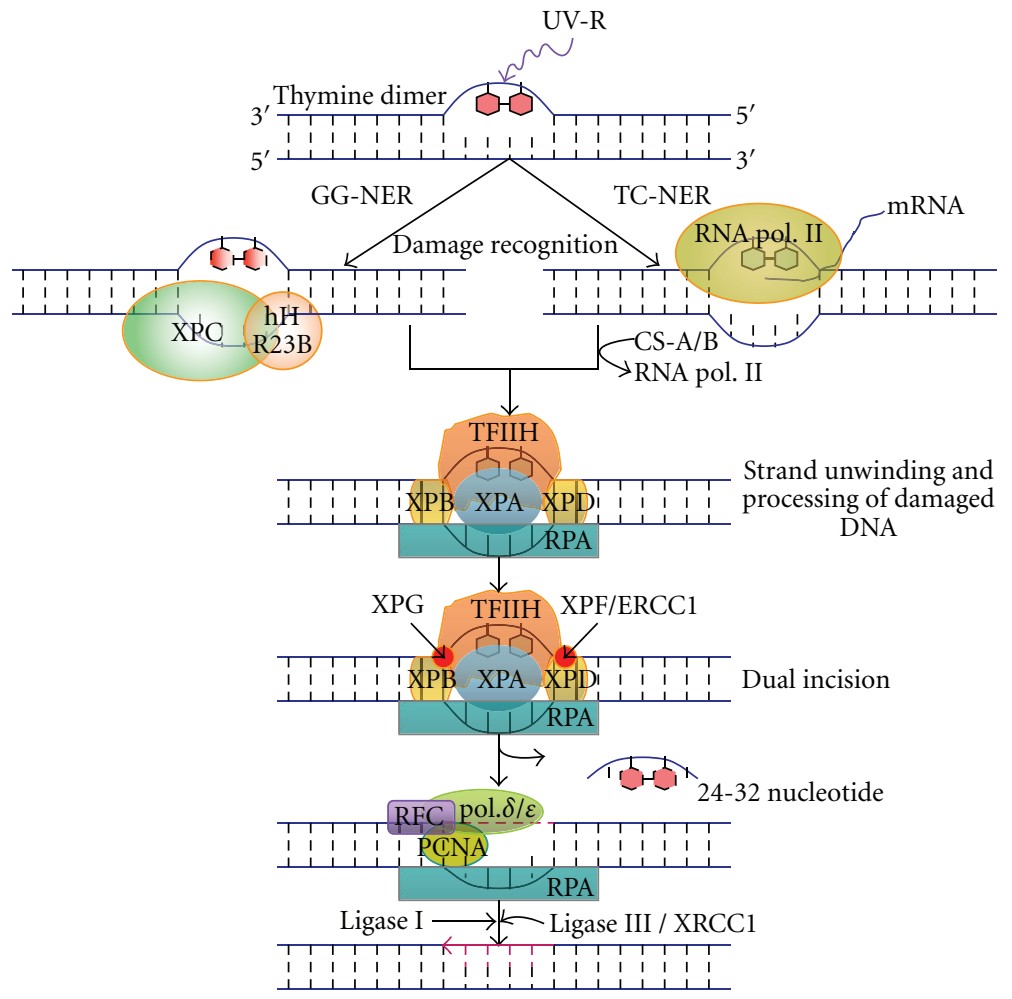

FIGURE 11: Molecular mechanisms of global genome nucleotide excision repair (GG-NER) and transcriptional coupled nucleotide excision repair (TC-NER) in mammals. For details see the text.

NER can be subdivided into differentially regulated subpathways such as global genome NER (GG-NER) and transcription-coupled NER (TC-NER): repair of lesions over the entire genome, referred to as global genome repair (GGR), and repair of transcription-blocking lesions present in transcribed DNA strands, referred to as transcription coupled repair (TCR). Both repair systems removed a wide range of UV-induced DNA lesions in a sequential way that includes damage recognition, opening of DNA double helix at damage site, and dual incisions on both sides of the lesion followed by resynthesis and ligation [210, 216] (Figure 11). In human XP-C cells, where the removal of 6-4PP takes place through the TCR pathway, the repair seems to be threefold slower as compared to normal cells. This indicates that the GGR is the most preferred and efficient pathway for 6-4PP removal [211].

\section{Mechanistic Differences between GG- and TC-NER in Mammalian Cells}

Global genome repair (GGR) is a random process that occurs gradually, whereas TCR, which is firmly linked to RNA polymerase II (RNA pol II) transcription, is highly specific and efficient. NER defects are associated with a surprisingly wide clinical heterogeneity.

It is assumed that TC-NER proceeds when the transcription machinery RNA pol II encounters a lesion. To progress the transcription-coupled repair (TCR), the stalled polymerase must be displaced, which is brought about by the recruitment of two proteins CSA and CSB. The CSA protein $(44 \mathrm{kDa})$ which belongs to "WD repeat" family of proteins exhibits structural and regulatory roles and CSB proteins $(168 \mathrm{kDa})$ which belong to SWI/SNF family of proteins exhibit DNA-stimulated ATPase activity [217219]. As stated earlier, elongation of active RNA pol II is prerequisite for efficient TCR; the CSA and CSB gene products are required for efficient repair only during the elongation stages of RNA pol II transcription. It has been suggested that the RNA pol II backs up some nucleotides upon encountering the lesion to facilitate the accessibility of the repair machinery to the lesion site $[220,221]$. It is expected that the CSB protein ubiquitinates the stalled elongating RNA pol II complex at the lesion and enhances the assembly of repair factors [222]. However, the fate and the role of ubiquitylated RNA pol II have yet to be clarified [223]. Recently, Fousteri et al. [224] has revealed that CSB is a prerequisite factor in vivo to assemble NER proteins while it is not essential to recruit TFIIH or NER complex in vitro. In living human cells, Proietti-De-Santis et al. [225] have shown that CSB is required during the first phases of RNA pol II transcription initiation. At higher dose of UV radiation (i.e., used for 6-4PP detection), elongation of RNA pol II is greatly impaired, affecting the efficiency of TCR. Hence, at higher UV radiation the GGR overrules the TCR pathway [55]. The probable relationship between TCR and blockage of RNA transcription subsequent to UV-irradiation may possibly be due to CSB which acts as a chromatin remodeling 


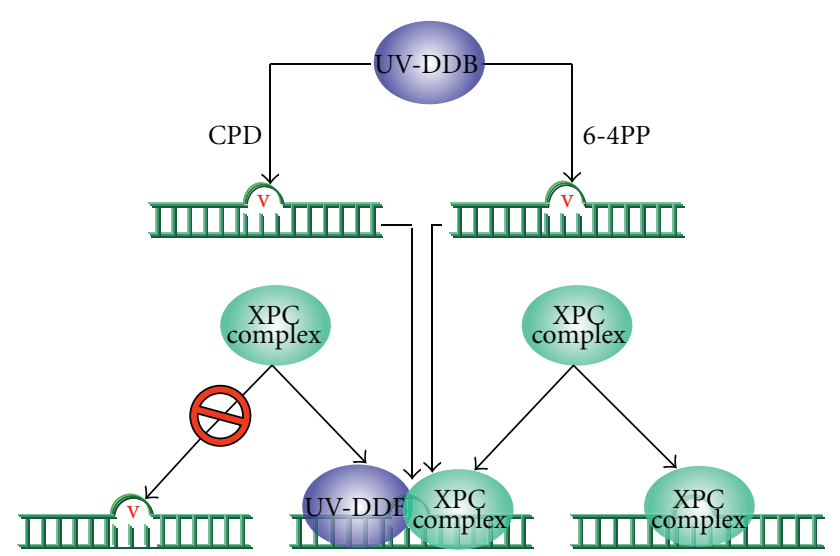

FIGURE 12: Different pathway for recognition of DNA lesions such as $\mathrm{CPD}$ and $6-4 \mathrm{PP}$. In case of CPD photoproduct (cause little distortion), XPC complex binds to the lesion after recruitment of UV-DDB whereas 6-4PP that distorts the DNA helix to a great extent can be recognized either by interacting with prebound UV$\mathrm{DDB}$ or directly by XPC complex.

factor at both levels, allowing either the recruitment of the transcription machinery at the initiation sites or the remodeling of the stalled RNA polymerase allowing the NER factors to access the lesion [223].

In GG-NER pathway, lesions produced in transcriptionally silent areas of the genome are recognized by hHR23BXPC protein complex in an energy-independent manner. The rate of GGR strongly depends on the type of lesion. For instance, 6-4PPs are removed much faster from the genome than CPDs, possibly because of disparity in affinity of the damage sensor hHR23B-XPC. XPC is the sole XP factor not essential for TCR and is restricted to GGR [211]. It is supposed that XPC binds preferentially to the stretch of ssDNA that occurs in the nondamaged strand, opposite to a lesion [252]. However, association of UV-damaged DNAbinding protein (UV-DDB) with a cullin-based ubiquitin ligase has revealed novel mechanistic and regulatory aspects of mammalian GG- NER. It was reported that XPC and UV-DDB materialize to assist for the efficient recognition of UV-induced photolesions and that both factors are ubiquitylated [250, 253]. Lesions that cause little distortion can be recognized by the DDB complex which is also part of an E3 ubiquitin (Ub) ligase that poly-ubiquitinates XPC and XPE [216]. A mechanistic pathway for recruitment of XPC complex to the major UV-induced photolesions (i.e., CPDs and 6-4PPs) has recently been elucidated [216, 253]. It was shown that $\mathrm{DDB}$ complex is recruited first to the lesion (CPD) before the XPC complex, on little distorted DNA helix; however, in case of large distortion of the DNA helix caused by $6-4 \mathrm{PPs}$, direct recognition by XPC is also possible for this lesion (Figure 12) $[216,253]$. However, the method by which XPC locates a lesion in the vast excess of undamaged DNA in the enormous mammalian genome is not clear [254] and it needs more investigation. On the basis of DNase I footprinting, Sugasawa et al. [226] showed that hHR23B-XPC attaches directly to DNA damage and alters the DNA conformation around the lesion. The
XPC protein $(125 \mathrm{kDa})$ is complexed with hHR23B protein $(58 \mathrm{kDa})$. These two proteins are human homologs of the yeast (S. cerevisiae) NER factor Rad4 and Rad23, respectively (Table 4). In mammalian cells, the quantity of hHR23B is higher than the XPC [255] and in vitro activation of the later protein is stimulated by hHR23B possibly in a structural quite than a catalytic way $[256,257]$. It has been assumed that hHR23A can substitute for hHR23B in complex formation and stimulation of XPC repair activity [258]. Both hHR23A and $-\mathrm{B}$ harbor a ubiquitin-like moiety at their amino terminus [230]. hHR23B-XPC complex or only XPC exhibits a similar high affinity for both UV-induced single-stranded DNA (ssDNA) and double-stranded DNA (dsDNA) [230, 259], preferentially binds to DNA with various lesions [259] and even to small bubble structures with or without a lesion [260]. hHR23B-XPC is absolutely required for dual incision as well as for open complex formation during GG-NER [243, 261]. Overall, it has been distinguished that RNA pol II with the recruitment of two proteins (i.e., CSA and CSB) proceeds the TCR while hHR23B-XPC complex is the first factor in NER that initiates GGR by sensing and binding lesions, locally distorting the DNA double helix and recruiting the other factors of the system [227].

After initial steps of damage recognition, the subsequent pathway for both GGR and TCR system is almost similar. The unwinding of DNA double helix at the site of lesion takes place by the components of multi-subunit transcription factor-IIH (TFIIH). TFIIH is a ten-subunit protein complex (Table 4) composed of a core complex (XPB, XPD, p62, $\mathrm{p} 44, \mathrm{p} 34, \mathrm{p} 52, \mathrm{p} 8)$ and of a cdk activating kinase (CAK) subunit (Mat1, Cdk7, CyclinH) [236]. TFIIH is usually involved in initiation of RNA Pol II transcription, but upon DNA damage can be employed in cell cycle regulation and NER (both in global genome and TC-NER) [228, 235]. Two subunits of TFIIH such as XPB ( $3^{\prime}$ to $5^{\prime}$ helicase) and XPD ( $5^{\prime}$ to $3^{\prime}$ helicase) are responsible for opening of DNA double helix around the lesion in an energy (ATP) dependent manner. It has been found that the XPD helicase activity is dispensable for in vitro transcription [262] but seems to play an additional architectural role within the complex by connecting the core TFIIH with the CAK subunit $[228,236]$. After opening of DNA double helix by TFIIH, three proteins such as RPA, XPA, and XPG are recruited. The exact order of assembly of these proteins is not clear. Both XPA and RPA can recruit with the DNA lesions in absence of XPG, and similarly XPG can also join the damage sites in the absence of XPA [238, 239]. Moreover, XPA and heterotrimeric replication protein A (RPA; RPA70, 32 and 14) are recruited to confirm the presence of DNA damage and form a more stable preincision complex [185]. RPA was found to be required both for the dual incision and for the repair synthesis steps of NER [263]. It was assumed that RPA binds the nondamaged strand of the opened DNA bubble, thus allowing exact positioning and stimulation of the endonuclease activities of XPG and ERCC1-XPF [246, 247]. XPG, which belongs to flap endonuclease-1 (FEN1) family of structure-specific endonucleases [264], is not only involved in performing the $3^{\prime}$ incision in NER but also required for stabilizing the fully open DNA bubble structure 
TABLE 4: NER proteins and their probable role in human and S. cerevisiae.

\begin{tabular}{|c|c|c|c|c|c|}
\hline \multirow{2}{*}{ NER Factors } & \multicolumn{3}{|c|}{ Name } & \multirow{2}{*}{ Function } & \multirow{2}{*}{ References } \\
\hline & Human & Yeast S. cerevisiae & Size (a.a) & & \\
\hline \multirow{4}{*}{ XPC-hHR23B } & $\mathrm{XPC}$ & $\operatorname{Rad} 4$ & 940 & $\begin{array}{l}\text { Binds damaged DNA; recruits other NER } \\
\text { proteins; works with hHR23B. involved } \\
\text { only in GGR }\end{array}$ & {$[22,226,227]$} \\
\hline & hHR23B & $\operatorname{Rad} 23$ & 409 & $\begin{array}{l}\text { Stimulates XPC activity in vitro; contains } \\
\text { ubiquitin domain }\end{array}$ & {$[22,227-229]$} \\
\hline & hHR23A & $\operatorname{Rad} 23$ & 363 & Can substitute for hHR23B in vitro & {$[227,230]$} \\
\hline & CEN2 & - & 172 & Stabilizes the XPC-hHR23B complex & {$[216,231]$} \\
\hline \multirow{10}{*}{ TFIIH } & XPB & $\operatorname{Rad} 25 / S S L 2$ & 782 & $3^{\prime} \rightarrow 5^{\prime}$ helicase & {$[227,232,233]$} \\
\hline & $\mathrm{XPD}$ & $\operatorname{Rad} 3$ & 760 & $5^{\prime} \rightarrow 3^{\prime}$ helicase & {$[227,233,234]$} \\
\hline & $\mathrm{p} 34$ & TFB4 & 303 & DNA binding? & {$[227,228,235]$} \\
\hline & $\mathrm{p} 44$ & SSL1 & 395 & DNA binding? & {$[227,228,233]$} \\
\hline & p62 & TFB1 & 548 & Core TFIIH subunit & {$[227,228,236]$} \\
\hline & p52 & TFB2 & 462 & Core TFIIH subunit & {$[227,228,233,236]$} \\
\hline & Mat1 & TFB3 & 309 & CDK assembly factor; CAK subcomplex & {$[227,228]$} \\
\hline & Cdk7 & Kin 28 & 346 & $\begin{array}{l}\text { CDK, C-terminal domain kinase; (CAK) } \\
\text { subcomplex; phosphorylates RNA pol. II } \\
\text { and other substrates }\end{array}$ & {$[227,228]$} \\
\hline & Cyclin $\mathrm{H}$ & CCL1 & 323 & Cyclin; CAK subcomplex & {$[227,228]$} \\
\hline & TFB5/TTDA (p8) & Tfb5 & 71 & Stabilizing subunit & {$[228,237]$} \\
\hline XPA & XPA & Rad14 & 273 & $\begin{array}{l}\text { Binds damaged DNA and facilitates } \\
\text { repair complex assembly; affinity for } \\
\text { ssDNA }\end{array}$ & {$[183,238,239]$} \\
\hline \multirow{3}{*}{ RPA } & RPA70 & Rfal & 616 & $\begin{array}{l}\text { Stabilizes opened DNA complex; } \\
\text { positions nucleases; ssDNA binding }\end{array}$ & {$[227,240-242]$} \\
\hline & RPA32 & $\mathrm{Rfa} 2$ & 270 & $\begin{array}{l}\text { Stabilizes opened DNA complex; } \\
\text { positions nucleases; ssDNA binding }\end{array}$ & {$[227,240-242]$} \\
\hline & RPA14 & Rfa3 & 121 & $\begin{array}{l}\text { Stabilizes open complex (with } \\
\text { XPA/Rad14) }\end{array}$ & {$[22,240,241]$} \\
\hline XPG & XPG & $\operatorname{Rad} 2$ & 1186 & $\begin{array}{l}\text { Endonuclease (catalyzes } 3^{\prime} \text { incision); } \\
\text { stabilizes full open complex }\end{array}$ & {$[228,243-245]$} \\
\hline \multirow[t]{2}{*}{ ERCC1-XPF } & ERCC1 & $\operatorname{Rad} 10$ & 297 & $\begin{array}{l}\text { Part of structure-specific endonuclease; } \\
\text { catalyzes } 5^{\prime} \text { incision; interstrand } \\
\text { cross-link repair }\end{array}$ & {$[227,246-248]$} \\
\hline & $\mathrm{XPF}$ & Rad1 & 905 & $\begin{array}{l}\text { Part of endonuclease }\left(5^{\prime} \text {-incision }\right) ; \\
\text { recombination via single-strand } \\
\text { annealing }\end{array}$ & {$[227,246,249]$} \\
\hline \multirow{2}{*}{ DDB } & DDB1 & - & 1140 & CPD recognition? & {$[228,250,251]$} \\
\hline & DDB2 & - & 428 & Chromatin remodeling? & {$[228,251]$} \\
\hline
\end{tabular}

and to permit the $5^{\prime}$ incision by ERCC1- XPF [265]. Subsequently, the injured part of the DNA is removed by cleaving the damaged strand towards $3^{\prime}$ and $5^{\prime}$ of the lesion by endonuclease XPG and XPF/ERCC1 complex, respectively, generating a 24-32 base oligonucleotide fragment [183]. It has been found that E2F1 plays a direct, non-transcriptional role in DNA repair involving increased recruitment of NER factors to sites of UV-induced DNA damage [266]. Finally the gap is filled by DNA polymerase $\delta$ or $\varepsilon$ (along with some accessory proteins, like PCNA and RFC) and sealed by DNA ligase. It is assumed that ligase-I is responsible for ligation of remaining nick [267], but very recently it has been reported that mostly ligase III, in cooperation with its partner XRCC1 seals the DNA nicks and ligase I plays a minor role in actively replicating cells, but not in quiescent cells [268]. Recently, several workers have tried to dissect the molecular mechanisms of TC-NER [216, 223, 244, 269]. In spite of the above facts, more investigations are still required to improve our understanding of the GGR and TCR pathways. 
Several observations provide evidence that "dark" repair of UV-induced NER is a significant DNA repair mechanisms in plants that is capable of excising dimers, particularly 64PPs [30, 270]. Genetic and genomic analysis indicates that plant NER pathway is homologous to that of mammals and fungi and unrelated to the bacterial system [204, 271273]. Based on the reduction of nuclear CPD frequency, the presence of NER has been reported to occur in several plants such as Glycine max and cultivars of Oryza sativa [274, 275]. Furthermore, CPDs were found to be excised from the nuclear DNA of Daucus carota and Wolffia microscopia at rates dependent on damage levels and comparable to those in animal cells $[205,275]$. A UV-specific endonuclease resembling UvrABC nuclease in activity was partially characterized from spinach [206]. Classical genetic analysis has resulted in the identification of at least four complementation groups required for this repair in Arabidopsis (UVR1, UVR5, UVR7 and UVH1) [276-278] and many more UV-sensitive mutants await further genetic and phenotypic characterization [206]. Moreover, a plant homologue of human NER gene of the endonuclease, ERCC1, has been cloned from Lilium longiflorum which showed a similar role in DNA repair in plants [279].

\section{Recombinational Repair}

It is one of the widespread mechanisms which efficiently repair double-strand breaks (DSBs) and single-strand gaps in damaged DNA by a series of complex biochemical reactions, as a result of ionizing radiation, UVR, ROS, and chemotherapeutic genotoxic chemicals [5]. The lethal effects of double strand breaks (DSBs) can be conquered by the existence of two independent pathway, such as homologous recombination (HR) and non-homologous end joining (NHEJ). Multiple proteins are required for DSB repair by recombination, which are conserved among all eukaryotes and deficiencies in this repair mechanism can cause hereditary diseases. For instance, mutation of at least one of these repair proteins, called BRCA1 may lead to hereditary breast cancer [280]. Evidence suggests that BRCA1 could be one of the key players in DNA damage response [281]. DSB repair through HR process is an error free pathway, since, it requires an extensive region of sequence homology between the damaged and template strands, whereas NHEJ is an error prone, alternate pathway for the repair of DSBs, essentially joins broken chromosomal ends independent of sequence homology.

12.1. Homologous Recombination. Repair of DSBs by HR requires the genes of "RAD52 epistasis group" such as RAD50, RAD51, RAD52, RAD54, RAD55, RAD57, RAD59, $M R E 11$ and XRS2, which were first defined in yeast Saccharomyces cerevisiae mutants. Homologues of most of the genes are highly conserved among all eukaryotes including human $[282,283]$ highlighting these genes for cell survival. Among all, E. coli recA gene and its eukaryotic homologs $R A D 51$ s are the best recombination genes [284]. The recA gene encodes a DNA-dependent ATPase that binds to
ssDNA and promotes strand invasion and exchange between homologous DNA molecules [285]. Among eukaryotes, the yeast $S$. cerevisiae and Schizosaccharomyces pombe have four RAD51-like genes (RAD51, DMC1, RAD55/rhp55, and $R A D 57 / r h p 57)[286,287]$ whereas vertebrate animals and plants have seven types of RAD51-like genes ( $R A D 51$, $-51 B,-51 C,-51 D, D M C 1, X R C C 2$, and XRCC3) [288]. The eukaryotic $R A D 51$ s play a significant role in $\mathrm{HR}$, maintaining genome integrity in both mitotic as well as meiotic cell cycle [288, 289]. There are 59\% identity between S. cerevisiae, human and mouse in the case of Rad51 protein (Rad51p) and 30\% identity to RecA protein of bacteria [290], whereas yeast and human proteins are $60 \%$ identical in case of Rad52 proteins (Rad52p) [291]. Yeast cell can exhibit both "allelic" [292, 293] as well as "ecotopic recombination" [294, 295] to repair a broken chromosome. Recombinational repair is a significant UV-tolerance mechanism in plants where UV-induced chromosomal rearrangements including homologous intrachromosomal recombination events have been found [296]. In mammalian cells the recombinational pathway of DSBs, seems to be operated in late S- and G2phase, when DNA molecules are replicated and spatially juxtaposed [297].

The first step of DSB repair via $\mathrm{HR}$ is the resection of $5^{\prime}$ ends to produce a $3^{\prime}$ ssDNA overhang by means of an exonuclease (such as RecBCD in E. coli, MRX-complex in S. cerevisiae and MRN-complex in vertebrates). Rad51 (a functional homolog of the E. coli RecA) [298] is the central protein in HR, binds the exposed single-stranded tails forming a nucleoprotein filament and this early step is promoted by a Rad55/Rad57 protein heterodimer [299] by overcoming the inhibitory effects of the heterotrimeric single-stranded DNA binding protein RPA [300]. Recently, it has been reported that a member of the histone $\mathrm{H} 2 \mathrm{~A}$ family, $\gamma$-H2AX protein plays an important role in the recruitment of Rad51 protein in HR in eukaryotes [301]. The Rad51 nucleoprotein filament in association with other repair protein searches the genome for an intact copy of the broken DNA on the sister chromatid to form a heteroduplex joint molecules or D-loop that is matured in to a Holliday junctions (HJs). HJ is then resolved to give crossover products (Figure 13). In E. coli, this $\mathrm{HJ}$ is resolved by the positioning of RuvABC resolvasome, however in eukaryotic cell, how this $\mathrm{HJ}$ is resolved to give crossover products is not known. In S. cerevisiae, DNA DSB repair by forming noncrossover product has been reported which does not involve the processing of a double HJ structure. Virtually, the joint molecule formation is followed by extension of the incoming strand by DNA polymerases and branch migration, leading to restoration of the genetic information $[283,302]$.

12.2. Non-Homologous End Joining. When HR is inactivated, an alternate pathway, that is, NHEJ becomes operative for the repair of DSBs [303], that also involves a multiprotein complex and has been found in organisms ranging from a few prokaryotes to mammals. This suggests that this mechanism has been conserved during the course of 


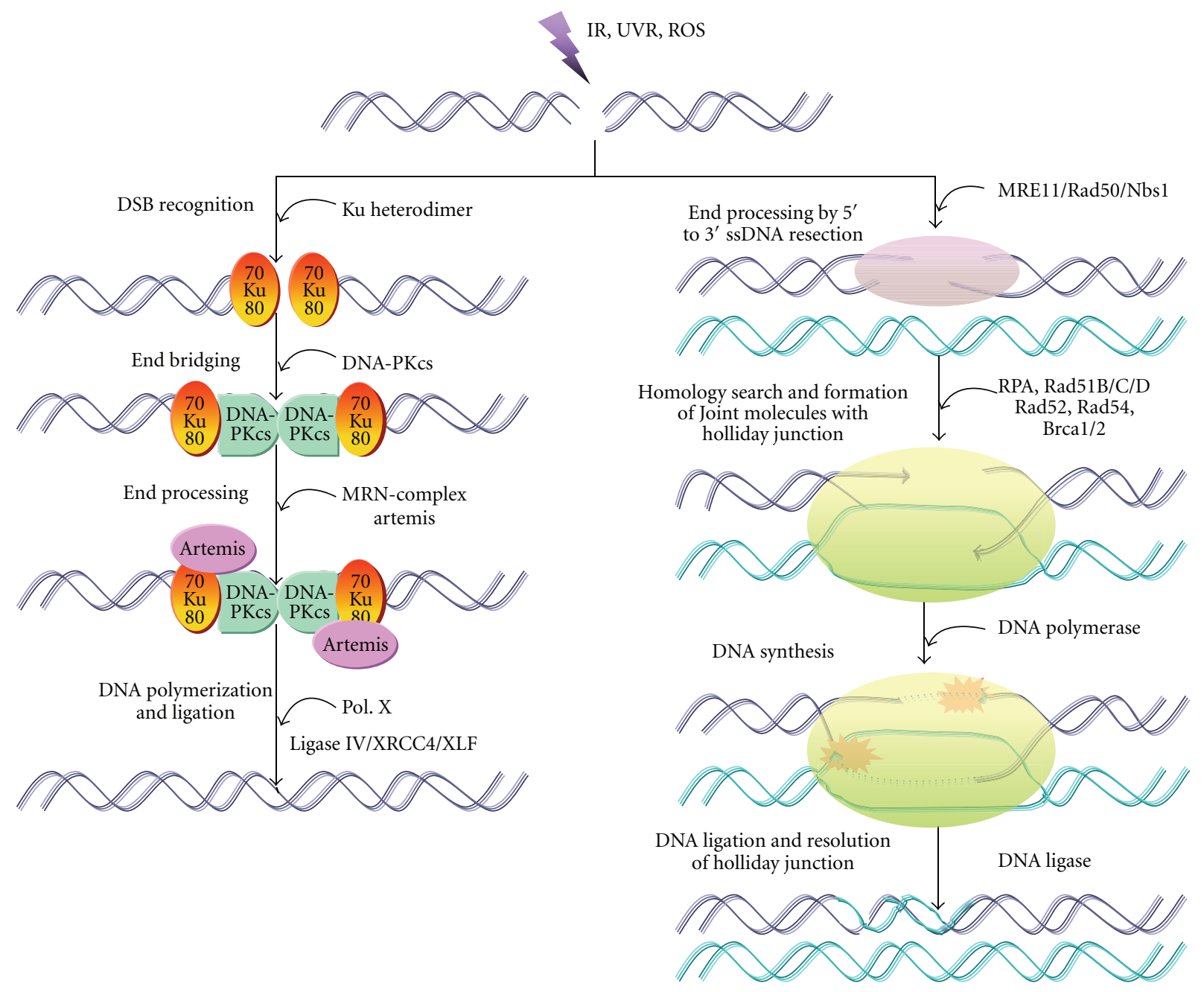

(a) NHEJ

(b) HR

Figure 13: Schematic representation of recombinational repair by (a) non-homologous end joining (NHEJ), and (b) homologous recombination (HR).

evolution, although, most of the protein factors, involved in NHEJ were initialy identified in the mammalian cells [304]. Most of the DSBs produced by DNA damaging agents, do not have ligatable termini, hence requires the action of nucleases and DNA polymerases to generate them. The participation of DNA polymerase in the NHEJ pathways is still a matter of debate, however in vitro biochemical analysis in mammals, suggest that DNA polymerase $\lambda$ (Pol. $\lambda$ ) and/or polymerase $\mu$ (Pol. $\mu$ ) participates in NHEJ process at incompatible DNA ends $[80,305,306]$. The NHEJ process is initiated by the binding of specific protein to the broken ends, which may acts as end bridging factor [307]. It has been shown that $\mathrm{Ku}$ complex (a heterodimer of Ku70/Ku80 [ $\approx 86]$ ) is a major end binding factor in mammalian cells, possess end bridging activity [308, 309]. The catalytic subunit of DNA protein kinase (DNA-PKcs) is required in mammalian NHEJ to bridge the DNA ends through their protein-protein interactions [310, 311]. Cells lacking functional DNA-PK components are known to have elevated sensitivity toward UV irradiation [312].

Association of DNA-PKcs is followed by the recruitment of other repair proteins (such as ligaseIV/Xrcc4, Artemis, PNK and Polymerase X) to proceed the NHEJ repair [304] (Figure 13). Recently, a third protein, designated as XLF or Cernunnos [313] that has homology to Xrcc4, has been identified and shown to co-associate with the DNA ligaseIV/Xrcc4 complex $[314,315]$. Artemis, a member of $\beta$-lactamase superfamily, has $5^{\prime} \rightarrow 3^{\prime}$ exonuclease activity. In the presence of DNA-PKcs, Artemis can also function as a $5^{\prime} \rightarrow 3^{\prime}$ endonuclease. It has been found that Artemis dependant DSB rejoining also requires ATM, Mre11-Rad50Nbs1 (MRN) complex, 53BP1 and H2AX [316-318]. The yeast Hdf1/2 and Dnl4/Lif1 are the functional homology of mammalian $\mathrm{Ku}$ and DNA ligaseIV/Xrcc4, respectively. DNA ligase IV is absent in bacteria, however, in Bacillus subtilis, the gene $y k o u / v$ has been found that encodes a 


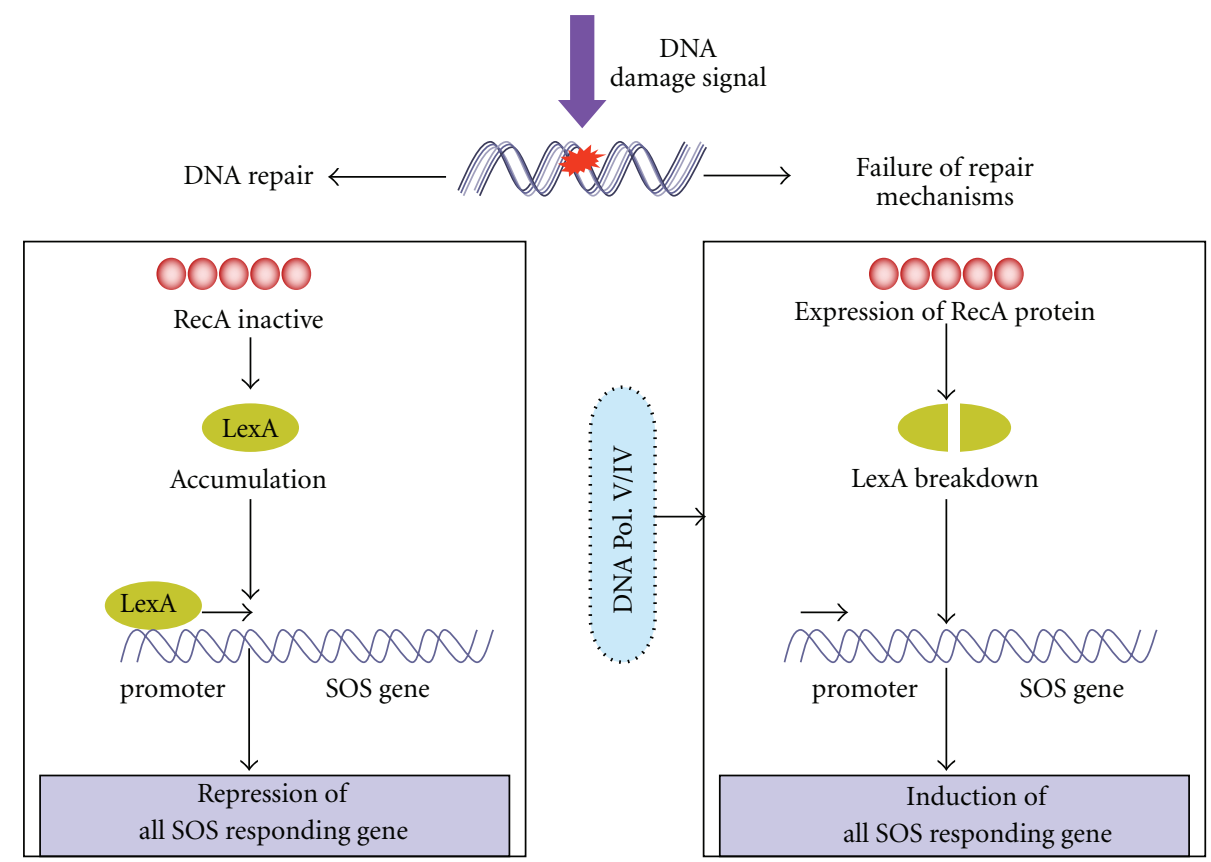

FIGURE 14: SOS response: As a result of massive DNA damage and failure of all possible repair mechanisms, RecA proteins is expressed, which activate the auto breakdown of LexA proteins, allowing the induction of all SOS responding genes. The pathway of SOS response is reversed when damages are repaired through the damage specific mechanisms. Here the inactivation of RecA protein allows the accumulation of LexA, which bind to SOS promoters and repress all SOS responding genes. SOS response is highly mutagenic due to involvement of DNA polymerase V/IV.

polypeptide with ligase, primase and nuclease domains. Genetic and biochemical evidence suggest that Mre11Rad50-Xrs2 (MRX) act as end bridging factor in yeast NHEJ, since DNA-PKcs is absent in them $[319,320]$. In case of bacteria, the $\mathrm{Ku}$ proteins occur in homodimeric forms and exhibits homology with eukaryotic Ku protein in some extent [321]. Recombinational repair is a significant UV tolerance mechanism in plants where UV-induced chromosomal rearrangements including homologous intrachromosomal recombination events have been found [296]. Very few of the plant genes involved in DSB repair have been identified. The sequence of an Arabidopsis Rad51 homologue has been made available [322]. It has been suggested that as in mammals, breaks are repaired by nonhomologous recombination far more frequently than via $\mathrm{HR}[202,323]$.

\section{SOS Repair/Response}

The accumulation of massive amount of DNA lesions within the cells under different specific physiological responses [324] may lead to the occurrence of SOS repair system which was well described in $E$. coli, where the involvement of more than 40 genes have been found [325]. It has been found that the bacterial NER is linked with all DNA damage response through a network of reactions, known as SOS response [326].

The accumulation of DNA lesions may interfere with replication process, prompting cells to stop division, therefore giving time to the cell to repair damaged DNA and proceeds DNA replication process [324]. SOS repair system is initiated by interaction of two crucial proteins the RecA and the LexA repressor which curbs the expression of SOS genes by binding to their promoters [327] (Figure 14). The proteolytic activity of RecA protein inactivates the LexA repressor and induces all the genes to which LexA is associated. A number of genes (or operon) collectively known as din (damage inducible) gene such as $u v r A$, uvrB, cho (uvrC homolog) and uvrD of E. coli NER take part in SOS response $[325,328]$. The SOS response is induced with damage signal but it is highly mutagenic due to engagement of error-prone DNA polymeraseV (UmuC/UmuD 2 complex) [329] and DNA polymerase IV [330] in E. coli. Interestingly, it has been found that DNA polymerase IV (dinB) is also involved in translesion synthesis in E. coli [331]. Majchrzak et al. [324] examined the effects of SOS response on genome stability of trinucleotide repeat sequences (TRS) in E. coli and observed that SOS response genes destabilized the TRS tracts and also altered the superhelical density of the plasmids. Recently, the genes imuA and imuB have been described that induce SOS mutagenesis in Caulobacter crescentus, but absent in E. coli [332]. However, the number of genes responsible for SOS repair system has still to be investigated.

\section{Cell-Cycle Checkpoint Activation}

In response to diverse genotoxic stresses such as UV radiation, IR, chemicals used in medical therapy, by-products of intra-cellular metabolism, several protective mechanisms 


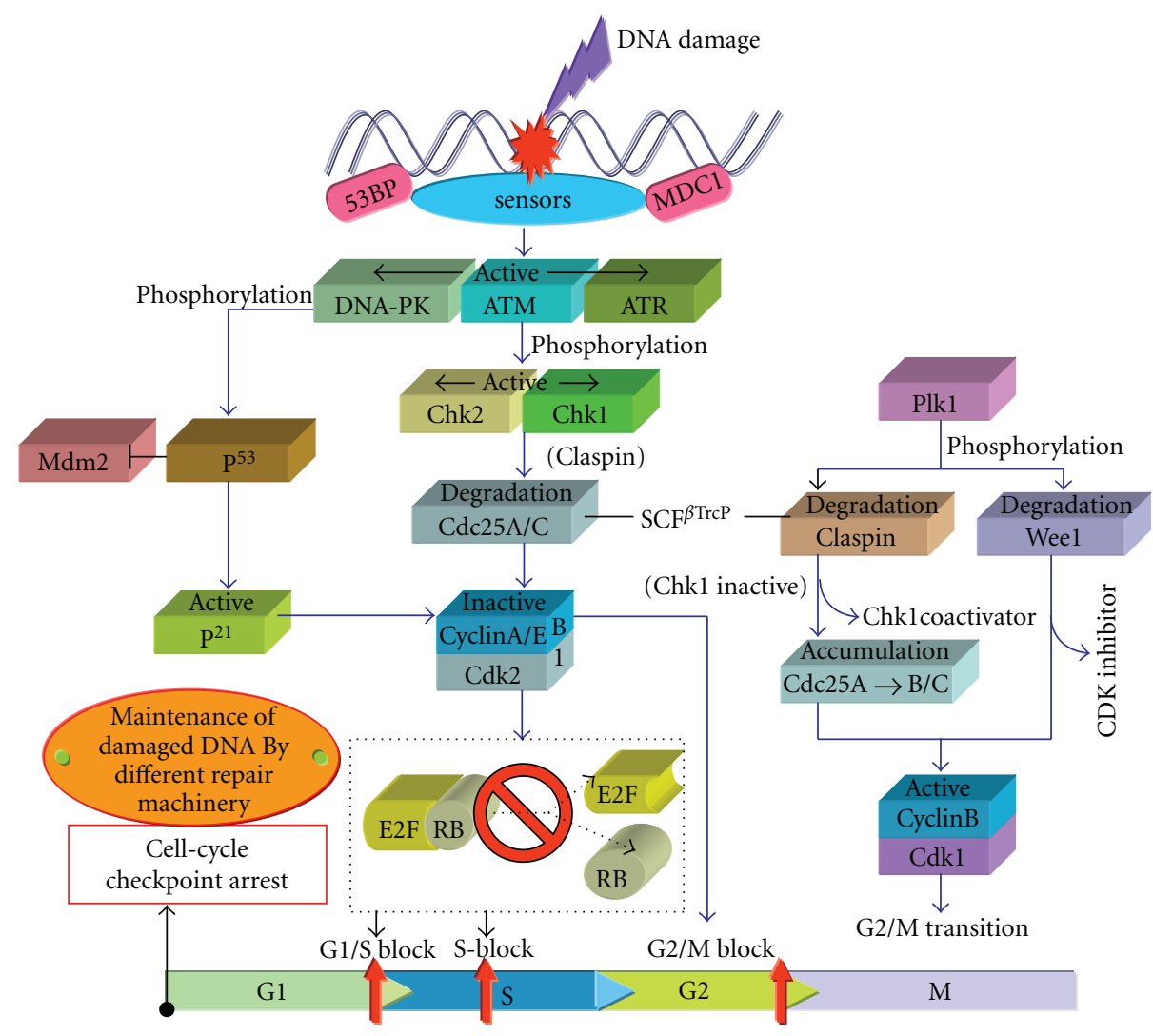

FIGURE 15: Schematic illustration of DNA damage-induced cell-cycle checkpoint activation (for details, see text).

including processes of DNA repair, Cell-cycle checkpoint arrest and apoptosis (programmed cell death) develop within the organisms to secure the genomic integrity. DNA damage such as altered DNA bases, abasic site, DNA lesions (CPDs/64PPs), strand breaks (DSBs/SSBs) may stop the progression of cell-cycle temporarily to give opportunities to the cell for DNA repair before replication or segregation of the affected chromosome [333], or may induce an apoptotic program to eliminate the damaged cells to avoid their carcinogenic potential [334]. ROS may induce several types of DNA lesions such as DSBs and SSBs, DNA-DNA and DNAprotein cross links and base modifications [335]. It has been shown that most of the chromosomal translocations produce via aberrant processing of a DNA DSBs. Hence forth, we discuss the DSBs/SSBs-induced cell-cycle checkpoint arrest in eukaryotes mainly in mammals that play a critical role in preventing chromosomal instability. Regulation of cell-cycle checkpoint proceeds through a network of damage sensors, signal transducers, mediators, and various effector proteins [183]. Phosphatidylinositol-3 (PI3)-kinase related kinases (PIKKs) ATM (ataxia telangiectasia mutated) protein, ATR (ATM and Rad3 related) protein, and DNA-PK, with effector proteins mediated cell-cycle checkpoint arrest (at G1/S, G2/M, and intra S-phase), DNA repair and cell death have been observed in mammalian cells [336]. It has been shown that ATM and DNA-PK are activated by the presence of DSBs where as activation of ATR takes place by single strand regions of DNA $[337,338]$. Activation of both ATM and ATR results in phosphorylation of Chk2 and Chk1 respectively which transfer the DNA damage signal to the cell-division cycle proteins Cdc25(A-C). Phosphorylation of Cdc25 by Chk1/Chk2 leads to its ubiquitin mediated degradation that results in G1 and S-phase arrest (Figure 15). The prevailing evidence suggests that damage response mediated activation of ATM/ATR either directly or via Chk2 phosphorylates $\mathrm{p} 53$, which transcriptionally activates the Cdk inhibitor, p21, which arrest G1/S cell-cycle checkpoint [336]. Recently, it has been reported that DNA damage caused by UV radiation or ROS such as hydroxyl $(\mathrm{OH})$ freeradical results in ATM mediated phosphorylation of BID protein that induce cell-cycle arrest in S-phase $[339,340]$. The occurrence of DNA damage response in G2-phase, leads to checkpoint mediator (claspin) dependent activation of $\mathrm{Chk} 1 / 2$, followed by $\mathrm{SCF}^{\beta}{ }^{\mathrm{TrCP}}$ mediated degradation of CDK-activating phosphatase Cdc25A [341, 342], that results in arrest of multiple cell-cycle transition including the G2 checkpoint $[343,344]$. The ubiquitin mediated destruction of claspin and WEE1 (both proteins have conserved $\beta$ $\operatorname{TrcP}$ phosphodegrons) eliminates the essential coactivator of Chk1 and CDK inhibitor respectively allowing reaccumulation of Cdc25A followed by Cdc25B and C, which results in activation of cyclin-Cdk (cyclinB-Cdk1) complex [345]. Under normal conditions, this latter complex being active promotes $\mathrm{G} 2 / \mathrm{M}$ transition and upon inactivation due to DNA damage, blocks the G2 cell-cycle and unlike the G1/S checkpoint this arrest seems to be partly p53/p21 
independent [183]. The intermediate component of this pathway is $\beta$-TrcP (an adaptor protein) that links both WEE1 [346] and claspin [347-349] with the SCF ubiquitin ligase complex and this $\mathrm{SCF}^{\beta}{ }^{\mathrm{TrcP}}$ acts as trigger of checkpoint initiation where recognition of phosphodegron $\beta$ - $\operatorname{TrcP}$ is exposed after Chk1 mediated Phosphorylation of Cdc25A [350], as well as checkpoint recovery which is linked with Plk1 mediated phosphorylation of claspin and WEE1 [347, 348]. Although, the exact mechanism(s) regarding the reactivation of Plk1 during checkpoint recovery is still in dispute. The malfunctioning of cell-cycle checkpoint as a result of chronic damage and/or defects in DNA damage response (DDR) components such as p53, p21, ATM, Chk2, BRCA1/2 tumor suppressors, may induce several types of human disorder at the expence of enhanced genomic instability [351].

In addition to the above mentioned repair mechanisms several other repair machineries such as mutagenic repair (or lesion bypass) and programmed cell death (PCD) or apoptosis may become effective for the recovery of genome against constant attack of numerous genotoxins. UV-radiation, ionizing radiation and various chemicals are responsible for most of the mutagenesis due to a process of translesion synthesis in which a polymerase or replicative assembly encounters a noncoding or miscoding lesion, inserts an incorrect nucleotide opposite the lesion and then continues elongation [5]. It has been reported that translesion synthesis past a CPD, facilitated by pol. $\eta$, with the insertion of adenines opposite both bases of a $\mathrm{T}^{\wedge} \mathrm{T}$ CPD [352], where as 6-4TT may lead to a G insertion. In Saccharomyces cerevisiae, pol. $\eta$ and pol. $\zeta$ (consisting of Rev3 and Rev7 proteins) has been reported to replicate across a $\mathrm{T}^{\wedge} \mathrm{T}$ CPD [353]. Polymerase $\eta$ (pol. $\eta$ ) can also replicate across a basic sites, AAF (acetylaminofluorene), guanine adducts and cis-platinated guanines [352].

When the repair mechanisms are unsuccessful, it may cause cellular senescence (permanent cell cycle arrest), oncogenesis or apoptosis [354]. Apoptosis plays an essential role in survival of the organisms by preventing the multiplication of mutated chromosomes, normal embryonic development, elimination of indisposed cells and maintenance of cell homeostasis.

\section{Acknowledgments}

R. P. Rastogi acknowledges University Grants Commission, New Delhi, India, for financial support in the form of a fellowship. Works related to UV-B radiation effects are partly supported by the project grant sanctioned by Department of Science and Technology, Govt. of India, New Delhi (SR/SO/PS-49/09).

\section{References}

[1] D. Lubin and E. H. Jensen, "Effects of clouds and stratospheric ozone depletion on ultraviolet radiation trends," Nature, vol. 377, no. 6551, pp. 710-713, 1995.

[2] R. P. Sinha, H. D. Kumar, A. Kumar, and D. P. Hader, "Effects of UV-B irradiation on growth, survival, pigmentation and nitrogen metabolism enzymes in cyanobacteria," Acta Protozoologica, vol. 34, no. 3, pp. 187-192, 1995.
[3] R. P. Sinha, R. P. Rastogi, N. K. Ambasht, and D.-P. Häder, "Life of wetland cyanobacteria under enhancing solar UV-B radiation," Proceedings of the National Academy of Sciences, India B, vol. 78, pp. 53-65, 2008.

[4] D.-P. Häder and R. P. Sinha, "Solar ultraviolet radiationinduced DNA damage in aquatic organisms: potential environmental impact," Mutation Research, vol. 571, no. 1-2, pp. 221-233, 2005.

[5] E. C. Friedberg, G. C. Walker, W. Siede, R. D. Wood, R. A. Schultz, and T. Ellenberger, DNA Repair and Mutagenesis, ASM Press, Washington, DC, USA, 2006.

[6] D.-P. Häder, H. D. Kumar, R. C. Smith, and R. C. Worrest, "Effects of solar UV radiation on aquatic ecosystems and interactions with climate change," Photochemical and Photobiological Sciences, vol. 6, no. 3, pp. 267-285, 2007.

[7] M. Norval, A. P. Cullen, F. R. De Gruijl et al., "The effects on human health from stratospheric ozone depletion and its interactions with climate change," Photochemical and Photobiological Sciences, vol. 6, no. 3, pp. 232-251, 2007.

[8] K. R. Solomon, "Effects of ozone depletion and UV-B radiation on humans and the environment," AtmosphereOcean, vol. 46, no. 1, pp. 185-202, 2008.

[9] M. Zeeshan and S. M. Prasad, "Differential response of growth, photosynthesis, antioxidant enzymes and lipid peroxidation to UV-B radiation in three cyanobacteria," South African Journal of Botany, vol. 75, no. 3, pp. 466-474, 2009.

[10] M. Llabrés, S. Agustí, P. Alonso-Laita, and G. J. Herndl, "Synechococcus and Prochlorococcus cell death induced by UV radiation and the penetration of lethal UVR in the Mediterranean Sea," Marine Ecology Progress Series, vol. 399, pp. 27-37, 2010.

[11] A. Tabazadeh, M. L. Santee, M. Y. Danilin et al., "Quantifying denitrification and its effect on ozone recovery," Science, vol. 288, no. 5470, pp. 1407-1411, 2000.

[12] R. L. McKenzie, L. O. Björn, A. Bais, and M. Ilyasd, "Changes in biologically active ultraviolet radiation reaching the Earth's surface," Photochemical and Photobiological Sciences, vol. 2, no. 1, pp. 5-15, 2003.

[13] R. G. Alscher, J. L. Donahue, and C. L. Cramer, "Reactive oxygen species and antioxidants: relationships in green cells," Physiologia Plantarum, vol. 100, no. 2, pp. 224-233, 1997.

[14] L. Chalker-Scott, "Survival and sex ratios of the intertidal copepod, Tigriopus californicus, following ultraviolet-B (290$320 \mathrm{~nm}$ ) radiation exposure," Marine Biology, vol. 123, no. 4, pp. 799-804, 1995.

[15] M. J. Peak and J. G. Peak, "Single-strand breaks induced in Bacillus subtilis DNA by ultraviolet light: action spectrum and properties," Photochemistry and Photobiology, vol. 35, no. 5, pp. 675-680, 1982.

[16] M. J. Peak, J. G. Peak, M. P. Moehring, and R. B. Webb, "Ultraviolet action spectra for DNA dimer induction, lethality, and mutagenesis in Escherichia coli with emphasis on the UVB region," Photochemistry and Photobiology, vol. 40, no. 5, pp. 613-620, 1984.

[17] R. P. Sinha, M. Dautz, and D.-P. Häder, "A simple and efficient method for the quantitative analysis of thymine dimers in cyanobacteria, phytoplankton and macroalgae," Acta Protozoologica, vol. 40, no. 3, pp. 187-195, 2001.

[18] A. G. J. Buma, M. K. De Boer, and P. Boelen, "Depth distributions of DNA damage in antarctic marine phyto and bacterioplankton exposed to summertime UV radiation," Journal of Phycology, vol. 37, no. 2, pp. 200-208, 2001. 
[19] H. Pakker, C. A. C. Beekman, and A. M. Breeman, "Efficient photoreactivation of UVBR-induced DNA damage in the sublittoral macroalga Rhodymenia pseudopalmata (Rhodophyta)," European Journal of Phycology, vol. 35, no. 2, pp. 109-114, 2000.

[20] F. E. Quaite, B. M. Sutherland, and J. C. Sutherland, "Quantitation of pyrimidine dimers in DNA from UVBirradiated alfalfa (Medicago sativa L.) seedlings," Applied and Theoretical Electrophoresis, vol. 2, no. 6, pp. 171-175, 1992.

[21] B. Stein, H. J. Rahmsdorf, A. Steffen, M. Litfin, and P. Herrlich, "UV-induced DNA damage is an intermediate step in UV-induced expression of human immunodeficiency virus type 1, collagenase, c-fos, and metallothionein," Molecular and Cellular Biology, vol. 9, no. 11, pp. 5169-5181, 1989.

[22] R. P. Sinha and D.-P. Häder, "UV-induced DNA damage and repair: a review," Photochemical and Photobiological Sciences, vol. 1, no. 4, pp. 225-236, 2002.

[23] K. M. D. Lima-Bessa, M. G. Armelini, V. Chiganças et al., "CPDs and 6-4PPs play different roles in UV-induced cell death in normal and NER-deficient human cells," DNA Repair, vol. 7, no. 2, pp. 303-312, 2008.

[24] K. McAteer, Y. Jing, J. Kao, J.-S. Taylor, and M. A. Kennedy, "Solution-state structure of a DNA dodecamer duplex containing a cis-syn thymine cyclobutane dimer, the major UV photoproduct of DNA," Journal of Molecular Biology, vol. 282, no. 5, pp. 1013-1032, 1998.

[25] J.-H. Lee, G.-S. Hwang, and B.-S. Choi, "Solution structure of a DNA decamer duplex containing the stable $3^{\prime} \mathrm{T} \cdot \mathrm{G}$ base pair of the pyrimidine (6-4)pyrimidone photoproduct [ $(6-$ 4) adduct]: implications for the highly specific $3^{\prime} \mathrm{T} \rightarrow \mathrm{C}$ transition of the (6-4) adduct," Proceedings of the National Academy of Sciences of the United States of America, vol. 96, no. 12, pp. 6632-6636, 1999.

[26] J.-H. Lee, S.-H. Bae, and B.-S. Choi, "The Dewar photoproduct of thymidylyl $\left(3^{\prime} \rightarrow 5^{\prime}\right)$-thymidine (Dewar product) exhibits mutagenic behavior in accordance with the "A rule"," Proceedings of the National Academy of Sciences of the United States of America, vol. 97, no. 9, pp. 4591-4596, 2000.

[27] DeLano Scientific LLC, 400 Oyster Point Blvd., Suite 213, South San Francisco, CA 94080-1918, USA. http://www .pymol.org/.

[28] R. P. Sinha, M. Krywult, and D.-P. Häder, "Effects of ultraviolet, monochromatic and PAR waveband on nitrate reductase activity and pigmentation in a rice field cyanobacterium, Anabaena sp," Acta Hydrobiologica, vol. 2, pp. 105-112, 1998.

[29] R. P. Sinha, S. P. Singh, and D.-P. Häder, "Database on mycosporines and mycosporine-like amino acids (MAAs) in fungi, cyanobacteria, macroalgae, phytoplankton and animals," Journal of Photochemistry and Photobiology B, vol. 89, no. 1, pp. 29-35, 2007.

[30] A. B. Britt, "Repair of DNA damage induced by solar UV," Photosynthesis Research, vol. 81, no. 2, pp. 105-112, 2004.

[31] R. P. Rastogi, Richa, R. P. Sinha, S. P. Singh, and D.-P. Häder, "Photoprotective compounds from marine organisms," Journal of Industrial Microbiology and Biotechnology, vol. 37, no. 6, pp. 537-558, 2010.

[32] R. P. Rastogi, Richa, S. P. Singh, D.-P. Häder, and R. P. Sinha, "Mycosporine-like amino acids profile and their activity under PAR and UVR in a hot-spring cyanobacterium Scytonema sp. HKAR-3," Australian Journal of Botany, vol. 58, no. 4, pp. 286-293, 2010.
[33] Z. Xie, Y. Wang, Y. Liu, and Y. Liu, "Ultraviolet-B exposure induces photo-oxidative damage and subsequent repair strategies in a desert cyanobacterium Microcoleus vaginatus Gom," European Journal of Soil Biology, vol. 45, no. 4, pp. 377-382, 2009.

[34] H. Wiseman and B. Halliwell, "Damage to DNA by reactive oxygen and nitrogen species: role in inflammatory disease and progression to cancer," Biochemical Journal, vol. 313, no. 1, pp. 17-29, 1996.

[35] J.-S. Taylor, "DNA, sunlight, and skin cancer," Journal of Chemical Education, vol. 67, no. 10, pp. 833-841, 1990.

[36] T. Lindahl, "Instability and decay of the primary structure of DNA," Nature, vol. 362, no. 6422, pp. 709-715, 1993.

[37] M. Valko, C. J. Rhodes, J. Moncol, M. Izakovic, and M. Mazur, "Free radicals, metals and antioxidants in oxidative stress-induced cancer," Chemico-Biological Interactions, vol. 160, no. 1, pp. 1-40, 2006.

[38] B. Halliwell and J. Gutteridge, Free Radicals in Biology and Medicine, Oxford University Press, Oxford, UK, 4th edition, 2007.

[39] M. Dizdaroglu, "Oxidative damage to DNA in mammalian chromatin,” Mutation Research, vol. 275, no. 3-6, pp. 331342, 1992.

[40] M. Valko, D. Leibfritz, J. Moncol, M. T. D. Cronin, M. Mazur, and J. Telser, "Free radicals and antioxidants in normal physiological functions and human disease," International Journal of Biochemistry and Cell Biology, vol. 39, no. 1, pp. 44-84, 2007.

[41] Y.-H. You, P. E. Szabo, and G. P. Pfeifer, "Cyclobutane pyrimidine dimers form preferentially at the major $\mathrm{p}^{53}$ mutational hotspot in UVB-induced mouse skin tumors," Carcinogenesis, vol. 21, no. 11, pp. 2113-2117, 2000.

[42] J.-L. Ravanat, T. Douki, and J. Cadet, "Direct and indirect effects of UV radiation on DNA and its components," Journal of Photochemistry and Photobiology B, vol. 63, no. 1-3, pp. 88102, 2001.

[43] J. Cadet, E. Sage, and T. Douki, "Ultraviolet radiationmediated damage to cellular DNA," Mutation Research, vol. 571, no. 1-2, pp. 3-17, 2005.

[44] D. I. Pattison and M. J. Davies, "Actions of ultraviolet light on cellular structures," in Cancer: Cell Structures, Carcinogens and Genomic Instability, L. P. Bignold, Ed., Birkhäuser, Switzerland, 2006.

[45] J. S. Taylor, H. F. Lu, and J. J. Kotyk, “Quantitative conversion of the (6-4) photoproduct of TpdC to its Dewar valence isomer upon exposure to simulated sunlight," Photochemistry and Photobiology, vol. 51, no. 2, pp. 161-167, 1990.

[46] S. Courdavault, C. Baudouin, M. Charveron et al., "Repair of the three main types of bipyrimidine DNA photoproducts in human keratinocytes exposed to UVB and UVA radiations," DNA Repair, vol. 4, no. 7, pp. 836-844, 2005.

[47] T. Carell and R. Epple, "Repair of UV light induced DNA lesions: a comparative study with model compounds," European Journal of Organic Chemistry, no. 7, pp. 1245-1258, 1998.

[48] T. Douki, A. Reynaud-Angelin, J. Cadet, and E. Sage, "Bipyrimidine photoproducts rather than oxidative lesions are the main type of DNA damage involved in the genotoxic effect of solar UVA radiation," Biochemistry, vol. 42, no. 30, pp. 9221-9226, 2003.

[49] J. E. Donnellan Jr. and R. B. Setlow, “Thymine photoproducts but not thymine dinners found in ultraviolet-irradiated bacterial spores," Science, vol. 149, no. 3681, pp. 308-310, 1965. 
[50] M. M. Becker and Z. Wang, "Origin of ultraviolet damage in DNA," Journal of Molecular Biology, vol. 210, no. 3, pp. 429438, 1989.

[51] V. Lyamichev, "Unusual conformation of (dA)n.(dT)ntracts as revealed by cyclobutane thymine-thymine dimer formation," Nucleic Acids Research, vol. 19, no. 16, pp. 44914496, 1991.

[52] J. R. Pehrson and L. H. Cohen, "Effects of DNA looping on pyrimidine dimer formation," Nucleic Acids Research, vol. 20, no. 6, pp. 1321-1324, 1992.

[53] A. Aboussekhra and F. Thoma, "TATA-binding protein promotes the selective formation of UV-induced (6-4) photoproducts and modulates DNA repair in the TATA box," EMBO Journal, vol. 18, no. 2, pp. 433-443, 1999.

[54] T. Douki and J. Cadet, "Individual determination of the yield of the main UV-induced dimeric pyrimidine photoproducts in DNA suggests a high mutagenicity of CC photolesions," Biochemistry, vol. 40, no. 8, pp. 2495-2501, 2001.

[55] A. S. Balajee and V. A. Bohr, "Genomic heterogeneity of nucleotide excision repair," Gene, vol. 250, no. 1-2, pp. 1530,2000

[56] J. M. Gale, K. A. Nissen, and M. J. Smerdon, "UV-induced formation of pyrimidine dimers in nucleosome core DNA is strongly modulated with a period of 10.3 bases," Proceedings of the National Academy of Sciences of the United States of America, vol. 84, no. 19, pp. 6644-6648, 1987.

[57] R. M. Tyrrell, "Induction of pyrimidine dimers in bacterial DNA by $365 \mathrm{~nm}$ radiation," Photochemistry and Photobiology, vol. 17, no. 1, pp. 69-73, 1973.

[58] E. Kvam and R. M. Tyrrell, "Induction of oxidative DNA base damage in human skin cells by UV and near visible radiation," Carcinogenesis, vol. 18, no. 12, pp. 2379-2384, 1997.

[59] D. Perdiz, P. Gróf, M. Mezzina, O. Nikaido, E. Moustacchi, and E. Sage, "Distribution and repair of bipyrimidine photoproducts in solar UV-irradiated mammalian cells: possible role of dewar photoproducts in solar mutagenesis," Journal of Biological Chemistry, vol. 275, no. 35, pp. 26732-26742, 2000.

[60] S. Courdavault, C. Baudouin, M. Charveron, A. Favier, J. Cadet, and T. Douki, "Larger yield of cyclobutane dimers than 8-oxo-7,8-dihydroguanine in the DNA of UVAirradiated human skin cells," Mutation Research, vol. 556, no. 1-2, pp. 135-142, 2004.

[61] D. G. T. Su, J.-S. A. Taylor, and M. L. Gross, "A new photoproduct of 5-methylcytosine and adenine characterized by high-performance liquid chromatography and mass spectrometry," Chemical Research in Toxicology, vol. 23, no. 3, pp. 474-479, 2010.

[62] K. L. Wierzchowski and D. Shugar, "Photochemistry of cytosine nucleosides and nucleotides, II," Acta Biochimica Polonica, vol. 8, pp. 219-234, 1961.

[63] R. J. Boorstein, T. P. Hilbert, R. P. Cunningham, and G. W. Teebor, "Formation and stability of repairable pyrimidine photohydrates in DNA," Biochemistry, vol. 29, no. 46, pp. 10455-10460, 1990.

[64] N. J. Duker and P. E. Gallagher, "Purine photoproducts," Photochemistry and Photobiology, vol. 48, no. 1, pp. 35-39, 1988.

[65] S. Kumar, N. D. Sharma, R. J. Davies, D. W. Phillipson, and J. A. McCloskey, "The isolation and characterisation of a new type of dimeric adenine photoproduct in UV-irradiated deoxyadenylates," Nucleic Acids Research, vol. 15, no. 3, pp. 1199-1216, 1987.
[66] T. M. G. Koning, R. J. H. Davies, and R. Kaptein, "The solution structure of the intramolecular photoproduct of $\mathrm{d}(\mathrm{TpA})$ derived with the use of NMR and a combination of distance geometry and molecular dynamics," Nucleic Acids Research, vol. 18, no. 2, pp. 277-284, 1990.

[67] S. N. Bose, R. J. H. Davies, S. K. Sethi, and J. A. McCloskey, "Formation of an adenine-thymine photoadduct in the deoxydinucleoside monophosphate $\mathrm{d}(\mathrm{TpA})$ and in DNA," Science, vol. 220, no. 4598, pp. 723-725, 1983.

[68] S. N. Bose and R. J. Davies, "The photoreactivity of T-A sequences in oligodeoxyribonucleotides and DNA," Nucleic Acids Research, vol. 12, no. 20, pp. 7903-7914, 1984.

[69] P. H. Clingen, R. Jeremy, and H. Davies, "Quantum yields of adenine photodimerization in poly(deoxyadenylic acid) and DNA," Journal of Photochemistry and Photobiology B, vol. 38, no. 1, pp. 81-87, 1997.

[70] D. Porschke, "A specific photoreaction in polydeoxyadenylic acid," Proceedings of the National Academy of Sciences of the United States of America, vol. 70, no. 9, pp. 2683-2686, 1973.

[71] N. D. Sharma and R. J. H. Davies, "Extent of formation of a dimeric adenine photoproduct in polynucleotides and DNA," Journal of Photochemistry and Photobiology B, vol. 3, no. 2, pp. 247-258, 1989.

[72] R. O. Rahn, "Search for an adenine photoproduct in DNA," Nucleic Acids Research, vol. 3, no. 4, pp. 879-890, 1976.

[73] P. W. Doetsch, T. H. Zastawny, A. M. Martin, and M. Dizdaroglu, "Monomeric base damage products from adenine, guanine and thymine induced by exposure of DNA to ultraviolet radiation," Biochemistry, vol. 34, pp. 737-742, 1995.

[74] D. B. Hall, R. E. Holmlin, and J. K. Barton, "Oxidative DNA damage through long-range electron transfer," Nature, vol. 382, no. 6593, pp. 731-735, 1996.

[75] M. Lukin and C. de los Santos, "NMR structures of damaged DNA," Chemical Reviews, vol. 106, no. 2, pp. 607-686, 2006.

[76] J.-H. Lee, G.-S. Hwang, J.-K. Kim, and B.-S. Choi, "The solution structure of DNA decamer duplex containing the Dewar product of thymidylyl $\left(3^{\prime} \rightarrow 5^{\prime}\right)$ thymidine by NMR and full relaxation matrix refinement," FEBS Letters, vol. 428, no. 3, pp. 269-274, 1998.

[77] S. N. Rao, J. W. Keepers, and P. Kollman, "The structure of d(CGCGAAT[ ]TCGCG)-d(CGCGAATTCGCG): the incorporation of a thymine photodimer into a B-DNA helix," Nucleic Acids Research, vol. 12, no. 11, pp. 4789-4807, 1984.

[78] F. E. Hruska, D. J. Wood, K. K. Ogilvie, and J. L. Charlton, "A proton magnetic resonance study of the ultraviolet photoproduct of $\mathrm{d}(\mathrm{TpT})$ in aqueous solution," Canadian Journal of Chemistry, vol. 53, pp. 1193-1203, 1975.

[79] L.-S. Kan, L. Voituriez, and J. Cadet, "Nuclear magnetic resonance studies of Cis-Syn, Trans-Syn, and 6-4 photodimers of thymidylyl $\left(3^{\prime}-5^{\prime}\right)$ thymidine monophosphate and CisSyn photodimers of thymidylyl $\left(3^{\prime}-5^{\prime}\right)$ thymidine cyanoethyl phosphotriester," Biochemistry, vol. 27, no. 15, pp. 57965803, 1988.

[80] J.-H. Lee, C.-J. Park, J.-S. Shin, T. Ikegami, H. Akutsu, and B.-S. Choi, "NMR structure of the DNA decamer duplex containing double T.G mismatches of cis-syn cyclobutane pyrimidine dimer: implications for DNA damage recognition by the XPC-hHR23B complex," Nucleic Acids Research, vol. 32, no. 8, pp. 2474-2481, 2004.

[81] C. Suquet and M. J. Smerdon, "UV damage to DNA strongly influences its rotational setting on the histone surface of reconstituted nucleosomes," Journal of Biological Chemistry, vol. 268, no. 32, pp. 23755-23757, 1993. 
[82] A. E. Rumora, K. M. Kolodziejczak, A. M. Wagner, and M. E. Núñez, "Thymine dimer-induced structural changes to the DNA duplex examined with reactive probes," Biochemistry, vol. 47, no. 49, pp. 13026-13035, 2008.

[83] J.-K. Kim and B.-S. Choi, "The solution structure of DNA duplex-decamer containing the (6-4) photoproduct of thymidylyl $\left(3^{\prime} \rightarrow 5^{\prime}\right)$ thymidine by NMR and relaxation matrix refinement," European Journal of Biochemistry, vol. 228, no. 3, pp. 849-854, 1995.

[84] G.-S. Hwang, J.-K. Kim, and B.-S. Choi, "NMR structural studies of DNA decamer duplex containing the Dewar photoproduct of thymidylyl $\left(3^{\prime} \rightarrow 5^{\prime}\right)$ thymidine: conformational changes of the oligonucleotide duplex by photoconversion of a (6-4) adduct to its Dewar valence isomer," European Journal of Biochemistry, vol. 235, no. 1-2, pp. 359-365, 1996.

[85] D. A. Pearlman, S. R. Holbrook, D. H. Pirkle, and S.-H. Kim, "Molecular models for DNA damaged by photoreaction," Science, vol. 227, no. 4692, pp. 1304-1308, 1985.

[86] T. V. Wang and K. C. Smith, "Postreplication repair in ultraviolet-irradiated human fibroblasts: formation and repair of DNA double-strand breaks," Carcinogenesis, vol. 7, no. 3, pp. 389-392, 1986.

[87] T. A. Slieman and W. L. Nicholson, "Artificial and solar UV radiation induces strand breaks and cyclobutane pyrimidine dimers in Bacillus subtilis spore DNA," Applied and Environmental Microbiology, vol. 66, no. 1, pp. 199-205, 2000.

[88] C. Baumstark-Khan, U. Hentschel, Y. Nikandrova, J. Krug, and G. Horneck, "Fluorometric analysis of DNA unwinding (FADU) as a method for detecting repair-induced DNA strand breaks in UV-irradiated mammalian cells," Photochemistry and Photobiology, vol. 72, no. 4, pp. 477-484, 2000.

[89] R. P. Rastogi, S. P. Singh, D.-P. Häder, and R. P. Sinha, "Detection of reactive oxygen species (ROS) by the oxidantsensing probe $2^{\prime}, 7^{\prime}$-dichlorodihydrofluorescein diacetate in the cyanobacterium Anabaena variabilis PCC 7937," Biochemical and Biophysical Research Communications, vol. 397, no. 3, pp. 603-607, 2010.

[90] C. L. Limoli, E. Giedzinski, W. M. Bonner, and J. E. Cleaver, "UV-induced replication arrest in the xeroderma pigmentosum variant leads to DNA doublestrand breaks, $\gamma$-H2AX formation, and Mre11 relocalization," Proceedings of the National Academy of Sciences of the United States of America, vol. 99, no. 1, pp. 233-238, 2002.

[91] L. F. Z. Batista, B. Kaina, R. Meneghini, and C. F. M. Menck, "How DNA lesions are turned into powerful killing structures: insights from UV-induced apoptosis," Mutation Research, vol. 681, no. 2-3, pp. 197-208, 2009.

[92] T. R. Dunkern and B. Kaina, "Cell proliferation and DNA breaks are involved in ultraviolet light-induced apoptosis in nucleotide excision repair-deficient Chinese hamster cells," Molecular Biology of the Cell, vol. 13, no. 1, pp. 348-361, 2002.

[93] W. P. Roos and B. Kaina, "DNA damage-induced cell death by apoptosis," Trends in Molecular Medicine, vol. 12, no. 9, pp. 440-450, 2006.

[94] M. M. Vilenchik and A. G. Knudson, "Endogenous DNA double-strand breaks: production, fidelity of repair, and induction of cancer," Proceedings of the National Academy of Sciences of the United States of America, vol. 100, no. 22, pp. 12871-12876, 2003.

[95] A. Takahashi and T. Ohnishi, "Does $\gamma \mathrm{H} 2 \mathrm{AX}$ foci formation depend on the presence of DNA double strand breaks?" Cancer Letters, vol. 229, no. 2, pp. 171-179, 2005.
[96] G. Wang, L. M. Hallberg, E. Saphier, and E. W. Englander, "Short interspersed DNA element-mediated detection of UVB-induced DNA damage and repair in the mouse genome, in vitro, and in vivo in skin," Mutation Research, vol. 433, no. 3, pp. 147-157, 1999.

[97] G. Wang, L. M. Hallberg, E. Saphier, and E. W. Englander, "Pyrimidine (6-4) pyrimidone photoproduct mapping after sub-lethal UVC doses: nucleotide resolution using terminal transferase-dependent PCR," Photochemistry and Photobiology, vol. 82, pp. 1370-1376, 2006.

[98] A. Kumar, M. B. Tyagi, and P. N. Jha, "Evidences showing ultraviolet-B radiation-induced damage of DNA in cyanobacteria and its detection by PCR assay," Biochemical and Biophysical Research Communications, vol. 318, no. 4, pp. 1025-1030, 2004.

[99] A. Karakoula, M. D. Evans, I. D. Podmore, P. E. Hutchinson, J. Lunec, and M. S. Cooke, "Quantification of UVR-induced DNA damage: global- versus gene-specific levels of thymine dimers," Journal of Immunological Methods, vol. 277, no. 1-2, pp. 27-37, 2003.

[100] P. L. Olive, J. P. Banath, and R. E. Durand, "Heterogeneity in radiation-induced DNA damage and repair in tumor and normal cells measured using the 'comet' assay," Radiation Research, vol. 122, no. 1, pp. 86-94, 1990.

[101] N. Morley, A. Rapp, H. Dittmar et al., "UVA-induced apoptosis studied by the new apo/necro-Comet-assay which distinguishes viable, apoptotic and necrotic cells," Mutagenesis, vol. 21, no. 2, pp. 105-114, 2006.

[102] J. L. R. Roti and W. D. Wright, "Visualization of DNA loops in nucleoids from HeLa cells: assays for DNA damage and repair," Cytometry, vol. 8, no. 5, pp. 461-467, 1987.

[103] P. Sestili, C. Martinelli, and V. Stocchi, "The fast halo assay: an improved method to quantify genomic DNA strand breakage at the single-cell level," Mutation Research, vol. 607, no. 2, pp. 205-214, 2006.

[104] J. Chen, K. Jin, M. Chen et al., "Early detection of DNA strand breaks in the brain after transient focal ischemia: implications for the role of DNA damage in apoptosis and neuronal cell death," Journal of Neurochemistry, vol. 69, no. 1, pp. 232-245, 1997.

[105] C. Stecco, A. Porzionato, V. Macchi et al., "Detection of apoptosis in human brainstem by TUNEL assay," Italian Journal of Anatomy and Embryology, vol. 110, no. 4, pp. 255260, 2005.

[106] F. Xu, J. M. Vlak, A. P .M. Eker, and M. M. van Oers, "DNA photolyases of Chrysodeixis chalcites nucleopolyhedrovirus target to the nucleus and interact with chromosomes and mitotic spindle structures," Journal of General Virology, vol. 91, pp. 907-914, 2010.

[107] S. K. Murthy and D. J. Demetrick, "New approaches to fluorescence in situ hybridization," Methods in Molecular Biology, vol. 319, pp. 237-259, 2006.

[108] S. Kumari, R. P. Rastogi, K. L. Singh, S. P. Singh, and R. P. Sinha, "DNA damage: detection strategies," EXCLI Journal, vol. 7, pp. 44-62, 2008.

[109] G. Koopman, C. P. Reutelingsperger, G. A. Kuiiten, R. M. Keehnen, and S. T. Pals, "Annexin V for flow cytometric detection of phosphotidylserine expression on B cells undergoing apoptosis," Blood, vol. 4, pp. 1415-1420, 1994.

[110] J. W. Bickham, "Flow cytometry as a technique to monitor the effects of environmental genotoxins on wild life populations," in In Situ Evaluation of Biological Hazards of Environmental Pollutants, S. S. Sandhu, W. R. Lower, F. J. de 
Serres, W. A. Suk, and R. R. Tice, Eds., pp. 97-108, Plenum Press, New York, NY, USA, 1990.

[111] H. Watanabe, Y. Murata, M. Miura, M. Hasegawa, T. Kawamoto, and H. Shibuya, "In-vivo visualization of radiation-induced apoptosis using 125I-annexin V," Nuclear Medicine Communications, vol. 27, no. 1, pp. 81-89, 2006.

[112] M. Klisch, R. P. Sinha, E. W. Helbling, and D.-P. Häder, "Induction of thymine dimers by solar radiation in natural freshwater phytoplankton assemblages in Patagonia, Argentina," Aquatic Sciences, vol. 67, no. 1, pp. 72-78, 2005.

[113] S. Otero, E. Núñez-Olivera, J. Martínez-Abaigar, R. Tomás, M. Arróniz-Crespo, and N. Beaucourt, "Effects of cadmium and enhanced UV radiation on the physiology and the concentration of UV-absorbing compounds of the aquatic liverwort Jungermannia exsertifolia subsp. cordifolia," Photochemical and Photobiological Sciences, vol. 5, no. 8, pp. 760769, 2006.

[114] D. L. Mitchell, C. A. Haipek, and J. M. Clarkson, “(64)photoproducts are removed from the DNA of UVirradiated mammalian cells more efficiently than cyclobutane pyrimidine dimers," Mutation Research, vol. 143, no. 3, pp. 109-112, 1985.

[115] W. H. Jeffrey, P. Aas, M. M. Lyons, R. B. Coffin, R. J. Pledger, and D. L. Mitchell, "Ambient solar radiation-induced photodamage in marine bacterioplankton," Photochemistry and Photobiology, vol. 64, no. 3, pp. 419-427, 1996.

[116] H. C. Birnboim and J. J. Jevcak, "Fluorometric method for rapid detection of DNA strand breaks in human white blood cells produced by low doses of radiation," Cancer Research, vol. 41, no. 5, pp. 1889-1892, 1981.

[117] T. Iwasa, S. Tokutomi, and F. Tokunaga, "Photoreactivation of Halobacterium halobium: action spectrum and role of pigmentation," Photochemistry and Photobiology, vol. 47, pp. 267-270, 1988.

[118] A. Yasui, A. P. M. Eker, S. Yasuhira et al., "A new class of DNA photolyases present in various organisms including aplacental mammals," EMBO Journal, vol. 13, no. 24, pp. 6143-6151, 1994.

[119] A. Kiener, I. Husain, A. Sancar, and C. Walsh, "Purification and properties of Methanobacterium thermoautotrophicum DNA photolyase," Journal of Biological Chemistry, vol. 264, no. 23, pp. 13880-13887, 1989.

[120] M. Fujihashi, N. Numoto, Y. Kobayashi et al., "Crystal structure of archaeal photolyase from Sulfolobus tokodaii with two FAD molecules: implication of a novel lightharvesting cofactor," Journal of Molecular Biology, vol. 365, no. 4, pp. 903-910, 2007.

[121] K. Malhotra, S.-T. Kim, and A. Sancar, "Characterization of a medium wavelength type DNA photolyase: purification and properties of photolyase from Bacillus firmus," Biochemistry, vol. 33, no. 29, pp. 8712-8718, 1994.

[122] J. L. Johnson, S. Hamm-Alvarez, G. Payne, G. B. Sancar, K. V. Rajagopalan, and A. Sancar, "Identification of the second chromophore of Escherichia coli and yeast DNA photolyases as 5,10-methenyltetrahydrofolate," Proceedings of the National Academy of Sciences of the United States of America, vol. 85, no. 7, pp. 2046-2050, 1988.

[123] G. B. Sancar, F. W. Smith, M. C. Lorence, C. S. Rupert, and A. Sancar, "Sequences of the Escherichia coli photolyase gene and protein," Journal of Biological Chemistry, vol. 259, no. 9, pp. 6033-6038, 1984.
[124] A. P. M. Eker, P. Kooiman, J. K. C. Hessels, and A. Yasui, "DNA photoreactivating enzyme from the cyanobacterium Anacystis nidulans," Journal of Biological Chemistry, vol. 265, no. 14, pp. 8009-8015, 1990.

[125] W.-O. Ng, R. Zentella, Y. Wang, J.-S. A. Taylor, and H. B. Pakrasi, "phrA, the major photoreactivating factor in the cyanobacterium Synechocystis sp. strain PCC 6803 codes for a cyclobutane-pyrimidine-dimer- specific DNA photolyase," Archives of Microbiology, vol. 173, no. 5-6, pp. 412-417, 2000.

[126] A. P. Eker, R. H. Dekker, and W. Berends, "Photoreactivating enzyme from Streptomyces griseus-IV. On the nature of the chromophoric cofactor in Streptomyces griseus photoreactivating enzyme," Photochemistry and Photobiology, vol. 33, no. 1, pp. 65-72, 1981.

[127] K. A. O’Connor, M. J. McBride, M. West et al., "Photolyase of Myxococcus xanthus, a Gram-negative eubacterium, is more similar to photolyases found in archaea and "higher" eukaryotes than to photolyases of other eubacteria," Journal of Biological Chemistry, vol. 271, no. 11, pp. 6252-6259, 1996.

[128] E. N. Worthington, I. H. Kavakli, G. Berrocal-Tito, B. E. Bondo, and A. Sancar, "Purification and characterization of three members of the photolyase/cryptochrome family blue-light photoreceptors from Vibrio cholerae," Journal of Biological Chemistry, vol. 278, no. 40, pp. 39143-39154, 2003.

[129] H. Yajima, H. Inoue, A. Oikawa, and A. Yasui, "Cloning and functional characterization of a eucaryotic DNA photolyase gene from Neurospora crassa," Nucleic Acids Research, vol. 19, no. 19 , pp. 5359-5362, 1991.

[130] A. P. M. Eker, H. Yajima, and A. Yasui, "DNA photolyase from the fungus Neurospora crassa. Purification, characterization and comparison with other photolyases," Photochemistry and Photobiology, vol. 60, no. 2, pp. 125-133, 1994.

[131] T. Todo, H. Takemori, H. Ryo et al., "A new photoreactivating enzyme that specifically repairs ultraviolet light-induced (64)photoproducts," Nature, vol. 361, no. 6410, pp. 371-374, 1993.

[132] A. Sancar, "No "End of history" for photolyases," Science, vol. 272, no. 5258, pp. 48-49, 1996.

[133] S. Yasuhira and A. Yasui, "Visible light-inducible photolyase gene from the goldfish Carassius auratus," Journal of Biological Chemistry, vol. 267, no. 36, pp. 25644-25647, 1992.

[134] T. S. Mikkelsen, M. J. Wakefield, B. Aken et al., "Genome of the marsupial Monodelphis domestica reveals innovation in non-coding sequences," Nature, vol. 447, no. 7141, pp. 167177, 2007.

[135] T. Todo, S.-T. Kim, K. Hitomi et al., "Flavin adenine dinucleotide as a chromophore of the Xenopus (6-4)photolyase," Nucleic Acids Research, vol. 25, no. 4, pp. 764-768, 1997.

[136] Q. Pang and J. B. Hays, "UV-B-inducible and temperaturesensitive photoreactivation of cyclobutane pyrimidine dimers in Arabidopsis thaliana," Plant Physiology, vol. 95, no. 2, pp. 536-543, 1991.

[137] J. L. Petersen, D. W. Lang, and G. D. Small, "Cloning and characterization of a class II DNA photolyase from Chlamydomonas," Plant Molecular Biology, vol. 40, no. 6, pp. 1063-1071, 1999.

[138] S. Takahashi, N. Nakajima, H. Saji, and N. Kondo, "Diurnal changes of cucumber CPD photolyase gene (CsPHR) expression and its physiological role in growth under UV-B irradiation," Plant and Cell Physiology, vol. 43, pp. 342-349, 2002. 
[139] Y. Takeuchi, T. Inoue, K. Takemura et al., "Induction and inhibition of cyclobutane pyrimidine dimer photolyase in etiolated cucumber (Cucumis sativus) cotyledons after ultraviolet irradiation depends on wavelength," Journal of Plant Research, vol. 120, pp. 365-374, 2007.

[140] J. E. Trosko and V. H. Mansour, "Photoreactivation of ultraviolet light-induced pyrimidine dimers in Ginkgo cells grown in vitro," Mutation Research, vol. 7, no. 1, pp. 120-121, 1969.

[141] R. Taylor, A. Tobin, and C. Bray, "Nucleotide sequence of an Arabidopsis cDNA At-phrII encoding a protein with high homology to the class II CPD photolyases present in higher eukaryotes," Plant Physiology, vol. 112, pp. 862-863, 1996.

[142] V. Srinivasan, W. M. Schnitzlein, and D. N. Tripathy, "Fowlpox virus encodes a novel DNA repair enzyme, CPDphotolyase, that restores infectivity of UV light-damaged virus," Journal of Virology, vol. 75, no. 4, pp. 1681-1688, 2001.

[143] C. L. Afonso, E. R. Tulman, Z. Lu, E. Oma, G. F. Kutish, and D. L. Rock, "The genome of Melanoplus sanguinipes entomopoxvirus," Journal of Virology, vol. 73, no. 1, pp. 533$552,1999$.

[144] T. Ohnishi, E. Mori, and A. Takahashi, "DNA doublestrand breaks: their production, recognition, and repair in eukaryotes," Mutation Research, vol. 669, no. 1-2, pp. 8-12, 2009.

[145] D. Strumberg, A. A. Pilon, M. Smith, R. Hickey, L. Malkas, and Y. Pommier, "Conversion of topoisomerase I cleavage complexes on the leading strand of ribosomal DNA into 5'-phosphorylated DNA double-strand breaks by replication runoff," Molecular and Cellular Biology, vol. 20, no. 11, pp. 3977-3987, 2000.

[146] H. C. Box, J. B. Dawidzik, and E. E. Budzinski, "Free radicalinduced double lesions in DNA," Free Radical Biology and Medicine, vol. 31, no. 7, pp. 856-868, 2001.

[147] J. P. Banáth and P. L. Olive, "Expression of phosphorylated histone $\mathrm{H} 2 \mathrm{AX}$ as a surrogate of cell killing by drugs that create DNA double-strand breaks," Cancer Research, vol. 63, no. 15 , pp. 4347-4350, 2003.

[148] J. V. Harper, J. A. Anderson, and P. O’Neill, “Radiation induced DNA DSBs: contribution from stalled replication forks?" DNA Repair, vol. 9, pp. 907-913, 2010.

[149] S. E. Freeman, A. D. Blackett, and D. C. Monteleone, "Quantitation of radiation-, chemical-, or enzyme-induced single strand breaks in nonradioactive DNA by alkaline gel electrophoresis: application to pyrimidine dimers," Analytical Biochemistry, vol. 158, no. 1, pp. 119-129, 1986.

[150] D. L. Mitchell, J. Jen, and J. E. Cleaver, "Relative induction of cyclobutane dimers and cytosine photohydrates in DNA irradiated in vitro and in vivo with ultraviolet- $C$ and ultraviolet-B light," Photochemistry and Photobiology, vol. 54, no. 5, pp. 741-746, 1991.

[151] B. Thyagarajan, K. E. Anderson, C. J. Lessard et al., "Alkaline unwinding flow cytometry assay to measure nucleotide excision repair," Mutagenesis, vol. 22, no. 2, pp. 147-153, 2007.

[152] P. Kara, K. Dağdeviren, and M. Özsöz, "An electrochemical DNA biosensor for the detection of DNA damage caused by radioactive iodine and technetium," Turkish Journal of Chemistry, vol. 31, no. 3, pp. 243-249, 2007.

[153] A. Hollaender and J. T. Curtis, "Effects of sublethal doses of monochromatic ultraviolet radiation on bacteria in liquid suspension," Proceedings of the Society for Experimental Biology and Medicine, vol. 33, pp. 61-62, 1935.
[154] A. Kelner, "Effects of visible light on the recovery of Streptomyces griseus conidia from ultraviolet irradiation injury," Proceedings of the National Academy of Sciences of the Unites States of America, vol. 35, pp. 73-79, 1949.

[155] R. Dulbecco, "Reactivation of ultra-violet-inactivated bacteriophage by visible light," Nature, vol. 163, no. 4155, pp. 949950, 1949.

[156] J. Essers, W. Vermeulen, and A. B. Houtsmuller, "DNA damage repair: anytime, anywhere?" Current Opinion in Cell Biology, vol. 18, no. 3, pp. 240-246, 2006.

[157] S.-T. Kim, P. F. Heelis, and A. Sancar, "Energy transfer (deazaflavin $\rightarrow$ FADH2) and electron transfer (FADH2 $\rightarrow$ $\mathrm{T}<>\mathrm{T}$ ) kinetics in Anacystis nidulans photolyase," Biochemistry, vol. 31, no. 45, pp. 11244-11248, 1992.

[158] L. O. Essen and T. Klar, "Light-driven DNA repair by photolyases," Cellular and Molecular Life Sciences, vol. 63, no. 11, pp. 1266-1277, 2006.

[159] A. B. Britt, "DNA damage and repair in plants," Annual Review of Plant Physiology and Plant Molecular Biology, vol. 47, no. 1, pp. 75-100, 1996.

[160] T. Todo, "Functional diversity of the DNA photolyase/blue light receptor family," Mutation Research, vol. 434, no. 2, pp. 89-97, 1999.

[161] B. M. Sutherland, "Photoreactivating enzyme from human leukocytes," Nature, vol. 248, no. 5444, pp. 109-112, 1974.

[162] B. M. Sutherland and P. V. Bennett, "Human white blood cells contain cyclobutyl pyrimidine dimer photolyase," Proceedings of the National Academy of Sciences of the United States of America, vol. 92, no. 21, pp. 9732-9736, 1995.

[163] H. Harm, "Damage and repair in mammalian cells after exposure to non-ionizing radiations. III. Ultraviolet and visible light irradiation of cells of placental mammals, including humans, and determination of photorepairable damage in vitro," Mutation Research, vol. 69, no. 1, pp. 167176, 1980.

[164] D. S. Hsu, X. Zhao, S. Zhao et al., "Putative human bluelight photoreceptors hCRY1 and hCRY2 are flavoproteins," Biochemistry, vol. 35, no. 44, pp. 13871-13877, 1996.

[165] T. Ueda, A. Kato, S. Kuramitsu, H. Terasawa, and I. Shimada, "Identification and characterization of a second chromophore of DNA photolyase from Thermus thermophilus HB27," Journal of Biological Chemistry, vol. 280, no. 43, pp. 36237-36243, 2005.

[166] C. Saxena, A. Sancar, and D. Zhong, "Femtosecond dynamics of DNA photolyase: energy transfer of antenna initiation and electron transfer of cofactor reduction," Journal of Physical Chemistry B, vol. 108, no. 46, pp. 18026-18033, 2004.

[167] Y.-T. Kao, C. Saxena, L. Wang, A. Sancar, and D. Zhong, "Direct observation of thymine dimer repair in DNA by photolyase," Proceedings of the National Academy of Sciences of the United States of America, vol. 102, no. 45, pp. 1612816132, 2005.

[168] A. E. Stapleton and V. Walbot, "Flavonoids can protect maize DNA from the induction of ultraviolet radiation damage," Plant Physiology, vol. 105, no. 3, pp. 881-889, 1994.

[169] R. Schmitz-Hoerner and G. Weissenbock, "Contribution of phenolic compounds to the UV-B screening capacity of developing barley primary leaves in relation to DNA damage and repair under elevated UV-B levels," Phytochemistry, vol. 64, pp. 243-255, 2003.

[170] G. Kaiser, O. Kleiner, C. Beisswenger, and A. Batschauer, "Increased DNA repair in Arabidopsis plants overexpressing CPD photolyase," Planta, vol. 230, no. 3, pp. 505-515, 2009. 
[171] N. Tuteja, M. B. Singh, M. K. Misra, P. L. Bhalla, and R. Tuteja, "Molecular mechanisms of DNA damage and repair: progress in plants," Critical Reviews in Biochemistry and Molecular Biology, vol. 36, no. 4, pp. 337-397, 2001.

[172] S. Kimura, Y. Tahira, T. Ishibashi et al., "DNA repair in higher plants; photoreactivation is the major DNA repair pathway in non-proliferating cells while excision repair (nucleotide excision repair and base excision repair) is active in proliferating cells," Nucleic Acids Research, vol. 32, pp. 2760-2767, 2004.

[173] J. J. Chen, D. L. Mitchell, and A. B. Britt, "A light-dependent pathway for the elimination of UV-induced pyrimidine (6-4) pyrimidinone photoproducts in Arabidopsis," Plant Cell, vol. 6, no. 9, pp. 1311-1317, 1994.

[174] H.-S. Kang, J. Hidema, and T. Kumagai, "Effects of light environment during culture on UV-induced cyclobutyl pyrimidine dimers and their photorepair in rice (Oryza sativa L.)," Photochemistry and Photobiology, vol. 68, no. 1, pp. 7177, 1998.

[175] A. Mees, T. Klar, P. Gnau et al., "Crystal structure of a photolyase bound to a CPD-like DNA lesion after in situ repair," Science, vol. 306, no. 5702, pp. 1789-1793, 2004.

[176] T. Torizawa, T. Ueda, S. Kuramitsu et al., "Investigation of the cyclobutane pyrimidine dimer (CPD) photolyase DNA recognition mechanism by NMR analyses," Journal of Biological Chemistry, vol. 279, no. 31, pp. 32950-32956, 2004.

[177] P. F. Heelis, R. F. Hartman, and S. D. Rose, "Photoenzymic repair of UV-damaged DNA — a chemist's perspective," Chemical Society Reviews, vol. 24, no. 4, pp. 289-297, 1995.

[178] A. W. MacFarlane and R. J. Stanley, "Cis-Syn thymidine dimer repair by DNA photolyase in real time," Biochemistry, vol. 42, no. 28, pp. 8558-8568, 2003.

[179] I. H. Kavakli and A. Sancar, "Analysis of the role of intraprotein electron transfer in photoreactivation by DNA photolyase in vivo," Biochemistry, vol. 43, no. 48, pp. 1510315110, 2004

[180] E. Schleicher, B. Heßling, V. Illarionova et al., "Light-induced reactions of Escherichia coli DNA photolyase monitored by Fourier transform infrared spectroscopy," FEBS Journal, vol. 272, no. 8, pp. 1855-1866, 2005.

[181] G. B. Sancar and F. W. Smith, "Interactions between yeast photolyase and nucleotide excision repair proteins in Saccharomyces cerevisiae and Escherichia coli," Molecular and Cellular Biology, vol. 9, no. 11, pp. 4767-4776, 1989.

[182] E. Seeberg, L. Eide, and M. Bjørås, "The base excision repair pathway," Trends in Biochemical Sciences, vol. 20, no. 10, pp. 391-397, 1995.

[183] J. H. Houtgraaf, J. Versmissen, and W. J. van der Giessen, "A concise review of DNA damage checkpoints and repair in mammalian cells," Cardiovascular Revascularization Medicine, vol. 7, no. 3, pp. 165-172, 2006.

[184] K. H. Almeida and R. W. Sobol, "A unified view of base excision repair: lesion-dependent protein complexes regulated by post-translational modification," DNA Repair, vol. 6, no. 6, pp. 695-711, 2007.

[185] K. Hitomi, S. Iwai, and J. A. Tainer, “The intricate structural chemistry of base excision repair machinery: implications for DNA damage recognition, removal, and repair," DNA Repair, vol. 6, no. 4, pp. 410-428, 2007.

[186] A. B. Robertson, A. Klungland, T. Rognes, and I. Leiros, "Base excision repair: the long and short of it," Cellular and Molecular Life Sciences, vol. 66, no. 6, pp. 981-993, 2009.
[187] D. E. Barnes and T. Lindahl, "Repair and genetic consequences of endogenous DNA base damage in mammalian cells," Annual Review of Genetics, vol. 38, pp. 445-476, 2004.

[188] J. L. Parsons, P. S. Tait, D. Finch, I. I. Dianova, S. L. Allinson, and G. L. Dianov, "CHIP-mediated degradation and DNA damage-dependent stabilization regulate base excision repair proteins," Molecular Cell, vol. 29, no. 4, pp. 477-487, 2008.

[189] K. W. Caldecott, "XRCC1 and DNA strand break repair," DNA Repair, vol. 2, no. 9, pp. 955-969, 2003.

[190] L. Lan, S. Nakajima, Y. Oohata et al., "In situ analysis of repair processes for oxidative DNA damage in mammalian cells," Proceedings of the National Academy of Sciences of the United States of America, vol. 101, no. 38, pp. 13738-13743, 2004.

[191] K. Sakumi and M. Sekiguchi, "Structures and functions of DNA glycosylases," Mutation Research, vol. 236, no. 2-3, pp. 161-172, 1990.

[192] Y. Matsumoto and K. Kim, "Excision of deoxyribose phosphate residues by DNA polymerase $\beta$ during DNA repair," Science, vol. 269, no. 5224, pp. 699-702, 1995.

[193] B. Demple and L. Harrison, "Repair of oxidative damage to DNA: enzymology and biology," Annual Review of Biochemistry, vol. 63, pp. 915-948, 1994.

[194] L. Gros, A. A. Ishchenko, H. Ide, R. H. Elder, and M. K. Saparbaev, "The major human AP endonuclease (Ape1) is involved in the nucleotide incision repair pathway," Nucleic Acids Research, vol. 32, no. 1, pp. 73-81, 2004.

[195] P. Fortini and E. Dogliotti, "Base damage and single-strand break repair: mechanisms and functional significance of short- and long-patch repair subpathways," DNA Repair, vol. 6, no. 4, pp. 398-409, 2007.

[196] U. Sattler, P. Frit, B. Salles, and P. Calsou, "Long-patch DNA repair synthesis during base excision repair in mammalian cells," EMBO Reports, vol. 4, no. 4, pp. 363-367, 2003.

[197] W. D. Henner, S. M. Grunberg, and W. A. Haseltine, "Enzyme action at 3' termini of ionizing radiation-induced DNA strand breaks," Journal of Biological Chemistry, vol. 258, no. 24, pp. 15198-151205, 1983.

[198] W. D. Henner, L. O. Rodriguez, S. M. Hecht, and W. A. Haseltine, "gamma Ray induced deoxyribonucleic acid strand breaks. 3' Glycolate termini," Journal of Biological Chemistry, vol. 258, no. 2, pp. 711-713, 1983.

[199] A. Jilani, D. Ramotar, C. Slack et al., "Molecular cloning of the human gene, PNKP, encoding a polynucleotide kinase $3^{\prime}$ phosphatase and evidence for its role in repair of DNA strand breaks caused by oxidative damage," Journal of Biological Chemistry, vol. 274, no. 34, pp. 24176-24186, 1999.

[200] R. Gary, K. Kim, H. L. Cornelius, M. S. Park, and Y. Matsumoto, "Proliferating cell nuclear antigen facilitates excision in long-patch base excision repair," Journal of Biological Chemistry, vol. 274, no. 7, pp. 4354-4363, 1999.

[201] P. Fortini, B. Pascucci, E. Parlanti, R. W. Sobol, S. H. Wilson, and E. Dogliotti, "Different DNA polymerases are involved in the short- and long-patch base excision repair in mammalian cells," Biochemistry, vol. 37, no. 11, pp. 3575-3580, 1998.

[202] A. B. Britt, "Molecular genetics of DNA repair in higher plants," Trends in Plant Science, vol. 4, no. 1, pp. 20-25, 1999.

[203] J. B. Hays, "Arabidopsis thaliana, a versatile model system for study of eukaryotic genome-maintenance functions," DNA Repair, vol. 1, no. 8, pp. 579-600, 2002.

[204] E. Hefner, S. B. Preuss, and A. B. Britt, "Arabidopsis mutants sensitive to gamma radiation include the homologue of the human repair gene ERCC1," Journal of Experimental Botany, vol. 54, no. 383, pp. 669-680, 2003. 
[205] A. G. McLennan, "The repair of ultraviolet light-induced DNA damage in plant cells," Mutation Research, vol. 181, no. 1, pp. 1-7, 1987.

[206] E. J. Vonarx, H. L. Mitchell, R. Karthikeyan, I. Chatterjee, and B. A. Kunz, "DNA repair in higher plants," Mutation Research, vol. 400, no. 1-2, pp. 187-200, 1998.

[207] E. Dandoy, R. Schyns, R. Deltour, and W. G. Verly, "Appearance and repair of apurinic/apyrimidinic sites in DNA during early germination of Zea mays," Mutation Research, vol. 181, no. 1, pp. 57-60, 1987.

[208] M. Talpaert-Borlè and M. Liuzzi, "Base-excision repair in carrot cells," European Journal of Biochemistry, vol. 124, no. 3, pp. 435-440, 1982.

[209] R. T. Hess, U. Schwitter, M. Petretta, B. Giese, and H. Naegeli, "Bipartite substrate discrimination by human nucleotide excision repair," Proceedings of the National Academy of Sciences of the United States of America, vol. 94, no. 13, pp. 6664-6669, 1997.

[210] R. M. A. Costa, V. Chiganças, R. D. S. Galhardo, H. Carvalho, and C. F. M. Menck, "The eukaryotic nucleotide excision repair pathway," Biochimie, vol. 85, no. 11, pp. 1083-1099, 2003.

[211] A. Van Hoffen, J. Venema, R. Meschini, A. A. Van Zeeland, and L. H. F. Mullenders, "Tvanscription-coupled repair removes both cyclobutane pyrimidine dimers and 6-4 photoproducts with equal efficiency and in a sequential way from transcribed DNA in xeroderma pigmentosum group C fibroblasts," EMBO Journal, vol. 14, no. 2, pp. 360-367, 1995.

[212] R. P. Boyce and P. Howard-Flanders, "Release of ultraviolet light-induced thymine dimers from DNA in E. coli K-12," Proceedings of the National Academy of Sciences of the United States of America, vol. 51, pp. 293-300, 1964.

[213] D. E. Pettijohn and P. C. Hanawalt, "Evidence for repairreplication of ultraviolet damaged DNA in bacteria," Journal of Molecular Biology, vol. 9, pp. 395-410, 1964.

[214] J.-J. Lin and A. Sancar, "Reconstitution of nucleotide excision nuclease with UvrA and UvrB proteins from Escherichia coli and UvrC protein from Bacillus subtilis," Journal of Biological Chemistry, vol. 265, no. 34, pp. 21337-21341, 1990.

[215] D. K. Orren, P. Selby, J. E. Hearst, and A. Sancar, "Postincision steps of nucleotide excision repair in Escherichia coli. Disassembly of the UvrBC-DNA complex by helicase II and DNA polymerase I," The Journal of Biological Chemistry, vol. 267, pp. 780-788, 1992.

[216] T. Nouspikel, "Nucleotide excision repair: variations on versatility," Cellular and Molecular Life Sciences, vol. 66, no. 6, pp. 994-1009, 2009.

[217] S. W. Matson, D. W. Bean, and J. W. George, "DNA helicases: enzymes with essential roles in all aspects of DNA metabolism," BioEssays, vol. 16, no. 1, pp. 13-22, 1994.

[218] K. A. Henning, L. Li, N. Iyer et al., "The Cockayne syndrome group a gene encodes a WD repeat protein that interacts with CSB protein and a subunit of RNA polymerase II TFIIH," Cell, vol. 82, no. 4, pp. 555-564, 1995.

[219] C. P. Selby and A. Sancar, "Human transcription-repair coupling factor CSB/ERCC6 is a DNA-stimulated ATPase but is not a helicase and does not disrupt the ternary transcription complex of stalled RNA polymerase II," Journal of Biological Chemistry, vol. 272, no. 3, pp. 1885-1890, 1997.

[220] P. C. Hanawalt, B. A. Donahue, and K. S. Sweder, "Repair and transcription: collision or collusion?" Current Biology, vol. 4, no. 6, pp. 518-522, 1994.
[221] S. Tornaletti and P. C. Hanawalt, "Effect of DNA lesions on transcription elongation," Biochimie, vol. 81, no. 1-2, pp. 139-146, 1999.

[222] J. N. Ratner, B. Balasubramanian, J. Corden, S. L. Warren, and D. B. Bregman, "Ultraviolet radiation-induced ubiquitination and proteasomal degradation of the large subunit of RNA polymerase II: implications for transcription-coupled DNA repair," Journal of Biological Chemistry, vol. 273, no. 9, pp. 5184-5189, 1998.

[223] A. Sarasin and A. Stary, "New insights for understanding the transcription-coupled repair pathway," DNA Repair, vol. 6, no. 2, pp. 265-269, 2007.

[224] M. Fousteri, W. Vermeulen, A. A. van Zeeland, and L. H. F. Mullenders, "Cockayne syndrome A and B proteins differentially regulate recruitment of chromatin remodeling and repair factors to stalled RNA polymerase II in vivo," Molecular Cell, vol. 23, no. 4, pp. 471-482, 2006.

[225] L. Proietti-De-Santis, P. Drané, and J.-M. Egly, "Cockayne syndrome $\mathrm{B}$ protein regulates the transcriptional program after UV irradiation," EMBO Journal, vol. 25, no. 9, pp. 19151923, 2006.

[226] K. Sugasawa, J. M. Y. Ng, C. Masutani et al., "Xeroderma pigmentosum group $\mathrm{C}$ protein complex is the initiator of global genome nucleotide excision repair," Molecular Cell, vol. 2, no. 2, pp. 223-232, 1998.

[227] W. L. De Laat, N. G. J. Jaspers, and J. H. J. Hoeijmakers, "Molecular mechanism of nucleotide excision repair," Genes and Development, vol. 13, no. 7, pp. 768-785, 1999.

[228] L. C. J. Gillet and O. D. Schärer, "Molecular mechanisms of mammalian global genome nucleotide excision repair," Chemical Reviews, vol. 106, no. 2, pp. 253-276, 2006.

[229] C. Petit and A. Sancar, "Nucleotide excision repair: from E. coli to man," Biochimie, vol. 81, no. 1-2, pp. 15-25, 1999.

[230] C. Masutani, K. Sugasawa, J. Yanagisawa et al., "Purification and cloning of a nucleotide excision repair complex involving the xeroderma pigmentosum group $\mathrm{C}$ protein and a human homologue of yeast RAD23," EMBO Journal, vol. 13, no. 8, pp. 1831-1843, 1994.

[231] M. Araki, C. Masutani, M. Takemura et al., "Centrosome protein centrin $2 /$ caltractin 1 is part of the xeroderma pigmentosum group $\mathrm{C}$ complex that initiates global genome nucleotide excision repair," Journal of Biological Chemistry, vol. 276, no. 22, pp. 18665-18672, 2001.

[232] L. Schaeffer, R. Roy, S. Humbert et al., "DNA repair helicase: a component of BTF2 (TFIIH) basic transcription factor," Science, vol. 260, pp. 58-63, 1993.

[233] F. Coin, V. Oksenych, and J.-M. Egly, "Distinct roles for the $\mathrm{XPB} / \mathrm{p} 52$ and XPD/p44 subcomplexes of TFIIH in damaged DNA opening during nucleotide excision repair," Molecular Cell, vol. 26, no. 2, pp. 245-256, 2007.

[234] L. Schaeffer, V. Moncollin, R. Roy et al., "The ERCC2/DNA repair protein is associated with the class II BTF2/TFIIH transcription factor," EMBO Journal, vol. 13, no. 10, pp. 2388-2392, 1994.

[235] J. Chen, S. Larochelle, X. Li, and B. Suter, "Xpd/Ercc2 regulates CAK activity and mitotic progression," Nature, vol. 424, no. 6945, pp. 228-232, 2003.

[236] P. Schultz, S. Fribourg, A. Poterszman, V. Mallouh, D. Moras, and J. M. Egly, "Molecular structure of human TFIIH," Cell, vol. 102, no. 5, pp. 599-607, 2000.

[237] J. A. Ranish, S. Hahn, Y. Lu et al., "Identification of TFB5, a new component of general transcription and DNA repair factor IIH," Nature Genetics, vol. 36, no. 7, pp. 707-713, 2004. 
[238] C. J. Jones and R. D. Wood, "Preferential binding of the xeroderma pigmentosum group A complementing protein to damaged DNA," Biochemistry, vol. 32, no. 45, pp. 1209612104, 1993.

[239] T. Matsuda, M. Saijo, I. Kuraoka et al., "DNA repair protein XPA binds replication protein A (RPA)," Journal of Biological Chemistry, vol. 270, no. 8, pp. 4152-4157, 1995.

[240] E. Stigger, R. Drissi, and S.-H. Lee, "Functional analysis of human replication protein A in nucleotide excision repair," Journal of Biological Chemistry, vol. 273, no. 15, pp. 93379343, 1998.

[241] Z. He, L. A. Henricksen, M. S. Wold, and C. J. Ingles, "RPA involvement in the damage-recognition and incision steps of nucleotide excision repair," Nature, vol. 374, no. 6522, pp. 566-569, 1995.

[242] J. L. Burns, S. N. Guzder, P. Sung, S. Prakash, and L. Prakash, "An affinity of human replication protein A for ultravioletdamaged DNA: implications for damage recognition in nucleotide excision repair," Journal of Biological Chemistry, vol. 271, no. 20, pp. 11607-11610, 1996.

[243] E. Evans, J. G. Moggs, J. R. Hwang, J.-M. Egly, and R. D. Wood, "Mechanism of open complex and dual incision formation by human nucleotide excision repair factors," EMBO Journal, vol. 16, no. 21, pp. 6559-6573, 1997.

[244] A. H. Sarker, S. E. Tsutakawa, S. Kostek et al., "Recognition of RNA polymerase II and transcription bubbles by XPG, CSB, and TFIIH: insights for transcription-coupled repair and Cockayne syndrome," Molecular Cell, vol. 20, no. 2, pp. 187-198, 2005.

[245] K. G. Cloud, B. Shen, G. F. Strniste, and M. S. Park, "XPG protein has a structure-specific endonuclease activity," Mutation Research, vol. 347, no. 2, pp. 55-60, 1995.

[246] W. L. De Laat, E. Appeldoorn, N. G. J. Jaspers, and J. H. J. Hoeijmakers, "DNA structural elements required for ERCC1-XPF endonuclease activity," Journal of Biological Chemistry, vol. 273, no. 14, pp. 7835-7842, 1998.

[247] J. H. Enzlin and O. D. Schärer, "The active site of the DNA repair endonuclease XPF-ERCC1 forms a highly conserved nuclease motif," EMBO Journal, vol. 21, no. 8, pp. 2045-2053, 2002.

[248] R. D. Wood, "Nucleotide excision repair in mammalian cells," Journal of Biological Chemistry, vol. 272, no. 38, pp. 2346523468, 1997.

[249] D. Mu, D. S. Hsu, and A. Sancar, "Reaction mechanism of human DNA repair excision nuclease," Journal of Biological Chemistry, vol. 271, no. 14, pp. 8285-8294, 1996.

[250] K. Sugasawa, Y. Okuda, M. Saijo et al., "UV-induced ubiquitylation of XPC protein mediated by UV-DDB-ubiquitin ligase complex," Cell, vol. 121, no. 3, pp. 387-400, 2005.

[251] J. Tang and G. Chu, "Xeroderma pigmentosum complementation group E and UV-damaged DNA-binding protein," DNA Repair, vol. 1, no. 8, pp. 601-616, 2002.

[252] O. Maillard, S. Solyom, and H. Naegeli, "An aromatic sensor with aversion to damaged strands confers versatility to DNA repair," PLoS Biology, vol. 5, no. 4, article no. e79, 2007.

[253] K. Sugasawa, "UV-induced ubiquitylation of XPC complex, the UV-DDB-ubiquitin ligase complex, and DNA repair," Journal of Molecular Histology, vol. 37, no. 5-7, pp. 189-202, 2006.

[254] D. Hoogstraten, S. Bergink, V. H. M. Verbiest et al., "Versatile DNA damage detection by the global genome nucleotide excision repair protein XPC," Journal of Cell Science, vol. 121, no. 17, pp. 2850-2859, 2008.
[255] P. J. Van der Spek, A. Eker, S. Rademakers et al., "XPC and human homologs of RAD23: intracellular localization and relationship to other nucleotide excision repair complexes," Nucleic Acids Research, vol. 24, no. 13, pp. 2551-2559, 1996.

[256] K. Sugasawa, C. Masutani, A. Uchida et al., "HHR23B, a human Rad23 homolog, stimulates XPC protein in nucleotide excision repair in vitro," Molecular and Cellular Biology, vol. 16, no. 9, pp. 4852-4861, 1996.

[257] C. Masutani, M. Araki, K. Sugasawa et al., "Identification and characterization of XPC-binding domain of hHR23B," Molecular and Cellular Biology, vol. 17, no. 12, pp. 6915-6923, 1997.

[258] K. Sugasawa, J. M. Y. Ng, C. Masutani et al., "Two human homologs of $\operatorname{Rad} 23$ are functionally interchangeable in complex formation and stimulation of XPC repair activity," Molecular and Cellular Biology, vol. 17, no. 12, pp. 6924-6931, 1997.

[259] J. T. Reardon, D. Mu, and A. Sancar, "Overproduction, purification, and characterization of the XPC subunit of the human DNA repair excision nuclease," Journal of Biological Chemistry, vol. 271, no. 32, pp. 19451-19456, 1996.

[260] K. Sugasawa, T. Okamoto, Y. Shimizu, C. Masutani, S. Iwai, and F. Hanaoka, "A multistep damage recognition mechanism for global genomic nucleotide excision repair," Genes and Development, vol. 15, no. 5, pp. 507-521, 2001.

[261] A. Aboussekhra, M. Biggerstaff, M. K. K. Shivji et al., "Mammalian DNA nucleotide excision repair reconstituted with purified protein components," Cell, vol. 80, no. 6, pp. 859-868, 1995.

[262] F. Tirode, D. Busso, F. Coin, and J.-M. Egly, "Reconstitution of the transcription factor TFIIH: assignment of functions for the three enzymatic subunits, XPB, XPD, and cdk7," Molecular Cell, vol. 3, no. 1, pp. 87-95, 1999.

[263] D. Mu, C.-H. Park, T. Matsunaga, D. S. Hsu, J. T. Reardon, and A. Sancar, "Reconstitution of human DNA repair excision nuclease in a highly defined system," Journal of Biological Chemistry, vol. 270, no. 6, pp. 2415-2418, 1995.

[264] M. R. Lieber, "The FEN-1 family of structure-specific nucleases in eukaryotic DNA replication, recombination and repair," BioEssays, vol. 19, no. 3, pp. 233-240, 1997.

[265] A. Constantinou, D. Gunz, E. Evans et al., "Conserved residues of human XPG protein important for nuclease activity and function in nucleotide excision repair," Journal of Biological Chemistry, vol. 274, no. 9, pp. 5637-5648, 1999.

[266] R. Guo, J. Chen, F. Zhu et al., "E2F1 Localizes to sites of UVinduced DNA damage to enhance nucleotide excision repair," The Journal of Biological Chemistry, vol. 285, pp. 1930819315, 2010.

[267] S. Nocentini, "Rejoining kinetics of DNA single- and doublestrand breaks in normal and DNA ligase-deficient cells after exposure to ultraviolet $\mathrm{C}$ and gamma radiation: an evaluation of ligating activities involved in different DNA repair processes," Radiation Research, vol. 151, no. 4, pp. 423432, 1999.

[268] J. Moser, H. Kool, I. Giakzidis, K. Caldecott, L. H.F. Mullenders, and M. I. Fousteri, "Sealing of chromosomal DNA nicks during nucleotide excision repair requires XRCC1 and DNA ligase III $\alpha$ in a cell-cycle-specific manner," Molecular Cell, vol. 27, no. 2, pp. 311-323, 2007.

[269] S. Tornaletti, "Transcription-coupled DNA repair: directing your effort where it's most needed," Cellular and Molecular Life Sciences, vol. 66, no. 6, pp. 1010-1020, 2009. 
[270] G. R. Harlow, M. E. Jenkins, T. S. Pittalwala, and D. W. Mount, "Isolation of uvh1, an Arabidopsis mutant hypersensitive to ultraviolet light and ionizing radiation," Plant Cell, vol. 6, no. 2, pp. 227-235, 1994.

[271] A. L. Fidantsef, D. L. Mitchell, and A. B. Britt, "The Arabidopsis UVH1 gene is a homolog of the yeast repair endonuclease RAD1," Plant Physiology, vol. 124, no. 2, pp. 579-586, 2000.

[272] Z. Liu, G. S. Hossain, M. A. Islas-Osuna, D. L. Mitchell, and D. W. Mount, "Repair of UV damage in plants by nucleotide excision repair: Arabidopsis UVH1 DNA repair gene is a homolog of Saccharomyces cerevisiae Rad1," Plant Journal, vol. 21, no. 6, pp. 519-528, 2000.

[273] Z. Liu, J. D. Hall, and D. W. Mount, "Arabidopsis UVH3 gene is a homolog of the Saccharomyces cerevisiae RAD2 and human XPG DNA repair genes," Plant Journal, vol. 26, no. 3, pp. 329-338, 2001.

[274] G. C. Cannon, L. A. Hedrick, and S. Heinhorst, "Repair mechanisms of UV-induced DNA damage in soybean chloroplasts," Plant Molecular Biology, vol. 29, no. 6, pp. 1267-1277, 1995.

[275] J. Hidema, T. Kumagai, J. C. Sutherland, and B. M. Sutherland, "Ultraviolet B-sensitive rice cultivar deficient in cyclobutyl pyrimidine dimer repair," Plant Physiology, vol. 113, no. 1, pp. 39-44, 1997.

[276] M. E. Jenkins, G. R. Harlow, Z. Liu, M. A. Shotwell, J. Ma, and D. W. Mount, "Radiation-sensitive mutants of Arabidopsis thaliana," Genetics, vol. 140, no. 2, pp. 725-732, 1995.

[277] C.-Z. Jiang, C.-N. Yen, K. Cronin, D. Mitchell, and A. B. Britt, "UV- and gamma-radiation sensitive mutants of Arabidopsis thaliana," Genetics, vol. 147, no. 3, pp. 1401-1409, 1997.

[278] S. Kimura and K. Sakaguchi, "DNA repair in plants," Chemical Reviews, vol. 106, no. 2, pp. 753-766, 2006.

[279] H. Xu, I. Swoboda, P. L. Bhalla et al., "Plant homologue of human excision repair gene ERCC1 points to conservation of DNA repair mechanisms," Plant Journal, vol. 13, no. 6, pp. 823-829, 1998.

[280] E. C. Friedberg, "DNA damage and repair," Nature, vol. 421, no. 6921, pp. 436-440, 2003.

[281] J. Wu, L.-Y. Lu, and X. Yu, "The role of BRCA1 in DNA damage response," Protein Cell, vol. 1, pp. 117-123, 2010.

[282] P. Sung, K. M. Trujillo, and S. Van Komen, "Recombination factors of Saccharomyces cerevisiae," Mutation Research, vol. 451, no. 1-2, pp. 257-275, 2000.

[283] G. A. Cromie, J. C. Connelly, and D. R. F. Leach, "Recombination at double-strand breaks and DNA ends: conserved mechanisms from phage to humans," Molecular Cell, vol. 8, no. 6, pp. 1163-1174, 2001.

[284] J. Thacker, "The RAD51 gene family, genetic instability and cancer," Cancer Letters, vol. 219, no. 2, pp. 125-135, 2005.

[285] K. McEntee, G. M. Weinstock, and I. R. Lehman, "recA protein-catalyzed strand assimilation: stimulation by Escherichia coli single-stranded DNA-binding protein," Proceedings of the National Academy of Sciences of the United States of America, vol. 77, no. 2, pp. 857-861, 1980.

[286] D. K. Bishop, D. Park, L. Xu, and N. Kleckner, "DMC1: a meiosis-specific yeast homolog of $E$. coli recA required for recombination, synaptonemal complex formation, and cell cycle progression," Cell, vol. 69, no. 3, pp. 439-456, 1992.

[287] S. T. Lovett, "Sequence of the RAD5 gene of Saccharomyces cerevisiae: similarity of RAD55 to prokaryotic RecA and other RecA-like proteins," Gene, vol. 142, no. 1, pp. 103-106, 1994.
[288] W. Li and H. Ma, "Double-stranded DNA breaks and gene functions in recombination and meiosis," Cell Research, vol. 16, no. 5, pp. 402-412, 2006.

[289] M. Kawabata, T. Kawabata, and M. Nishibori, "Role of recA/RAD51 family proteins in mammals," Acta Medica Okayama, vol. 59, no. 1, pp. 1-9, 2005.

[290] Y. Aylon and M. Kupiec, "New insights into the mechanism of homologous recombination in yeast," Mutation Research, vol. 566, no. 3, pp. 231-248, 2004.

[291] M. S. Park, "Expression of human RAD52 confers resistance to ionizing radiation in mammalian cells," Journal of Biological Chemistry, vol. 270, no. 26, pp. 15467-15470, 1995.

[292] Y. Aylon and M. Kupiec, "The checkpoint protein Rad24 of Saccharomyces cerevisiae is involved in processing doublestrand break ends and in recombination partner choice," Molecular and Cellular Biology, vol. 23, no. 18, pp. 6585-6596, 2003.

[293] S. Palmer, E. Schildkraut, R. Lazarin, J. Nguyen, and J. A. Nickoloff, "Gene conversion tracts in Saccharomyces cerevisiae can be extremely short and highly directional," Nucleic Acids Research, vol. 31, no. 4, pp. 1164-1173, 2003.

[294] O. Inbar and M. Kupiec, "Homology search and choice of homologous partner during mitotic recombination," Molecular and Cellular Biology, vol. 19, no. 6, pp. 4134-4142, 1999.

[295] Y. Aylon, B. Liefshitz, G. Bitan-Banin, and M. Kupiec, "Molecular dissection of mitotic recombination in the yeast Saccharomyces cerevisiae," Molecular and Cellular Biology, vol. 23, no. 4, pp. 1403-1417, 2003.

[296] H. Puchta, P. Swoboda, and B. Hohn, "Induction of intrachromosomal homologous recombination in whole plants," Plant Journal, vol. 7, no. 2, pp. 203-210, 1995.

[297] P. A. Jeggo, "Studies on mammalian mutants defective in rejoining double-strand breaks in DNA," Mutation Research, vol. 239, no. 1, pp. 1-16, 1990.

[298] G. Ira, A. Pellicioll, A. Balijja et al., "DNA end resection, homologous recombination and DNA damage checkpoint activation require CDK1," Nature, vol. 431, no. 7011, pp. 1011-1017, 2004.

[299] P. Sung, "Yeast Rad55 and Rad57 proteins form a heterodimer that functions with replication protein A to promote DNA strand exchange by Rad51 recombinase," Genes and Development, vol. 11, no. 9, pp. 1111-1121, 1997.

[300] B. Wolner, S. Van Komen, P. Sung, and C. L. Peterson, "Recruitment of the recombinational repair machinery to a DNA double-strand break in yeast," Molecular Cell, vol. 12, no. 1, pp. 221-232, 2003.

[301] E. Sonoda, G. Y. Zhao, M. Kohzaki et al., "Collaborative roles of $\gamma \mathrm{H} 2 \mathrm{AX}$ and the Rad51 paralog Xrcc3 in homologous recombinational repair," DNA Repair, vol. 6, no. 3, pp. 280292, 2007.

[302] F. Pâques and J. E. Haber, "Multiple pathways of recombination induced by double-strand breaks in Saccharomyces cerevisiae," Microbiology and Molecular Biology Reviews, vol. 63, no. 2, pp. 349-404, 1999.

[303] S. E. Critchlow and S. P. Jackson, "DNA end-joining: from yeast to man," Trends in Biochemical Sciences, vol. 23, no. 10, pp. 394-398, 1998.

[304] M. L. Hefferin and A. E. Tomkinson, "Mechanism of DNA double-strand break repair by non-homologous end joining," DNA Repair, vol. 4, no. 6, pp. 639-648, 2005. 
[305] S. A. McElhinny, J. M. Havener, M. Garcia-Diaz et al., "A gradient of template dependence defines distinct biological roles for family $\mathrm{X}$ polymerases in nonhomologous end joining," Molecular Cell, vol. 19, no. 3, pp. 357-366, 2005.

[306] J.-P. Capp, F. Boudsocq, P. Bertrand et al., "The DNA polymerase $\lambda$ is required for the repair of non-compatible DNA double strand breaks by NHEJ in mammalian cells," Nucleic Acids Research, vol. 34, no. 10, pp. 2998-3007, 2006.

[307] S. Thode, A. Schäfer, P. Pfeiffer, and W. Vielmetter, "A novel pathway of DNA end-to-end joining," Cell, vol. 60, no. 6, pp. 921-928, 1990.

[308] R. B. Cary, S. R. Peterson, J. Wang, D. G. Bear, E. M. Bradbury, and D. J. Chen, "DNA looping by $\mathrm{Ku}$ and the DNA-dependent protein kinase," Proceedings of the National Academy of Sciences of the United States of America, vol. 94, no. 9, pp. 4267-4272, 1997.

[309] D. A. Ramsden and M. Geliert, "Ku protein stimulates DNA end joining by mammalian DNA ligases: a direct role for $\mathrm{Ku}$ in repair of DNA double-strand breaks," EMBO Journal, vol. 17, no. 2, pp. 609-614, 1998.

[310] P. Baumann and S. C. West, "DNA end-joining catalyzed by human cell-free extracts," Proceedings of the National Academy of Sciences of the United States of America, vol. 95, no. 24, pp. 14066-14070, 1998.

[311] H. Yajima, K.-J. Lee, S. Zhang, J. Kobayashi, and B. P. C. Chen, "DNA double-strand break formation upon UV-induced replication stress activates ATM and DNA-PKcs kinases," Journal of Molecular Biology, vol. 385, no. 3, pp. 800-810, 2009.

[312] C. Muller, P. Calsou, P. Frit, C. Cayrol, T. Carter, and B. Salles, "UV sensitivity and impaired nucleotide excision repair in DNA-dependent protein kinase mutant cells," Nucleic Acids Research, vol. 26, no. 6, pp. 1382-1389, 1998.

[313] P. Hentges, P. Ahnesorg, R. S. Pitcher et al., "Evolutionary and functional conservation of the DNA non-homologous end-joining protein, XLF/Cernunnos," Journal of Biological Chemistry, vol. 281, no. 49, pp. 37517-37526, 2006.

[314] P. Ahnesorg, P. Smith, and S. P. Jackson, "XLF interacts with the XRCC4-DNA ligase IV complex to promote DNA nonhomologous end-joining," Cell, vol. 124, no. 2, pp. 301313, 2006.

[315] D. Buck, L. Malivert, R. De Chasseval et al., "Cernunnos, a novel nonhomologous end-joining factor, is mutated in human immunodeficiency with microcephaly," Cell, vol. 124, no. 2, pp. 287-299, 2006.

[316] E. Riballo, M. Kühne, N. Rief et al., "A pathway of doublestrand break rejoining dependent upon ATM, Artemis, and proteins locating to $\gamma$-H2AX foci," Molecular Cell, vol. 16, no. 5, pp. 715-724, 2004.

[317] J. Lloyd, J. R. Chapman, J. A. Clapperton et al., "A supramodular FHA/BRCT-repeat architecture mediates Nbs1 adaptor function in response to DNA damage," Cell, vol. 139, no. 1, pp. 100-111, 2009.

[318] R. S. Williams, G. E. Dodson, O. Limbo et al., "Nbs1 is an extended flexible arm binding to Ctp1 and Mre11-Rad50 to coordinate dsDNA break processing," Cell, vol. 139, pp. 8799, 2009.

[319] T. T. Paull and M. Gellert, "A mechanistic basis for Mre11directed DNA joining at microhomologies," Proceedings of the National Academy of Sciences of the United States of America, vol. 97, no. 12, pp. 6409-6414, 2000.
[320] L. Chen, K. Trujillo, W. Ramos, P. Sung, and A. E. Tomkinson, "Promotion of Dnl4-Catalyzed DNA end-joining by the Rad50/Mre11/Xrs2 and Hdf1/Hdf2 complexes," Molecular Cell, vol. 8, no. 5, pp. 1105-1115, 2001.

[321] L. Aravind, V. M. Dixit, and E. V. Koonin, "Apoptotic molecular machinery: vastly increased complexity in vertebrates revealed by genome comparisons," Science, vol. 291, no. 5507, pp. 1279-1284, 2001.

[322] M.-P. Doutriaux, F. Couteau, C. Bergounioux, and C. White, "Isolation and characterisation of the RAD51 and DMC1 homologs from Arabidopsis thaliana," Molecular and General Genetics, vol. 257, no. 3, pp. 283-291, 1998.

[323] A. C. Vergunst and P. J. J. Hooykaas, "Recombination in the plant genome and its application in biotechnology," Critical Reviews in Plant Sciences, vol. 18, no. 1, pp. 1-31, 1999.

[324] M. Majchrzak, R. P. Bowater, P. Staczek, and P. Parniewski, "SOS repair and supercoiling influence the genetic stability of DNA triplet repeats in Escherichia coli," Journal of Molecular Biology, vol. 364, no. 4, pp. 612-624, 2006.

[325] J. Courcelle, A. Khodursky, B. Peter, P. O. Brown, and P. C. Hanawalt, "Comparative gene expression profiles following UV exposure in wild-type and SOS-deficient Escherichia coli," Genetics, vol. 58, pp. 41-64, 2001.

[326] B. Michel, "After 30 years of study, the bacterial SOS response still surprises us," PLoS Biology, vol. 3, no. 7, pp. 1174-1176, 2005.

[327] M. Martins-Pinheiro, R. C. P. Marques, and C. F. M. Menck, "Genome analysis of DNA repair genes in the alpha proteobacterium Caulobacter crescentus," BMC Microbiology, vol. 7, article no. 17, 2007.

[328] B. Van Houten, J. A. Eisen, and P. C. Hanawalt, "A cut above: discovery of an alternative excision repair pathway in bacteria," Proceedings of the National Academy of Sciences of the United States of America, vol. 99, no. 5, pp. 2581-2583, 2002.

[329] R. P. Fuchs, S. Fujii, and J. Wagner, "Properties and functions of Escherichia coli Pol IV and Pol V," Advances in Protein Chemistry, vol. 69, pp. 229-264, 2004.

[330] M. F. Goodman, "Coping with replication 'train wrecks' in Escherichia coli using Pol V, Pol II and RecA proteins," Trends in Biochemical Sciences, vol. 25, no. 4, pp. 189-195, 2000.

[331] B. S. Strauss, R. Roberts, L. Francis, and P. Pouryazdanparast, "Role of the dinB gene product in spontaneous mutation in Escherichia coli with an impaired replicative polymerase," Journal of Bacteriology, vol. 182, no. 23, pp. 6742-6750, 2000.

[332] R. S. Galhardo, R. P. Rocha, M. V. Marques, and C. F. M. Menck, "An SOS-regulated operon involved in damageinducible mutagenesis in Caulobacter crescentus," Nucleic Acids Research, vol. 33, no. 8, pp. 2603-2614, 2005.

[333] L. H. Hartwell and T. A. Weinert, "Checkpoints: controls that ensure the order of cell cycle events," Science, vol. 246, no. 4930, pp. 629-634, 1989.

[334] H.-L. Lo, S. Nakajima, L. Ma et al., "Differential biologic effects of CPD and 6-4PP UV-induced DNA damage on the induction of apoptosis and cell-cycle arrest," BMC Cancer, vol. 5, article no. 135, 2005.

[335] J. Mercer, M. Mahmoudi, and M. Bennett, "DNA damage, $\mathrm{p}^{53}$, apoptosis and vascular disease," Mutation Research, vol. 621, no. 1-2, pp. 75-86, 2007.

[336] J. Lukas, C. Lukas, and J. Bartek, "Mammalian cell cycle checkpoints: signalling pathways and their organization in space and time," DNA Repair, vol. 3, no. 8-9, pp. 997-1007, 2004. 
[337] Y. Shiloh, "ATM and related protein kinases: safeguarding genome integrity," Nature Reviews Cancer, vol. 3, no. 3, pp. 155-168, 2003.

[338] P. A. Jeggo and M. Löbrich, "Contribution of DNA repair and cell cycle checkpoint arrest to the maintenance of genomic stability," DNA Repair, vol. 5, no. 9-10, pp. 1192-1198, 2006.

[339] S. S. Zinkel, K. E. Hurov, C. Ong, F. M. Abtahi, A. Gross, and S. J. Korsmeyer, "A role for proapoptotic BID in the DNAdamage response," Cell, vol. 122, no. 4, pp. 579-591, 2005.

[340] I. Kamer, R. Sarig, Y. Zaltsman et al., "Proapoptotic BID is an ATM effector in the DNA-damage response," Cell, vol. 122, no. 4, pp. 593-603, 2005.

[341] J. Jin, T. Shirogane, L. Xu et al., "SCF $\beta$-TRCP links Chk1 signaling to degradation of the Cdc25A protein phosphatase," Genes and Development, vol. 17, no. 24, pp. 3062-3074, 2003.

[342] Y. Kanemori, K. Uto, and N. Sagata, “ $\beta$-TrCP recognizes a previously undescribed nonphosphorylated destruction motif in Cdc25A and Cdc25B phosphatases," Proceedings of the National Academy of Sciences of the United States of America, vol. 102, no. 18, pp. 6279-6284, 2005.

[343] N. Mailand, J. Falck, C. Lukas et al., "Rapid destruction of human Cdc25A in response to DNA damage," Science, vol. 288, no. 5470, pp. 1425-1429, 2000.

[344] N. Mailand, A. V. Podtelejnikov, A. Groth, M. Mann, J. Bartek, and J. Lukas, "Regulation of $\mathrm{G}_{2} / \mathrm{M}$ events by Cdc25A through phosphorylation-dependent modulation of its stability," EMBO Journal, vol. 21, no. 21, pp. 5911-5920, 2002.

[345] J. Bartek and J. Lukas, "DNA damage checkpoints: from initiation to recovery or adaptation," Current Opinion in Cell Biology, vol. 19, no. 2, pp. 238-245, 2007.

[346] N. Watanabe, H. Arai, Y. Nishihara et al., "M-phase kinases induce phospho-dependent ubiquitination of somatic Wee1 by SCF $\beta$-TrCP," Proceedings of the National Academy of Sciences of the United States of America, vol. 101, no. 13, pp. 4419-4424, 2004.

[347] N. Mailand, S. Bekker-Jensen, J. Bartek, and J. Lukas, "Destruction of claspin by SCF $\beta \operatorname{TrCP}$ restrains Chk1 activation and facilitates recovery from genotoxic stress," Molecular Cell, vol. 23, no. 3, pp. 307-318, 2006.

[348] A. Peschiaroli, N. V. Dorrello, D. Guardavaccaro et al., "SCF $\beta \operatorname{TrCP}$-mediated degradation of claspin regulates recovery from the DNA replication checkpoint response," Molecular Cell, vol. 23, no. 3, pp. 319-329, 2006.

[349] I. Mamely, M. A. van Vugt, V. A. Smits et al., "Pololike kinase-1 controls proteasome-dependent degradation of Claspin during checkpoint recovery," Current Biology, vol. 16, no. 19, pp. 1950-1955, 2006.

[350] L. Busino, M. Donzelli, M. Chiesa et al., "Degradation of Cdc25A by $\beta$-TrCP during $S$ phase and in response to DNA damage," Nature, vol. 426, no. 6962, pp. 87-91, 2003.

[351] M. B. Kastan and J. Bartek, "Cell-cycle checkpoints and cancer," Nature, vol. 432, no. 7015, pp. 316-323, 2004.

[352] C. Masutani, R. Kusumoto, S. Iwai, and F. Hanaoka, "Mechanisms of accurate translesion synthesis by human DNA polymerase $\eta$," EMBO Journal, vol. 19, no. 12, pp. 3100-3109, 2000.

[353] R. E. Johnson, S. Prakash, and L. Prakash, "Efficient bypass of a thymine-thymine dimer by yeast DNA polymerase, Pol $\eta$," Science, vol. 283, no. 5404, pp. 1001-1004, 1999.

[354] R. P. Rastogi, Richa, and R. P. Sinha, "Apoptosis: molecular mechanisms and pathogenicity," EXCLI Journal, vol. 8, pp. 155-181, 2009. 

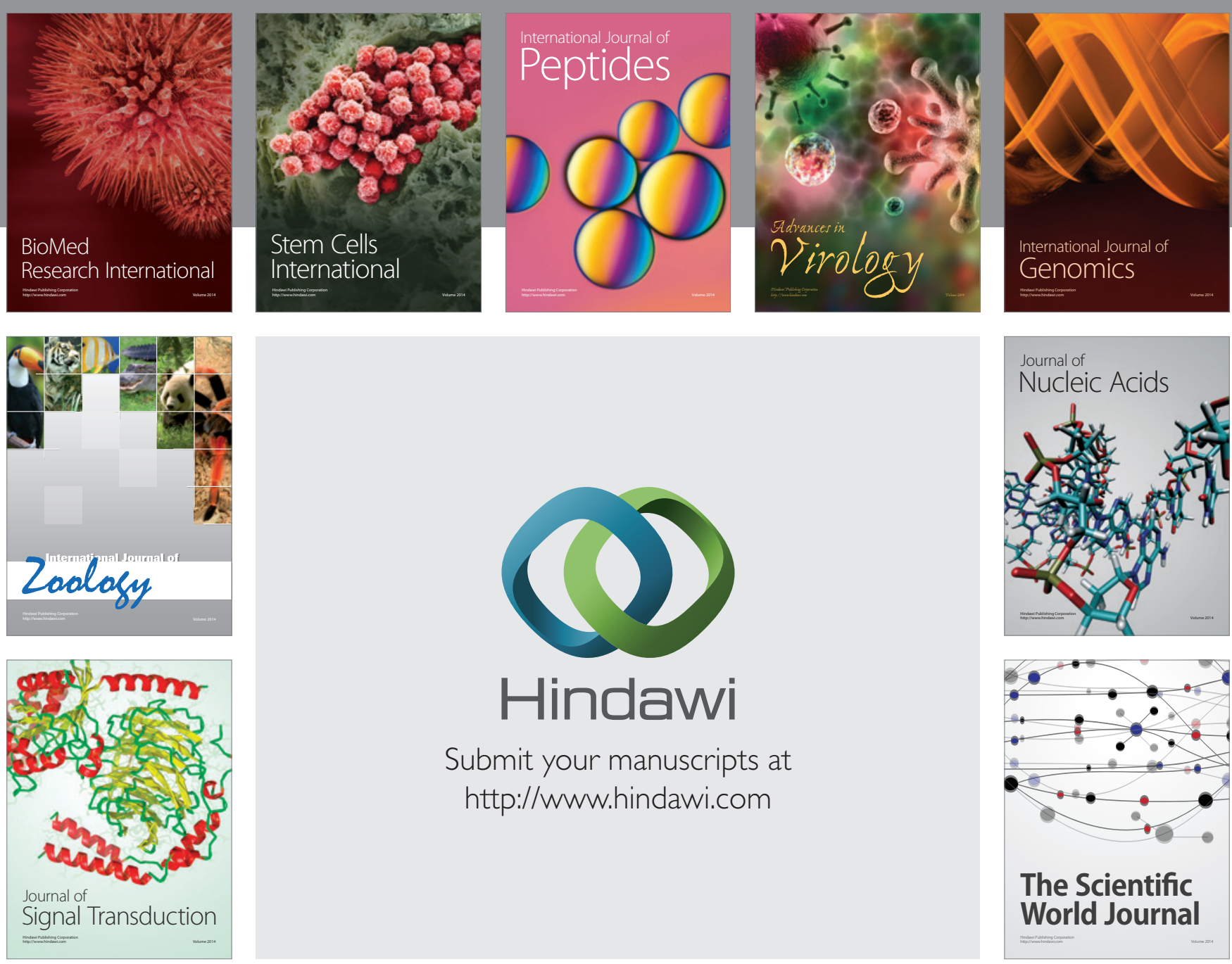

Submit your manuscripts at

http://www.hindawi.com
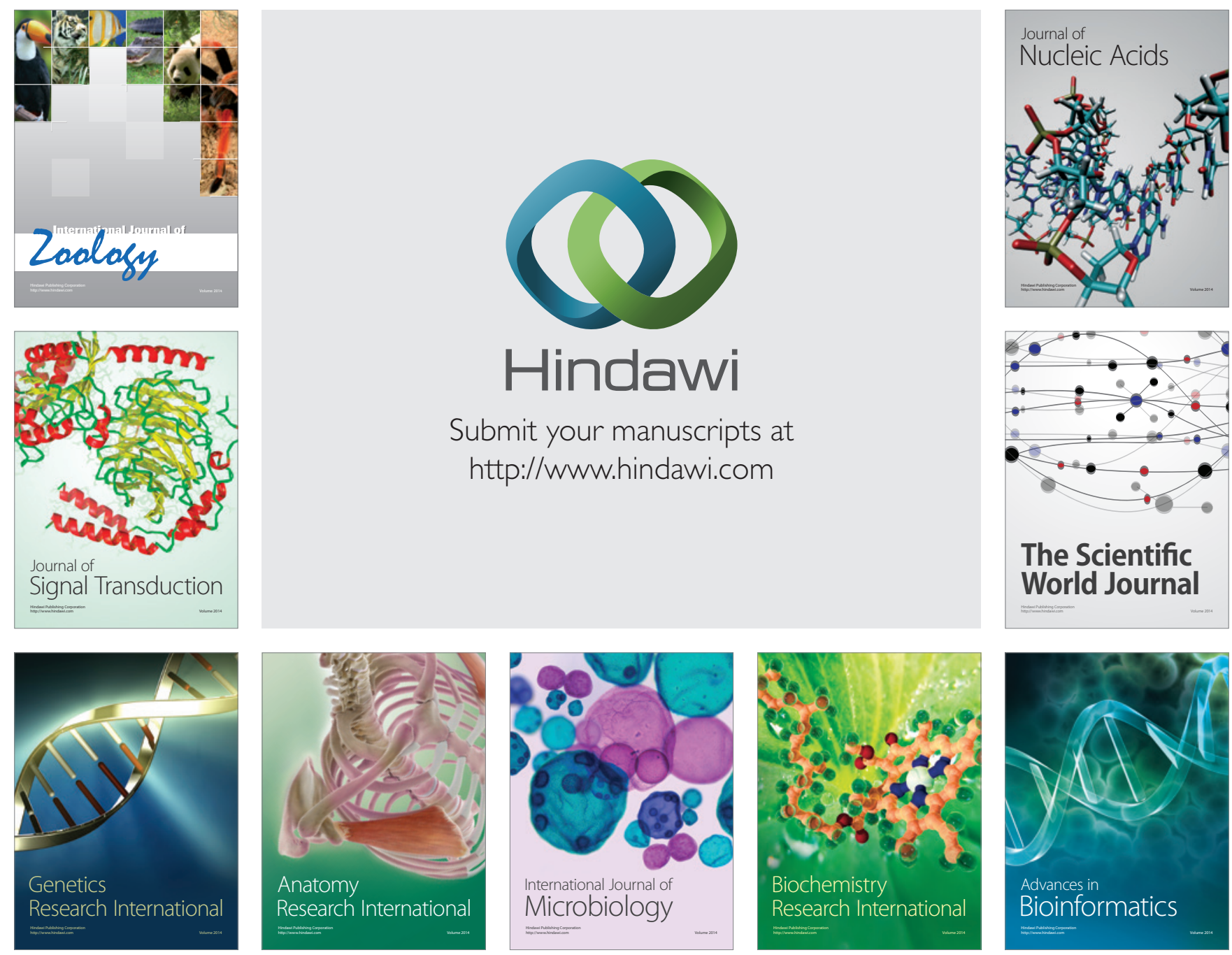

The Scientific World Journal
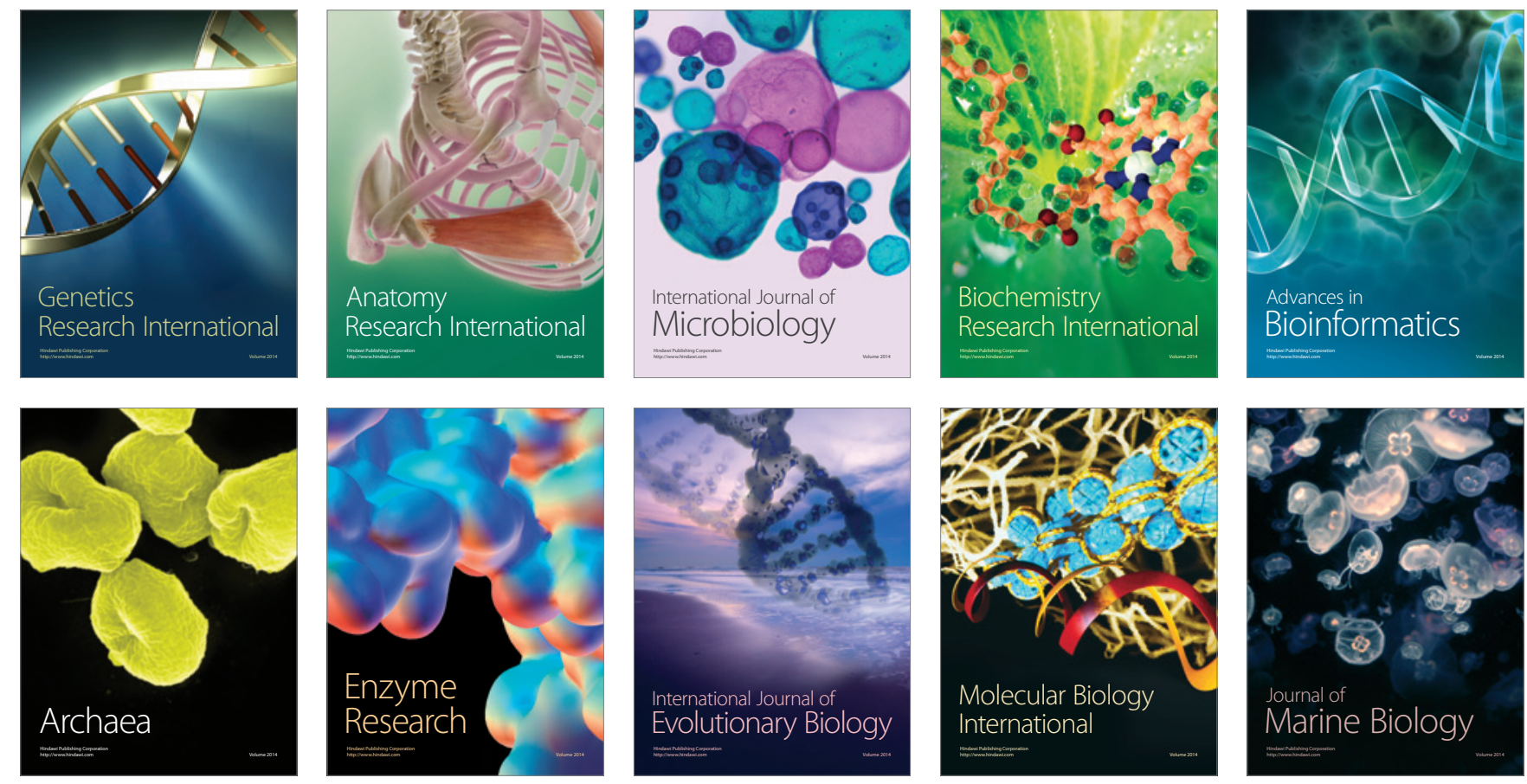